\title{
Evidence for a large strike-slip component during the 1960 Chilean earthquake
}

\author{
Hiroo Kanamori, ${ }^{1}$ Luis Rivera ${ }^{2}$ and Sophie Lambotte ${ }^{2}$ \\ ${ }^{1}$ Seismological Laboratory, California Institute of Technology, Pasadena, CA 91125, USA. E-mail: hiroo@gps.caltech.edu \\ ${ }^{2}$ Institut de Physique du Globe de Strasbourg; UMR7516, University of Strasbourg-CNRS, 67084 Strasbourg, France
}

Accepted 2019 February 28. Received 2019 February 5; in original form 2018 July 11

\begin{abstract}
S UMMAR Y
The strainmeter record observed at Isabella (ISA), California, for the 1960 Chilean earthquake $\left(M_{\mathrm{w}}=9.5\right)$ is one of the most important historical records in seismology because it was one of the three records that provided the opportunity for the first definitive observations of free oscillations of the Earth. Because of the orientation of the strainmeter rod with respect to the back azimuth to Chile, the ISA strainmeter is relatively insensitive to G (Love) waves and higher order (order $\geq 6$ ) toroidal modes, yet long-period $\mathrm{G}$ waves and toroidal modes were recorded with large amplitude on this record. This observation cannot be explained with the conventional low-angle thrust mechanism typical of great subduction-zone earthquakes and requires an oblique mechanism with half strike-slip and half thrust. The strain record at Ogdenburg, New Jersey, the Press-Ewing seismograms at Berkeley, California, and the ultra-long period displacement record at Pasadena, California, also support the oblique mechanism. We tested the performance of the ISA strainmeter using other events including the 1964 Alaskan earthquake and found no instrumental problems. Thus, the ISA observation of large $\mathrm{G} / \mathrm{R}$ and toroidal/spheroidal ratios most likely reflects the real characteristics of the 1960 Chilean earthquake, rather than an observational artefact. The interpretation of the large strike-slip component is not unique, but it may represent release of the strike-slip strain that has accumulated along the plate boundary as a result of oblique convergence at the NazcaSouth American plate boundary. The slip direction of the 2010 Chilean (Maule) earthquake $\left(M_{\mathrm{w}}=8.8\right)$ is rotated by about $10^{\circ}$ clockwise from the plate convergence direction suggesting that right-lateral strain comparable to that of an $M_{\mathrm{w}}=8.3$ earthquake remained unreleased and accumulates near the plate boundary. One possible scenario is that the strike-slip strain accumulated over several great earthquakes like the 2010 Maule earthquake was released during the 1960 Chilean earthquake. If this is the case, we cannot always expect a similar behaviour for all the great earthquakes occurring in the same subduction zone and such variability needs to be considered in long-term hazard assessment of subduction-zone earthquakes.
\end{abstract}

Key words: Earthquake dynamics; Earthquake source observation; Surface waves and free oscillations; Dynamics and mechanics of faulting; Subduction zone processes.

\section{INTRODUCTION}

The strainmeter record observed at Isabella (ISA), California, for the 1960 Chilean earthquake $\left(M_{\mathrm{w}}=9.5\right)$ is one of the most important historical seismograms because it allowed the first definitive observations of the Earth's free oscillations (Benioff Press \& Smith 1961, hereafter also referred to as BPS-1961), together with other observations at UCLA, California, (Ness et al. 1961) and Ogdensburg, New Jersey, (Alsop et al. 1961). The periods of the spectral peaks observed over a period range from a few hundred seconds to $54 \mathrm{~min}$ were in almost complete agreement with those theoretically predicted (e.g. Alterman et al. 1959). Fig. 1(a) shows the direct recording of the ISA strainmeter reproduced from Benioff (1962).

In the early 1960 s, the main interest of seismologists seemed to be in the period of normal modes rather than the amplitude. The periods are directly related to the internal structure of the earth, the subject of primary interest in those days. In contrast, only cursory analyses of normal mode amplitudes were made in early investigations. Although the amplitude information is of fundamental importance for understanding the size and the physical process of earthquakes, interpretation of amplitude data is difficult because it requires detailed knowledge of the instrument, geometry of the source and seismic excitation theories. 
(a)

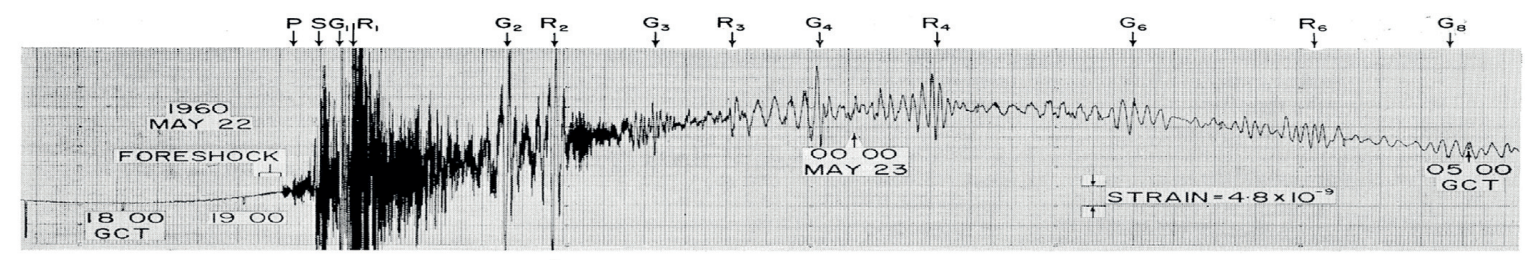

(b)

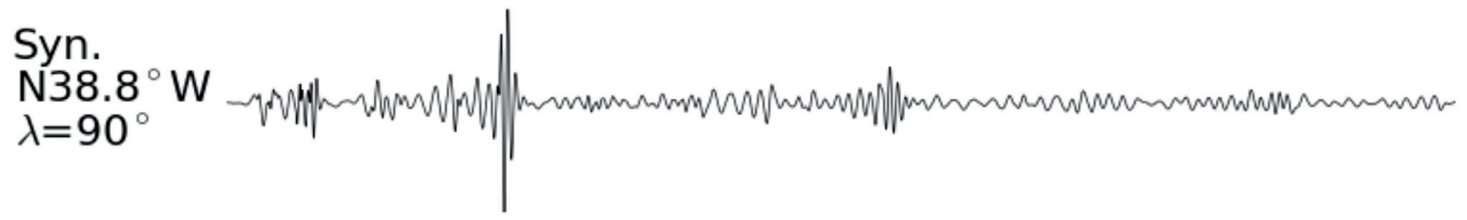

(c)

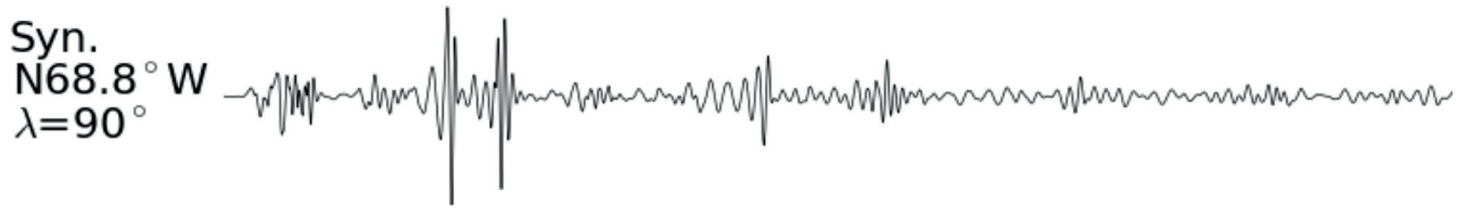

(d)

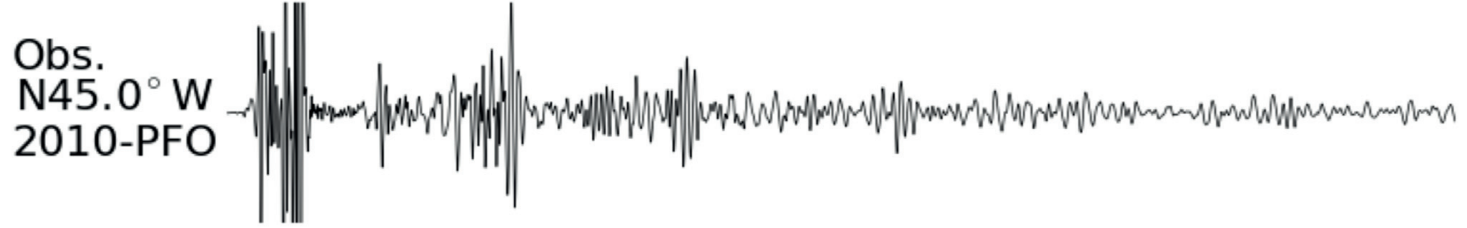

(e)

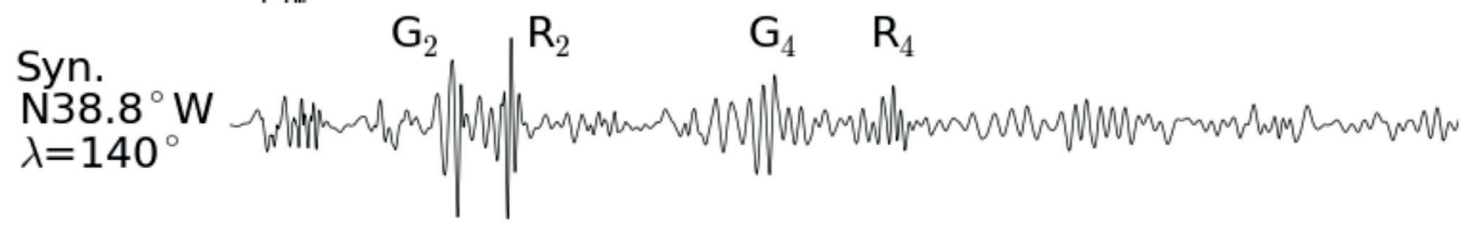

Figure 1. (a). The NW direct strain seismogram at Isabella (ISA), California, recorded for the 1960 Chilean earthquake (modified from Benioff 1962). Note the G2-R2 and G4-R4 pairs for which G (Love) and Rayleigh waves are with about the same amplitude. The odd-order waves are small due to directivity at the source. (b) Synthetic strain waveform computed for a low-angle pure thrust mechanism $\left(\delta=17^{\circ}, \lambda=90^{\circ}\right)$. Note the near absence of $\mathrm{G}$ waves. (c) Synthetic strain waveform computed for a low-angle thrust mechanism for a hypothetical rod orientation of N68. $8^{\circ} \mathrm{W}$. G and Rayleigh waves are comparable in amplitude. (d) The NW strain seismogram at Piñon Flat Observatory (PFO), California, recorded for the 2010 Maule, Chile, earthquake (courtesy of Dr Duncan Agnew). Note the small amplitude of G waves. (e). Synthetic strain waveform computed for the model of the 1960 Chilean earthquake with $\lambda=140^{\circ}$.

Since the ISA strain record is one of only a few records of the 1960 Chilean earthquake from which quantitative amplitude information at very long period can be extracted, we investigate it in detail in an attempt to understand the source characteristics of the 1960 Chilean earthquake which is now believed to be the largest instrumentally recorded earthquake $\left(M_{\mathrm{w}}=9.5\right.$; e.g. Ruiz \& Madariaga 2018).

We will show that it is difficult to explain the large amplitude $\mathrm{G}$ waves (we use ' $\mathrm{G}$ wave' to refer to long-period Love wave) and toroidal modes recorded on the Isabella strain record with the conventional low-angle thrust mechanism (strike, $\varphi_{\mathrm{s}}=10^{\circ}$, dip, $\delta=17^{\circ}$, rake, $\lambda=90^{\circ}$ ) typical of subduction-zone great earthquakes. Although we cannot determine the mechanism uniquely, a mechanism with an oblique slip (i.e. rake $\lambda=140^{\circ}$ ) can explain the observation satisfactorily.

\section{ISA STRAIN RECORD}

A visual inspection of the ISA strain record shown in Fig. 1(a) reveals two important features. First, it exhibits distinct even order $G$ and Rayleigh waves, but the odd order waves are small because of the strong directivity at the source caused by the southward rupture propagation over nearly $1000 \mathrm{~km}$ (BPS-1961; Press et al. 1961; Wada et al. 1963). Second, the amplitudes of $G$ and Rayleigh waves are comparable for each pair, G2-R2 and G4-R4. In fact, Benioff
(1962) noted that the large amplitude of the G waves is evidence for transcurrent faulting. However, the prominent $\mathrm{G}$ waves on this record are surprising. As shown by Benioff (1935), the sensitivity of the extensometer to transverse waves such as $\mathrm{G}$ waves is proportional to $\frac{1}{2} \sin (2 \alpha)$, and that to longitudinal waves such as Rayleigh waves is proportional to $\cos ^{2}(\alpha)$ where $\alpha$ is the angle between the strain rod and the great circle connecting the source and the station (Fig. 2). Since the backazimuth to Chile at ISA $\left(35.66^{\circ} \mathrm{N}\right.$, $\left.118.47^{\circ} \mathrm{W}\right)$ is $145.66^{\circ}$, and the listed orientation of the strain rod is $\mathrm{N} 32^{\circ} \mathrm{W}, \alpha$ is only $2.3^{\circ}$ which makes the ISA strainmeter very insensitive to $\mathrm{G}$ waves. The orientation $\mathrm{N} 32^{\circ} \mathrm{W}$ listed in BPS-1961 was changed to $\mathrm{N} 38.4^{\circ} \mathrm{W}$ in a later paper by Press (1966). To resolve this question, in September 2009, we remeasured the tunnel orientation at ISA with a modern gyroscopically controlled compass, OCTANS, with the help of the Incorporated Research Institutions for Seismology (IRIS). The result showed that the orientation is $\mathrm{N} 38.8^{\circ} \mathrm{W}$ instead of $\mathrm{N} 32^{\circ} \mathrm{W}$, and we will use $\mathrm{N} 38.8^{\circ} \mathrm{W}$ hereafter (i.e. $\alpha=4.46^{\circ}$ ).

The sensitivity of a strainmeter to transverse and longitudinal incoming waves discussed above and illustrated by Fig. 2 is for simple isolated purely transverse and longitudinal plane waves, and the actual situation can be more complex. For example, in a spherical earth model Love waves and toroidal modes are not purely transverse; likewise Rayleigh waves and spheroidal modes are not 


\section{Angle (a) between the ISA strain rod and the great circle to Chile}

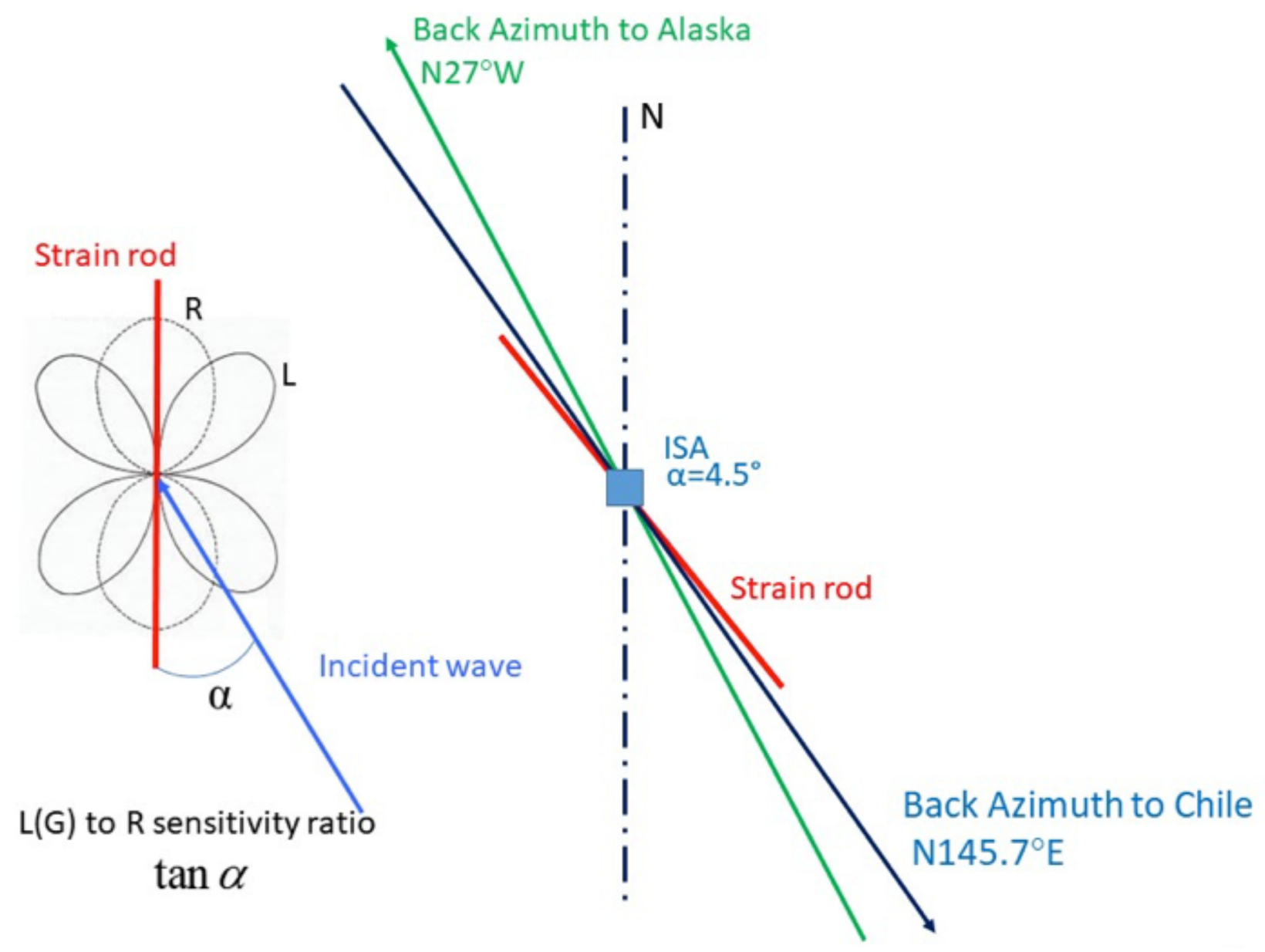

Figure 2. Left: Sensitivity of an extensometer to transverse (e.g. G waves) and longitudinal (e.g. Rayleigh waves) waves (Benioff 1935) where $\alpha$ is the angle between the strain rod and the wave path. Right: The ray-path geometry at ISA for the Chilean and the Alaskan earthquakes.

purely longitudinal. Also, Love and Rayleigh waves are not completely separated in time. In particular, the group velocity dispersion of Rayleigh waves is very large and Love and Rayleigh waves often overlap as pointed out by Brune et al. (1961). Thus, G2 marked on Fig. 1 is not entirely Love wave and some Rayleigh wave energy is superposed. In this paper the angle $\alpha$ is used only as a useful parameter to guide our investigation, and for any quantitative analysis, we use rigorous numerical approach as described below. More details on this issue are discussed in Supporting Information Section S1.

Ben-Menahem (1971) showed that if the Chilean earthquake is a vertical strike-slip event striking in $\mathrm{N} 10^{\circ} \mathrm{W}$, then ISA lies right on the node of $\mathrm{G}$ wave radiation, and no large $\mathrm{G}$ wave is expected at Isabella. After having tested several classes of mechanisms BenMenahem preferred a dip slip model dipping $45^{\circ}$ to the east. This model can explain the relatively large $G$ wave observed at PAS (Pasadena).

To illustrate how anomalous the Isabella observation is we computed synthetic strain records for the 1960 Chilean earthquake. The mechanism parameters used are strike, $\phi_{\mathrm{s}}=\mathrm{N} 10^{\circ} \mathrm{E}$, dip, $\delta=17^{\circ}$, and rake, $\lambda=90^{\circ}$, depth, $H=20 \mathrm{~km}$. This mechanism is taken from Kanamori \& Cipar (1974) with a slight modification of dip and depth in light of the various investigations since then (e.g. Krawczyk \& the SPOC Team 2003; Scherwath et al. 2006). The source consists of 10 sub-events distributed over about $1000 \mathrm{~km}$. The details of the rupture model are given in Appendix A.

We compute synthetic seismograms by normal-mode summation (Gilbert 1971). Depending on the earth model and the period range of interest, we have three groups of synthetic seismograms. For a non-rotating spherically symmetric earth model (PREM, Dziewonski \& Anderson 1981), no mode coupling and spectral splitting are involved. This group of seismograms is called 'NC' (non-coupled). For either a spherically symmetric rotating earth (PREM) or a 3-D rotating earth (S40RTS, Ritsema et al. 2011 and SP16b30, Masters et al. 1996), we use the perturbation theory (Dahlen \& Sailor 1979) for computing the synthetics for a frequency band of $0-3 \mathrm{mHz}$. This group is called ' $\mathrm{C}$ ' (coupled). For computation of synthetic seismograms over a broader frequency band, we combine the ' $\mathrm{C}$ ' group seismograms over a frequency band of $0-3 \mathrm{mHz}$ and the ' $\mathrm{NC}$ ' group seismograms for a frequency band of 3-40 $\mathrm{mHz}$. This group is called 'HY' (hybrid). In this case, we estimate the strain by numerical differentiation of the displacement as described in Appendix B. We present a more detailed description of our computational method in Appendix C.

We summarize the details of the method used for computation of synthetic waveforms and for processing the observed records in Table 1. Table 2 lists the event-station data. The details for Figs 1(a) 


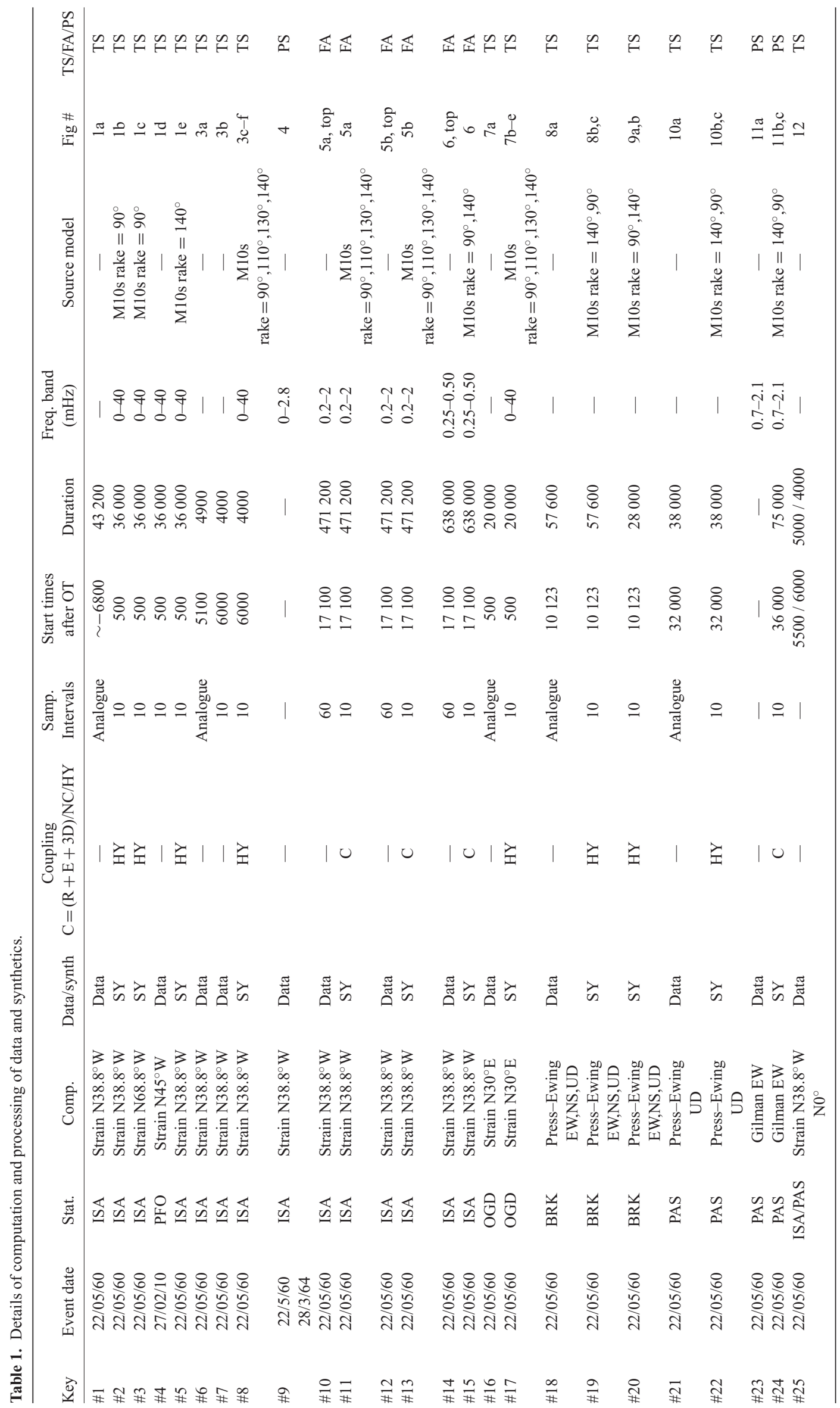




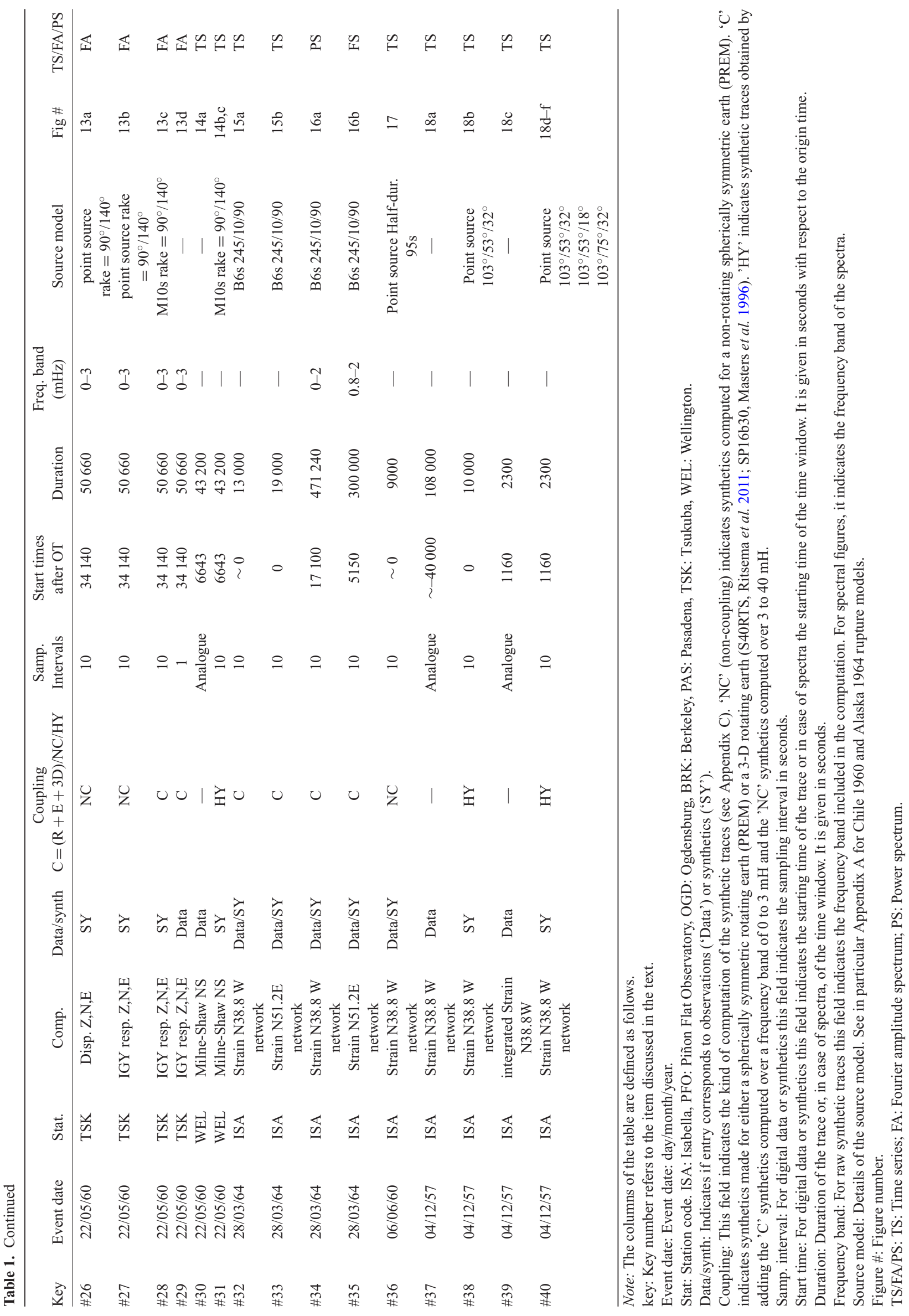


Table 2. Event-Station data.

\begin{tabular}{|c|c|c|c|}
\hline \multicolumn{4}{|c|}{ May 221960 Chile $-38.294,-73.054,35 \mathrm{~km}$} \\
\hline & $\Delta\left(^{\circ}\right)$ & $\phi\left(^{\circ}\right)$ & $\phi_{\mathrm{B}}\left({ }^{\circ}\right)$ \\
\hline ISA & 84.90 & 324.28 & 145.66 \\
\hline BRK & 88.46 & 323.07 & 143.31 \\
\hline OGD & 79.20 & 358.81 & 178.76 \\
\hline PAS & 83.51 & 323.63 & 145.76 \\
\hline NNA & 26.47 & 351.64 & 173.29 \\
\hline MAT & 155.59 & 279.52 & 98.41 \\
\hline TSK & 153.63 & 275.01 & 103.78 \\
\hline WEL & 79.40 & 225.11 & 132.30 \\
\hline TRI & 114.29 & 50.31 & 239.71 \\
\hline PAL & 79.11 & 359.34 & 179.31 \\
\hline RES & 113.77 & 353.77 & 161.31 \\
\hline SFA & 85.25 & 1.53 & 181.76 \\
\hline \multicolumn{4}{|c|}{1960 June 6 Chile $-45.70,-73.502,15 \mathrm{~km}$} \\
\hline & $\Delta\left(^{\circ}\right)$ & $\phi\left({ }^{\circ}\right)$ & $\phi_{\mathrm{B}}\left({ }^{\circ}\right)$ \\
\hline ISA & 90.75 & 324.75 & 150.22 \\
\hline \multicolumn{4}{|c|}{1964 March 28 Alaska 61.019, -147.50, $20 \mathrm{~km}$} \\
\hline & $\Delta\left(^{\circ}\right)$ & $\phi\left({ }^{\circ}\right)$ & $\phi_{\mathrm{B}}\left(^{\circ}\right)$ \\
\hline ISA & 31.35 & 130.61 & 333.04 \\
\hline \multicolumn{4}{|c|}{1957 Mongolia 45.182, 99.219, $25 \mathrm{~km}$} \\
\hline & $\Delta\left(^{\circ}\right)$ & $\phi\left({ }^{\circ}\right)$ & $\phi_{\mathrm{B}}\left({ }^{\circ}\right)$ \\
\hline ISA & 92.44 & 29.79 & 334.23 \\
\hline \multicolumn{4}{|c|}{2010 February 27 Chile $-36.12,-72.90,22.9$ km } \\
\hline & $\Delta\left(^{\circ}\right)$ & $\phi\left(^{\circ}\right)$ & $\phi_{\mathrm{B}}\left(^{\circ}\right)$ \\
\hline PFO & 80.57 & 324.24 & 145.46 \\
\hline \multicolumn{4}{|c|}{2011 March 11 Tohoku 38.29, 142.37, 29 km } \\
\hline & $\Delta\left(^{\circ}\right)$ & $\phi\left({ }^{\circ}\right)$ & $\phi_{\mathrm{B}}\left(^{\circ}\right)$ \\
\hline HRV & 93.69 & 24.35 & 333.97 \\
\hline
\end{tabular}

Note: $\Delta, \phi$ and $\phi_{\mathrm{B}}$ are the epicentral distance, azimuth and backazimuth.

and (b) are given in \#1 and \#2 of Table 1. For both G2-2 and G4-R4 pairs in the synthetic strain record, $G$ wave is much smaller than Rayleigh wave (Fig. 1b). This pattern is very different from what is observed (Fig. 1a). If we are to explain the observed G/R ratio with this mechanism, the strain rod would have to be rotated by almost $30^{\circ}$ as shown in Fig. 1(c) (Table 1, \#3).

The unusual feature of the 1960 earthquake record can also be clearly demonstrated by comparing it with the strain record of the 2010 Chile (Maule) earthquake $\left(M_{\mathrm{w}}=8.8\right)$ observed at the Piñon Flat Observatory $\left(\mathrm{PFO}, 33.611^{\circ} \mathrm{N}, 116.457^{\circ} \mathrm{W}\right)$, California. The 2010 Maule earthquake is located just north of the 1960 earthquake. The mechanism is a low-angle thrust typical of subduction-zone great earthquakes (NEIC, https://earthquake.usgs.gov/earthquake s/eventpage/official20100227063411530_30/executive; Lay et al. 2010a). The strain at PFO was recorded in three orientations, NS, EW and NW-SE. The source-receiver geometry of the 2010-PFONW-SE is similar to that of the 1960-ISA geometry. The angle $\alpha$ for the 2010-PFO-NW-SE geometry is about $10.5^{\circ}$ so that the G/R sensitivity is expected to be about 2.4 times larger for the 2010-PFONW-SE geometry than for the 1960-ISA geometry. Fig. 1(d) shows the NW component of strain record at PFO (Table 1,\#4). Despite the larger G/R sensitivity ratio for the 2010-PFO-NW-SE geometry, G waves are still very small on the PFO record; this strongly suggests that the 1960 event is significantly different in mechanism from the 2010 event. Then, the question is what mechanism can explain the observation better. After some trials and errors, we find that the simplest way to change the $\mathrm{G} / \mathrm{R}$ ratio is to increase the rake, $\lambda$, from $90^{\circ}$ to $140^{\circ}$. As we will show later, changing the strike of the pure thrust fault model cannot produce the observed large $G / R$ ratio. A synthetic record computed for $\lambda=140^{\circ}$ is shown in Fig. 1(e) (Table 1, \#5). It explains the overall features of G2-R2 (about the same amplitude), G3-R3 (small amplitude) and G4-R4 (prominent G4).

Since the effect of the propagation path is less on the G2-R2 pair than on the waves with a larger orbit index (e.g. G4, R4, etc.), we compare in Fig. 3 the observed R2 and G2 waveforms (Table 1, \#6, \#7) blown up from Fig. 1(a) with the G2 and R2 pairs computed for the cases $\lambda=90^{\circ}, 110^{\circ}, 130^{\circ}$ and $140^{\circ}$ (Table 1, \#8). This figure clearly shows that if the fault plane geometry is fixed, a rake angle as large as $140^{\circ}$ is required to explain the observed G2/R2 ratio. Fig. 3(g) shows radiation patterns of Rayleigh and $G$ waves at a period of $325 \mathrm{~s}$ for $\lambda=90^{\circ}$ and $140^{\circ}$ as a reference. Although the source directivity influences the amplitudes of the recorded wave trains, the amplitude ratios can be represented well with a point source because the phase speeds of Rayleigh and $\mathrm{G}$ waves are about the same. The amplitudes of G2 and R2 wave trains measured on the observed and synthetics are shown in Table 3. Since the synthetic seismograms are computed for $M_{0}=2.7 \times 10^{23} \mathrm{Nm}\left(M_{\mathrm{w}}=9.55\right)$, the amplitude ratio translates to an estimate of $M_{\mathrm{w}}=9.5$. Details of the calibration of the strainmeter are given in Kanamori \& Rivera (2017).

A similar comparison can be made at much longer period with the amplitudes of normal modes. Smith (1966) analysed the ISA strain records for the 1960 Chilean earthquake and the 1964 Alaskan earthquake $\left(M_{\mathrm{W}}=9.2\right)$ and compared the power spectra (Fig. 4, Table 1, \#9). The Chilean earthquake record used for the spectral analysis is similar to that shown in Fig. 1(a), but with a different recording system with an analogue filter and a faster paper speed. Smith (1966) used exactly the same analysis method for both events. Although the response of the recording system is slightly different between the Chilean and the Alaskan records (the response is given in Smith 1966), the observed spectra can be easily corrected for the difference in the filter. A notable observation is that the 1960 Chilean earthquake spectrum exhibits large toroidal mode peaks, ${ }_{0} \mathrm{~T}_{6},{ }_{0} \mathrm{~T}_{7}$, ${ }_{0} \mathrm{~T}_{8},{ }_{0} \mathrm{~T}_{9}$ and ${ }_{0} \mathrm{~T}_{10}$ which have on the average about 30 per cent of the power spectral amplitude of the corresponding spheroidal modes. Since the low order toroidal modes have significant longitudinal components, their appearance on the ISA extensometer record is not necessarily surprising, but the toroidal modes with the order number higher than 5 have primarily transverse component, and their strong appearance on the ISA record is surprising. This observation goes parallel with the observations of the relatively large $\mathrm{G}$ waves shown in Figs 1(a) and 3(a). In contrast, on the Alaskan earthquake spectrum, the amplitude of the low order toroidal modes is much smaller than that of the corresponding spheroidal modes. The angle $\alpha$ for the Alaskan earthquake is $11.8^{\circ}$ and this observation is normal in contrast to the Chilean earthquake spectrum for which the relative amplitudes of the observed toroidal modes are very large.

To investigate this observation more quantitatively, we compute the normal-mode spectrum and compare it with the observed. The digitized data file for the 1960 ISA strain record used by Smith (1966) is still available, and we compute the spectrum from it (Table 1, \#10). The amplitude response of the Isabella system has not been documented in detail, but we could calibrate it using the recently found archived data as described in Kanamori \& Rivera (2017). For computation of the synthetic spectrum, we use exactly the same starting time (after the origin time) and the duration as those of the observed seismograms used for analysis in the original publications. Figs 5(a) and (b) compare the observed and synthetic Fourier spectra for the 4 cases, $\lambda=90^{\circ}, 110^{\circ}, 130^{\circ}$ and $140^{\circ}$ (Table $1, \# 10$ to $\# 13)$. The strike, dip and depth are fixed at $10^{\circ}, 17^{\circ}$ and $20 \mathrm{~km}$, respectively. Fig. 5(a) is computed for the earth model 
(a)

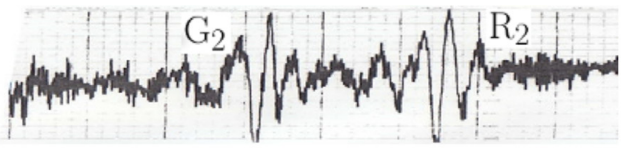

(g)

(b)

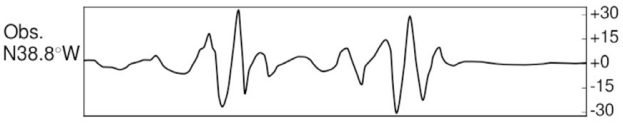

(c)
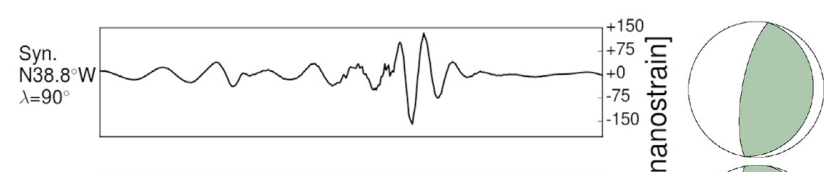

Love and Rayleigh waves radiation pattern ( $\mathrm{T}=325 \mathrm{~s}, \mathrm{H}=20 \mathrm{~km}$ )

(d)
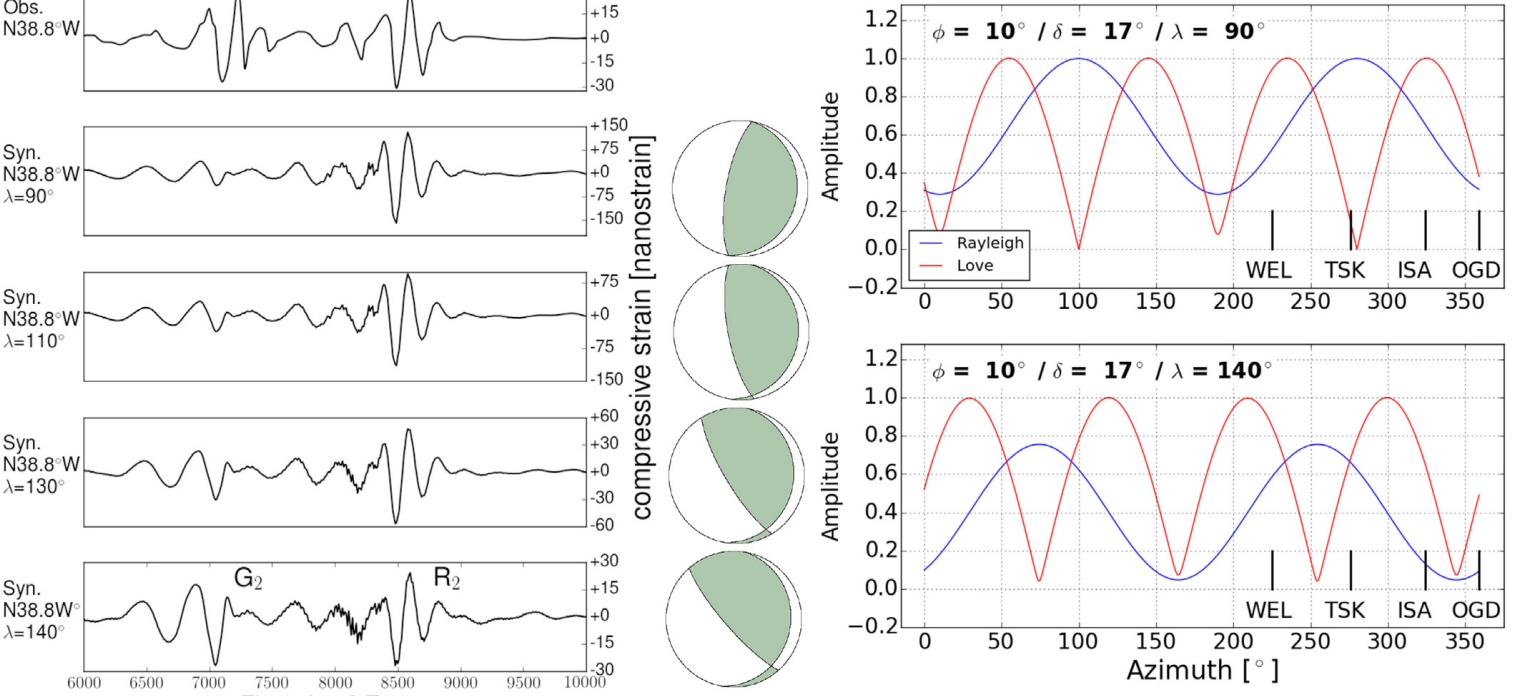

Figure 3. Comparison of $\mathrm{G} 2$ and $\mathrm{R} 2$ observed on the ISA direct strain record (a and b) with the synthetic waveforms computed for different rake angles: $\lambda=$ (c) $90^{\circ}$, (d) $110^{\circ}$, (e) $130^{\circ}$ and (f) $140^{\circ}$ for the 1960 Chilean earthquake. The mechanism diagrams are shown to the right of each synthetic seismograms. (g) Surface-wave radiation patterns for $\lambda=90^{\circ}$ and $140^{\circ}$ at a period of $325 \mathrm{~s}$. The blue curve is for the vertical component of the Rayleigh wave and the red curve is for the transverse component of the Love wave. The azimuths of representative stations are shown for reference. The azimuths of Japanese stations are similar to that of TSK.

Table 3. Peak-to-peak strain amplitudes (nanostrain) of G2 and R2 on the ISA $\left(\mathrm{N} 38.8^{\circ} \mathrm{W}\right)$ direct strain record for the 1960 Chilean earthquake.

\begin{tabular}{lccc}
\hline Phase & Obs. & $\lambda=90^{\circ}$ & $\lambda=140^{\circ}$ \\
\hline G2 & 50 & $78(0.64,9.42)$ & $44(1.1,9.58)$ \\
R2 & 51 & $298(0.17,9.05)$ & $51(1.0,9.55)$ \\
\hline
\end{tabular}

Note: The first and second numbers in the parentheses are the amplitude ratio of the observed to synthetic record and the estimated $M_{\mathrm{w}}$, respectively.

PREM (Dziewonski \& Anderson 1981), and the Earth's ellipticity and rotation are included in the computation (Dahlen \& Sailor 1979). In this paper, except for a few cases ('NC' entries in Table 1), the effects of ellipticity and rotation are always included in the computation with PREM or the 3-D models.

For comparison we mainly use the modes of the angular orders from 6 to 10 for the following reason. We estimate the modal harmonic amplitudes and find that the amplitude of low order modes (order $\leq 5$ ) are small, about 0.1 to 0.3 nanostrain, which is comparable or even smaller than the resolution of the hand-digitized record, and the amplitudes are not reliable (Supporting Information Section S2). On the other hand, at order numbers higher than 10 , it is difficult to separate toroidal and spheroidal modes. Thus, although we show the results for all the modes we focus on the average amplitude over a period range from 600 to $1000 \mathrm{~s}$ for comparison. This range corresponds to that of the spheroidal modes from ${ }_{0} \mathrm{~S}_{6}$ to ${ }_{0} \mathrm{~S}_{10}$. Fig. 5(a) shows that the T/S amplitude ratio for the observed spectrum for the period range of 600 to $1000 \mathrm{~s}$ is 0.75 and is much larger than that for the $\lambda=90^{\circ}$ case, 0.25 . The $\mathrm{T} / \mathrm{S}$ ratio is $0.34,0.36$ and 0.72 for $\lambda=110^{\circ}, \lambda=130^{\circ}$ and $\lambda=140^{\circ}$ cases, respectively.
This trend is the same as that found in the comparison of G/R ratio shown in Fig. 3.

Fig. 5(b) (Table 1, \#12,\#13) is a similar comparison between the observed and the spectra computed with the 3-D structure S40RTS (Ritsema et al. 2011) in which the effect of long-wave length lateral heterogeneity as well as ellipticity and rotation is included. Because of the complex mode coupling, the pattern is more complicated than that in Fig. 5(a), but the overall trend is the same: $\lambda=130^{\circ}$ to $140^{\circ}$ is required to bring the T/S ratio in agreement with the observed.

We also find that the normal-mode spectrum of the PFO strain record (NW-SE component) for the 2010 Maule, Chile, earthquake shows relatively small $\mathrm{T} / \mathrm{S}$ ratios, and is consistent with the spectrum computed for the Maule earthquake (Supporting Information Section S3). This observation also suggests that the 1960 Chilean earthquake and the 2010 Maule earthquake are significantly different in mechanism.

Geller \& Stein (1977) showed that the observed multiplet structure of the 1960 Chilean earthquake is consistent with that theoretically computed for the low-angle thrust mechanism given by Kanamori \& Cipar (1974). As shown in Fig. 6 (Table 1, \#14, \#15), the split multiplet structures for ${ }_{0} \mathrm{~S}_{2}$ and ${ }_{0} \mathrm{~S}_{3}$ vary little with the rake angle, and are similar to that shown by Geller \& Stein (1977). Thus, the model with rake $=140^{\circ}$ is compatible with their observation.

\section{OTHER OBSERVATIONS}

The 1960 Chilean earthquake was also recorded at several other stations, and we compare the $\lambda=90^{\circ}$ and $\lambda=140^{\circ}$ models with these records. 


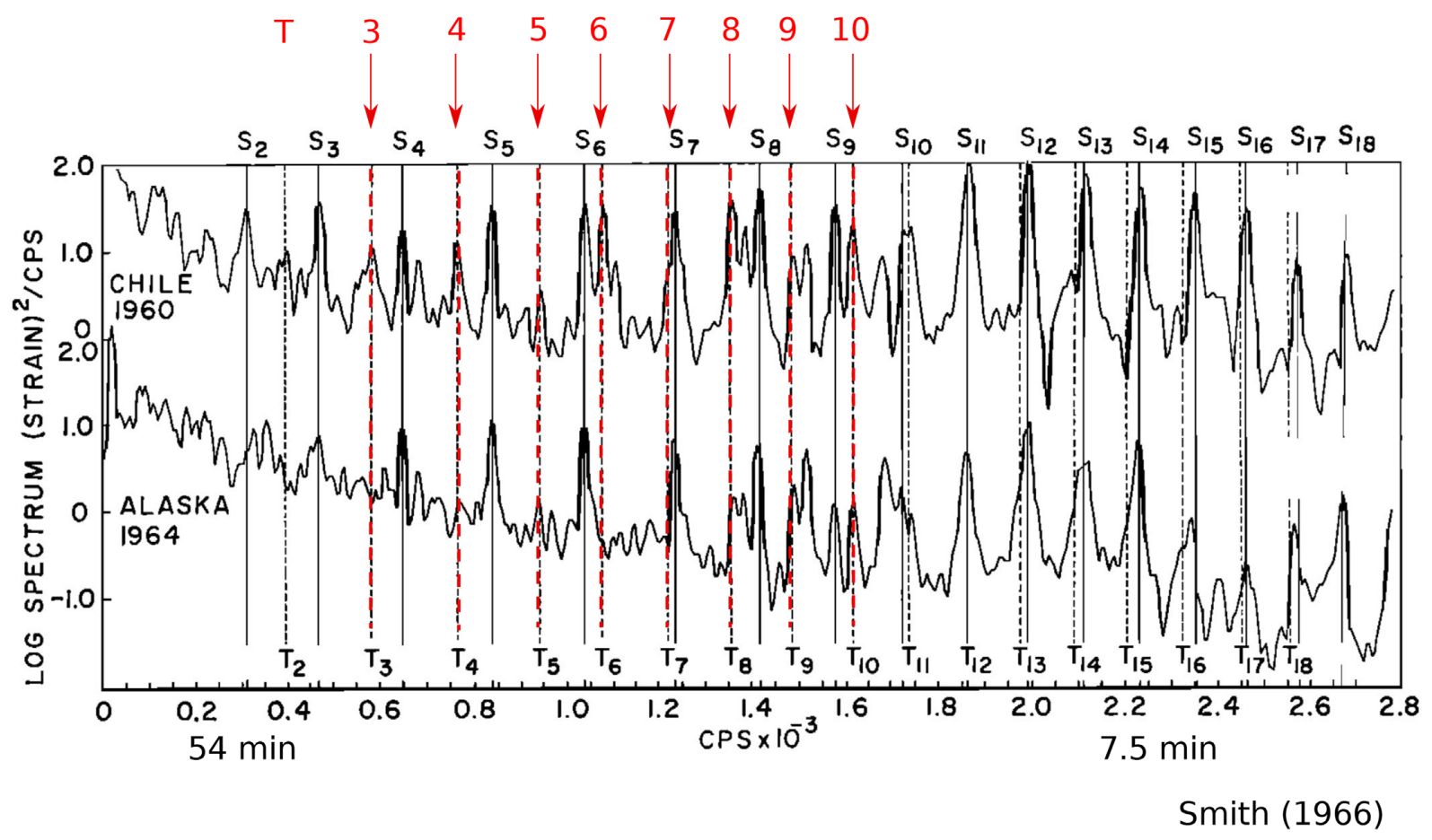

Figure 4. Power spectrum of the ISA strain record for the 1960 Chilean and the 1964 Alaskan earthquakes (modified from Smith 1966). Note the relatively large toroidal modes (indicated by red vertical lines) of the Chilean earthquake with respect to the Alaskan earthquake (the peak next to the line for ${ }_{0} \mathrm{~T}_{7}$ is the peak for ${ }_{0} \mathrm{~S}_{7}$ ). The spectra are computed in exactly the same way for both events.

\subsection{Ogdensburg (OGD), New Jersey}

The Chilean earthquake was recorded with a strainmeter at OGD $\left(41.080^{\circ} \mathrm{N}, 74.600^{\circ} \mathrm{W}\right)$, New Jersey (Alsop et al. 1961). The strainmeter is a $200 \mathrm{ft}$ long quartz rod extensometer with a capacitor transducer. The response is flat in strain at periods longer than $30 \mathrm{~s}$. Fig. 7(a) (Table 1,\#16) which is reproduced from Alsop et al. (1961) clearly shows G2 and R2 wave trains. The amplitude of G2 is about twice as large as that of R2. We compute synthetic strain seismograms for four rake angles $\lambda=90^{\circ}, 110^{\circ}, 130^{\circ}$ and $140^{\circ}$ (Figs $7 \mathrm{~b}-\mathrm{e}$, Table 1, \#17). The G2/R2 ratio progressively increases with $\lambda$, and the $\lambda=140^{\circ}$ case explains the observed ratio well. Since the time resolution of the observed record is limited, the waveforms cannot be compared in detail. The good agreement of the G2/R2 between the observed and computed strain records at both ISA and OGD which are $35^{\circ}$ apart in azimuth (Fig. 3 g) provides strong support for the $\lambda=140^{\circ}$ model. We calibrate the OGD strainmeter using the theoretical tidal strain in the same way as we did for the ISA strainmeter (Appendix D). The amplitudes of G2 and R2 wave trains measured on the observed and synthetics are shown in Table 4. The observed to synthetic amplitude ratios for the $\lambda=140^{\circ}$ model translate to $M_{\mathrm{w}}=9.40$ and 9.49 from G2 and R2, respectively.

\subsection{Berkeley (BRK) and Pasadena (PAS) Press-Ewing records}

The three-component Press-Ewing seismographs at Berkeley Seismological Observatory $\left(\mathrm{BRK}, 37.873^{\circ} \mathrm{N}, 122.260^{\circ} \mathrm{W}\right.$ ) also recorded the 1960 Chilean earthquake. Since the distance and azimuth of BRK and ISA from Chile are essentially the same, the BRK pendulum records are important to verify the unusually large $\mathrm{G} / \mathrm{R}$ ratio recorded with the Isabella strainmeter.
The BRK Press-Ewing seismograph is listed as a 30 (pendulum period)-90 (galvanometer period) system in the BRK station bulletin. However the gain is not given. The amplitudes of $20 \mathrm{~s}$ surface waves of an aftershock at May 23, 5:13 UT (ISC) recorded on the BRK records are $3.5 \mathrm{~cm}$ (UD), $2.8 \mathrm{~cm}$ (NS) and $2.1 \mathrm{~cm}(\mathrm{EW})$. Also, the appearance (mainly the duration) of a large foreshock on 1960 May 21 (10:03) recorded on the three-component BRK records is similar. These observations indicate that the three components are approximately matched in magnification. A matched three-component system is a fundamental feature of the PressEwing seismograph (Press et al. 1958). The gain of the standard Press-Ewing seismograph at PAS was 2300 but, as will be shown later, the gain of the BRK vertical component seismograph was probably about $\frac{1}{2}$ of that at PAS. Thus, we tentatively use both 2300 and 1000 for BRK.

The seismograms starting from May 22, 23:00 UT provide key information on this earthquake. Because of the very large ground motions, the lines are overlapped in a complicated way so that it is hard to see the details. Nevertheless, we can identify a few important phases as follows.

As shown in Fig. 8(a) (Table 1, \#18), a prominent Rayleigh-like wave and a G-like wave can be identified on the vertical and on the horizontal component record, respectively. Unfortunately, because of the large amplitudes, we cannot determine on which line these waves are. However, from the position of these waves from the left edge of the records, we can determine that the arrival time of the Rayleigh-like wave (peak-to-peak amplitude is about $14.9 \mathrm{~cm}$ ) must be about 23:40, 00:40 or 01:40, and the G-like wave on the EW component record (peak-to-peak amplitude is about $22.4 \mathrm{~cm}$ ), about $23: 10,00: 10,01: 10,02: 10$ or $03: 10$. To guide identification and interpretation of these waves, we compute synthetic seismograms for both $\lambda=90^{\circ}$ and $\lambda=140^{\circ}$ models, as shown in Fig. 9 (Table 1, \#20). (For computation of Press-Ewing seismograms, see Hagiwara 

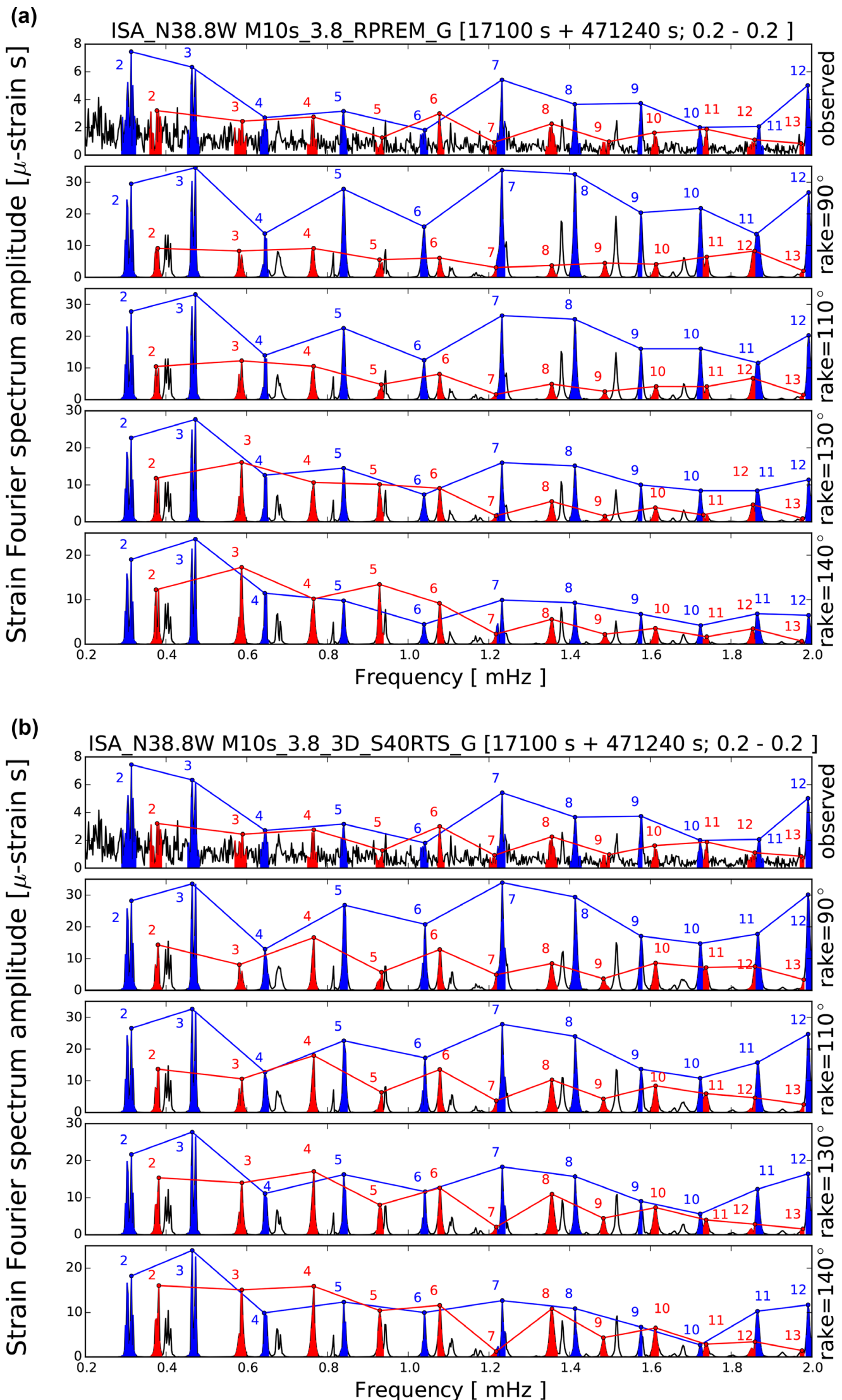

Figure 5. (a) Comparison of the observed spectrum at ISA strainmeter $\left(\mathrm{N} 38.8^{\circ} \mathrm{W}\right)$ with the spectrum computed for different rake angles: $\lambda=90^{\circ}, 110^{\circ}, 130^{\circ}$ and $140^{\circ}$ for the 1960 Chilean earthquake. The earth model used is PREM (Dziewonski \& Anderson 1981) with ellipticity and rotation corrections. (b) Similar to (a) for the earth model S40RTS (Ritsema et al. 2011). 


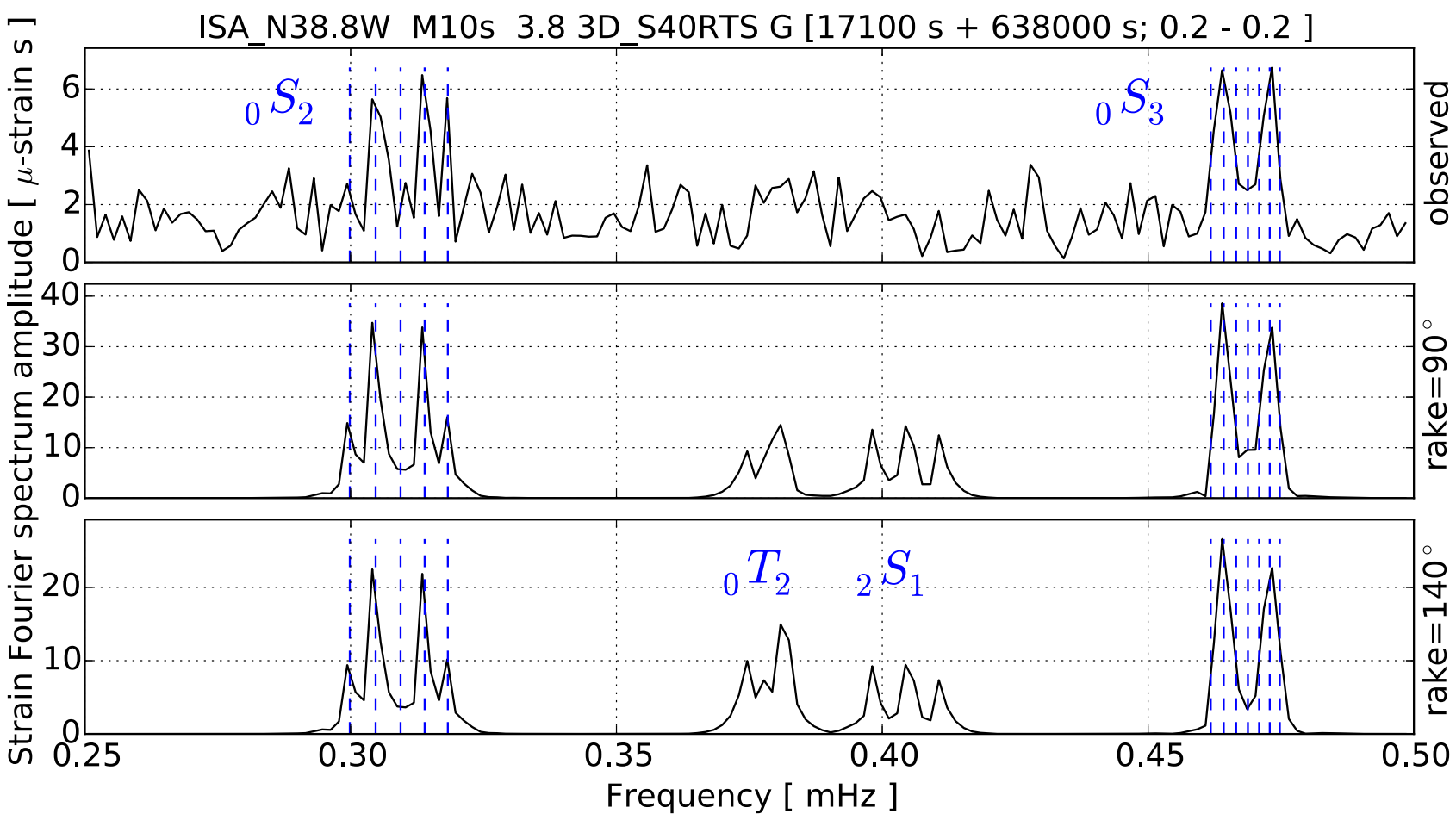

Figure 6. The split multiplet structures of ${ }_{0} \mathrm{~S}_{2}$ and ${ }_{0} \mathrm{~S}_{3}$ observed on the ISA strain record of the 1960 Chilean earthquake. Top: Observed. Middle: Computed for the $\lambda=90^{\circ}$ case. Bottom: Computed for the $\lambda=140^{\circ}$ case.

1958.) Since the starting time of the record is around May 22, 23:00, the first $G$ and $R$ waves on these records must be G4 and R4. The expected arrival times of R4, R6, G4, G6 and G8 are 00:40, 03:45, 23:40, 02:10 and 04:40, respectively. Thus, we conclude that the observed G-like wave is G6, and the R-like wave is either R4 or R6. Although the vertical component record is complex, we can see that the R-like wave is the first distinct large amplitude phase on the record. Thus, we conclude that the observed R-like phase is actually R4. Having identified R4 and G6, we can trace a large amplitude G4 on the NS component, as shown in Fig. 8(a).

To facilitate overall comparison, we compute synthetic seismograms in the format of helicoidal drum recording as shown in Figs 8 (b) $\left(\lambda=140^{\circ}\right)$ and (c) $\left(\lambda=90^{\circ}\right)$ (Table 1, \#19). From the amplitude ratios G6/R4 and G4/R4 the $\lambda=140^{\circ}$ model is clearly preferred to the $\lambda=90^{\circ}$ model. The peak-to-peak amplitude of G6 and R4 on the synthetic seismograms (Fig. 9, Table 1, \#20) are 72 and $179 \mathrm{~cm}$, respectively, for the $\lambda=90^{\circ}$ model, and 44 and $31 \mathrm{~cm}$, respectively, for the $\lambda=140^{\circ}$ model. The G6/R4 amplitude ratio is 0.40 and 1.42 for the $\lambda=90^{\circ}$ and $\lambda=140^{\circ}$ models, respectively. The ratio of the $\lambda=140^{\circ}$ model is much more consistent with the observed ratio, 1.5 , than the $\lambda=90^{\circ}$ model. From the amplitude ratio of the observed to synthetic seismograms for the $\lambda=140^{\circ}$ model we estimate $M_{\mathrm{w}}$ to be from 9.33 to 9.60 , allowing for the possible gain range (1000 to 2300) of the Press-Ewing seismograph.

Table 5 summarizes the results. The $\lambda=140^{\circ}$ model yields much more consistent values from G6 and R4 than the $\lambda=90^{\circ}$ model.

The 1960 Chilean earthquake was also recorded with the PressEwing seismograph at Pasadena, but we can find only the vertical component in the Caltech Archive. The digitized seismogram for about $10.5 \mathrm{hr}$ starting from just before the $\mathrm{R} 7$ wave train matches the synthetics well (Fig. 10,\#21, \#22). Although we cannot distinguish the $\lambda=90^{\circ}$ and $\lambda=140^{\circ}$ models from the waveform alone, we can estimate $M_{\mathrm{w}}$ to be 9.51 for the $\lambda=140^{\circ}$ model and 9.24 for the $\lambda=90^{\circ}$ model for a gain of 2300 (Table 6). Comparison of these results with those from the BRK records suggests that the effective gain of the BRK records at long period was probably about $\frac{1}{2}$ of that of PAS.

\subsection{Pasadena ultralong period record}

Since the key observation at ISA is the large amplitude of toroidal modes relative to spheroidal modes, a relevant test is to investigate the amplitude of toroidal modes relative to spheroidal modes at PAS, essentially at the same location as ISA as viewed from Chile. To this end, we investigate the power spectrum of the PAS experimental ultralong period seismogram (EW component) published in BPS-1961 (Fig. 5). Although the original seismogram is no longer available, the power spectrum shown in fig. 5 of BPS1961 provides important information on the relative strength of toroidal and spheroidal modes excited by the 1960 Chilean earthquake. Fig. 11(a) (Table 1, \#23) shows the published spectrum. On the figure, toroidal modes (red), ${ }_{0} \mathrm{~T}_{5},{ }_{0} \mathrm{~T}_{6},{ }_{0} \mathrm{~T}_{8},{ }_{0} \mathrm{~T}_{9}$ and ${ }_{0} \mathrm{~T}_{10}$ are clearly shown. Spheroidal modes (blue) are small; only ${ }_{0} \mathrm{~S}_{6},{ }_{0} \mathrm{~S}_{8}$ and ${ }_{0} \mathrm{~S}_{9}$ appear on the shoulder of the peaks of ${ }_{0} \mathrm{~T}_{6},{ }_{0} \mathrm{~T}_{8}$ and ${ }_{0} \mathrm{~T}_{10}$, respectively. We explore whether we can reproduce this pattern using the synthetic records computed with $\lambda=90^{\circ}$ or $\lambda=140^{\circ}$.

We use the coupled-synthetics computed for a finite source model (Figs $11 \mathrm{~b}$ and c, Table 1, \#24). The instrument used is the E-W Gilman pendulum seismograph with $T_{s}$ (pendulum period) $=60 \mathrm{~s}$ and $T_{g}$ (galvanometer period $)=480 \mathrm{~s}$. The response curve is given in Gilman (1960). The spectral ratio of toroidal to spheroidal mode depends on the starting time and the duration of the record used for spectral analysis because of the different attenuation of toroidal and spheroidal modes. According to BPS-1961, the start time for digitization is 21:01, 1960 May 22 with a record length of $1250 \mathrm{~min}$. The 
(a)

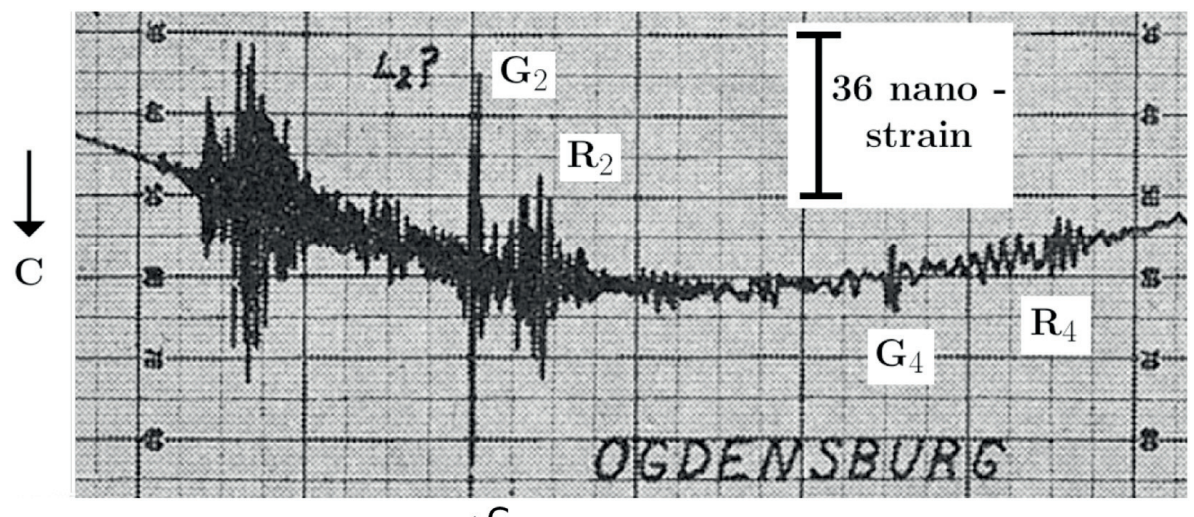

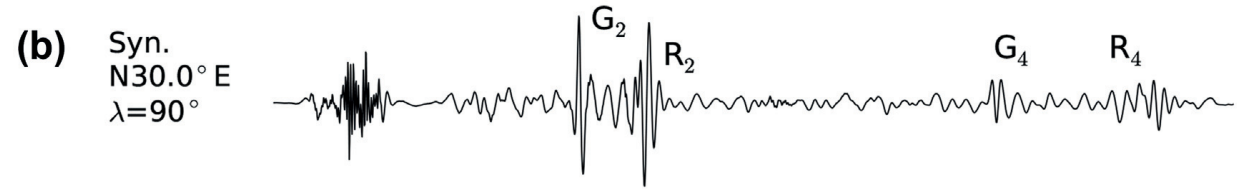

(c) Syn. $\mathrm{N} 30.0^{\circ} \mathrm{E}$ $\lambda=110^{\circ}$

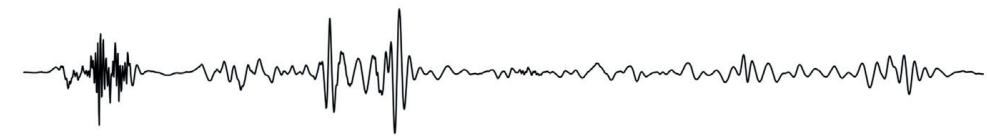

(d) Syn. $\mathrm{N} 30.0^{\circ} \mathrm{E}$ $\lambda=130^{\circ}$

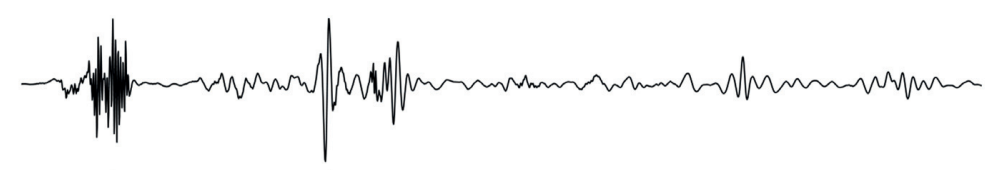

(e)

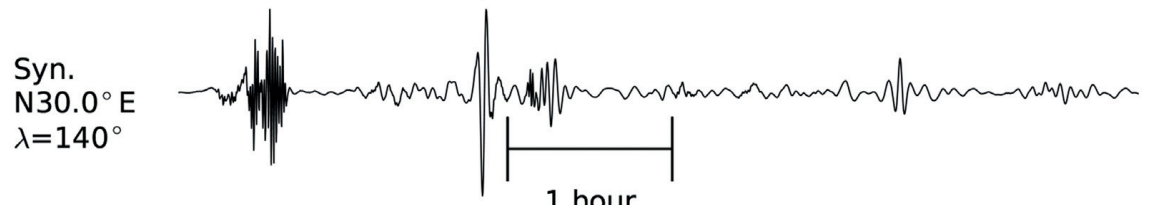

1 hour

Figure 7. Comparison of $\mathrm{G} 2$ and $\mathrm{R} 2$ observed on a direct strainmeter $\left(\mathrm{N} 30^{\circ} \mathrm{E}\right)$ at Ogdensburg (OGD), New Jersey for the 1960 Chilean earthquake (Alsop et al. 1961) with the synthetic seismograms computed for different rake angles: $\lambda=90^{\circ}, 110^{\circ}, 130^{\circ}$ and $140^{\circ}$.

Table 4. Peak-to-peak strain amplitudes (nanostrain) of G2 and R2 on the OGD (Ogdensburg) strainmeter (N30 ${ }^{\circ}$ ) for the 1960 Chilean earthquake.

\begin{tabular}{lccc}
\hline Phase & Obs. & $\lambda=90^{\circ}$ & $\lambda=140^{\circ}$ \\
\hline G2 & 88 & $122(0.72,9.45)$ & $147(0.60,9.40)$ \\
R2 & 46 & $129(0.36,9.25)$ & $56(0.82,9.49)$ \\
\hline
\end{tabular}

Note: The first and second numbers in the parentheses are the amplitude ratio of the observed to synthetic record and the estimated $M_{\mathrm{w}}$, respectively.

start time listed in BPS-1961 is only about $2 \mathrm{hr}$ after the origin time. The synthetic waveforms of Gilman records we computed yield a peak-to-peak amplitude of about $40 \mathrm{~m}$ at this time, obviously too large for recording and digitization. This is also obvious because Gilman (1960) shows that the gain at $200 \mathrm{~s}$ of this instrument is about six times higher than the standard Press-Ewing seismograph which had gone far off-scale by that time. We suspect that there is a typo for the listed start time and date, and the actual start time must have been somewhat later. We try several time windows, and find that a window from 5:11, 1960 May 23 (10 hr after the origin time) is reasonable from the decay pattern of the power spectrum (Supporting Information Section S4). (It is then possible that the listed time, 21:01, 1960 May 22, was the local time.) Fig. 11 compares the power spectrum of the synthetic seismograms computed for the cases with $\lambda=140^{\circ}$ and $\lambda=90^{\circ}$ with the observed power spectrum. Because of the complex mode pattern, we can make useful comparison for only three pairs of toroidal and spheroidal modes, ${ }_{0} \mathrm{~T}_{6}{ }_{0} \mathrm{~S}_{6}$,
${ }_{0} \mathrm{~T}_{8}{ }_{-} \mathrm{S}_{8}$ and ${ }_{0} \mathrm{~T}_{9}-{ }_{0} \mathrm{~S}_{9}$. For all of these modes, the T/S amplitude ratio for the $\lambda=140^{\circ}$ case (Fig. $11 \mathrm{~b}$ ) is more compatible with the observation than the $\lambda=90^{\circ}$ case (Fig. 11c). On the spectrum for the $\lambda=140^{\circ}$ case, ${ }_{0} \mathrm{~T}_{8}$ and ${ }_{0} \mathrm{~T}_{9}$ are much larger than ${ }_{0} \mathrm{~S}_{8}$ and ${ }_{0} \mathrm{~S}_{9}$, respectively, similar to the observed spectrum. In contrast, for the $\lambda=90^{\circ}$ case, ${ }_{0} \mathrm{~T}_{8}$ and ${ }_{0} \mathrm{~S}_{8}$, and ${ }_{0} \mathrm{~T}_{9}$ and ${ }_{0} \mathrm{~S}_{9}$ are comparable in amplitude. Although the exact peak position of ${ }_{0} \mathrm{~S}_{6}$ is a little unclear, the amplitude ratio ${ }_{0} \mathrm{~T}_{6} /{ }_{0} \mathrm{~S}_{6}$ for the $\lambda=140^{\circ}$ case appears more consistent with the observed than the $\lambda=90^{\circ}$ case. Also the observed spectrum shows two small peaks near ${ }_{0} \mathrm{~T}_{6}$ and ${ }_{0} \mathrm{~T}_{10}$ (green circles). The spectrum for the $\lambda=140^{\circ}$ model exhibits corresponding peaks (green circles), while these peaks are missing on the spectrum of the $\lambda=90^{\circ}$ model. These peaks probably correspond to ${ }_{1} \mathrm{~S}_{4}$ and ${ }_{2} \mathrm{~S}_{6}$. Thus, the spectral pattern of the Pasadena ultralong period record is consistent with the $\lambda=140^{\circ}$ model.

Although the patterns change as the start time changes, the change is not very significant at this long period. For example, the results for an early window (1.83-22.66 hr) and a late window (25-45.83 hr) are essentially the same and the $\lambda=140^{\circ}$ case is favoured in both time windows (Supporting Information Section S4).

\subsection{Pasadena (linear strain record)}

A linear strainmeter developed by Benioff (1935) had been in operation at Pasadena $\left(34.148^{\circ} \mathrm{N}, 118.172^{\circ} \mathrm{W}\right)$ from the $1930 \mathrm{~s}$ to $1960 \mathrm{~s}$. 
(a) BRK Press-Ewing

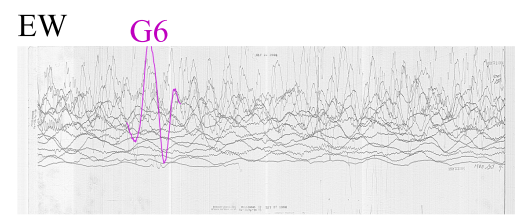

NS

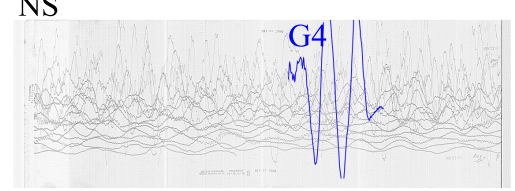

UD

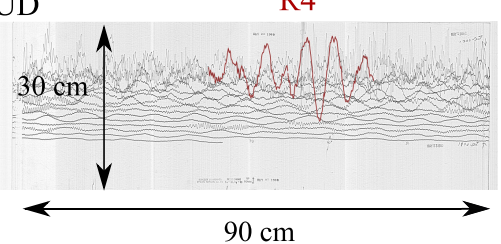

(b) $\left(\lambda=140^{\circ}\right)$
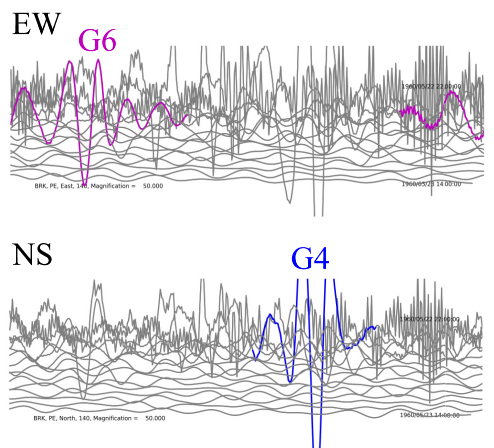

UD

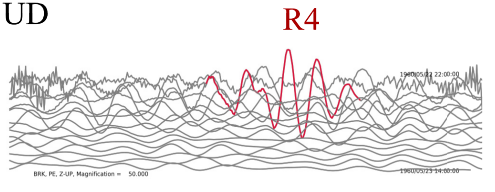

(c) $\left(\lambda=90^{\circ}\right)$

EW
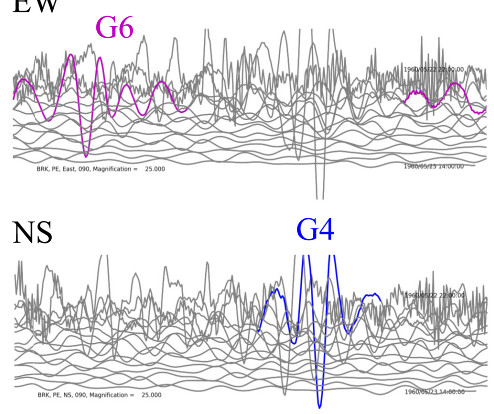

UD $\quad$ R4

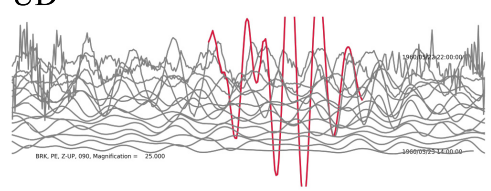

Figure 8. (a) Press-Ewing seismograms of the 1960 Chilean earthquake recorded at Berkeley (BRK), California. R4, G4 and G6 are traced. (b) Synthetic Press-Ewing seismograms of the 1960 Chilean earthquake for Berkeley computed with $\lambda=140^{\circ}$ and plotted in the helicoidal drum recording format to facilitate comparison with the observed. (c) Similar to (b) but with $\lambda=90^{\circ}$.

1960 Chile BRK Press-Ewing (30-90-2300) synthetics

(Start time 5/22/1960 22:00, Amplitude, $m$ )
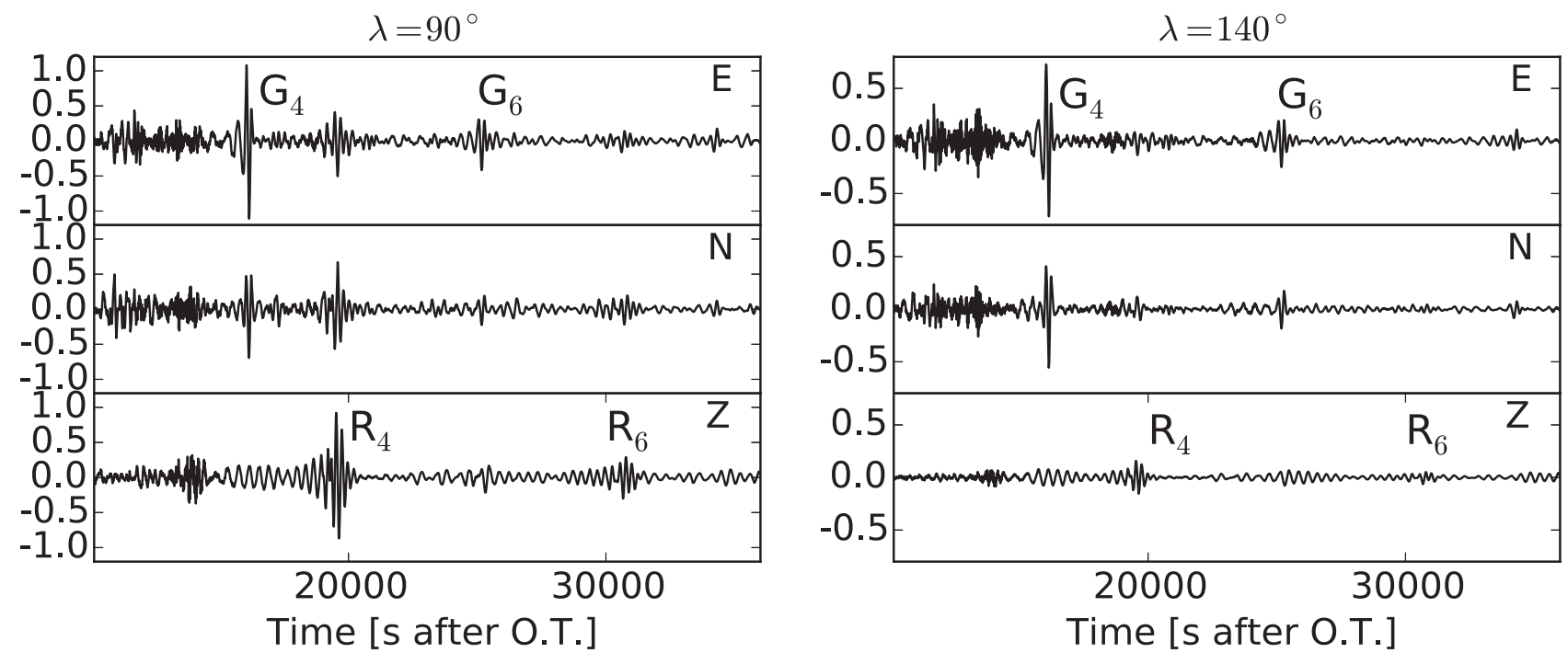

Figure 9. Synthetic Press-Ewing seismograms at Berkeley computed for $\lambda=90^{\circ}$ (left) and $\lambda=140^{\circ}$ (right) cases. The instrument constants are: pendulum period $=30 \mathrm{~s}$, pendulum damping constant $=1.0$, galvanometer period $=30 \mathrm{~s}$, galvanometer damping constant $=1.0$, coupling constant $=0.05$ and peak gain $=2300$.

Table 5. Peak-to-peak surface-wave amplitudes in $\mathrm{cm}$ on BRK Press-Ewing seismograms for the 1960 Chilean earthquake.

\begin{tabular}{lcccccc}
\hline & & \multicolumn{2}{c}{ Syn. Amp. (Gain $\times 2300)$} & & \multicolumn{2}{c}{ Syn. Amp. $($ Gain $\times 1000)$} \\
\cline { 3 - 3 } \cline { 6 - 7 } Phase & Obs. $(\mathrm{cm})$ & $\lambda=90^{\circ}$ & $\lambda=140^{\circ}$ & & $\lambda=90^{\circ}$ & $\lambda=140^{\circ}$ \\
\hline R4 & 14.9 & $178.8(8.84)$ & $31.0(9.33)$ & & $77.7(9.08)$ & $13.5(9.57)$ \\
G6 & 22.4 & $72.0(9.21)$ & $44.3(9.35)$ & & $31.3(9.45)$ & $19.3(9.60)$ \\
\hline
\end{tabular}

Note: The numbers in parentheses are estimated $M_{\mathrm{w} .}$. 
(a)

Synthetics (SP16b30) source $s / d=10 / 1710$ point source finite $M_{0}=2.7 \times 10^{23} \mathrm{Nm} 30-90-2300$

(b)

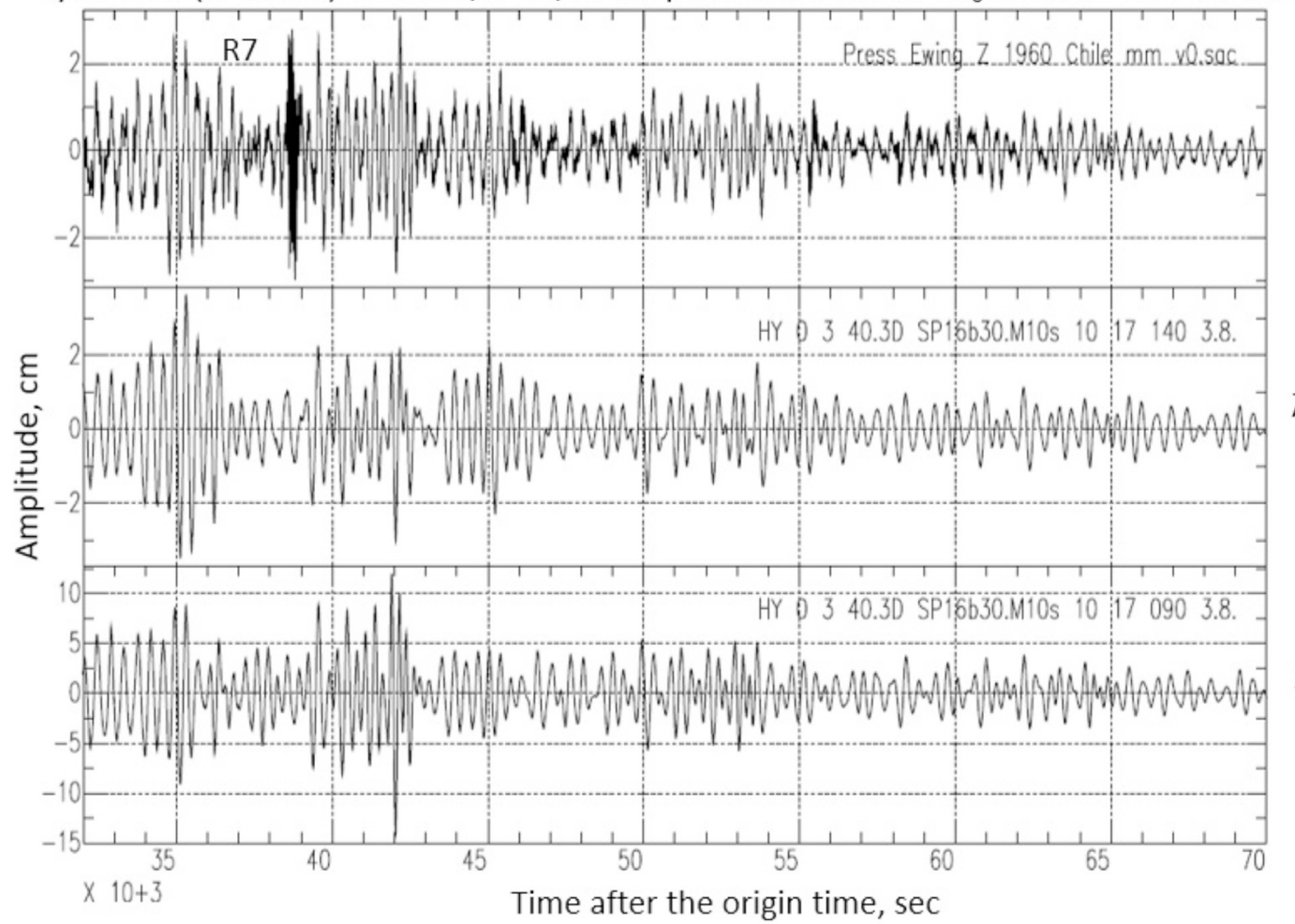

Obs.

(c)

(d)

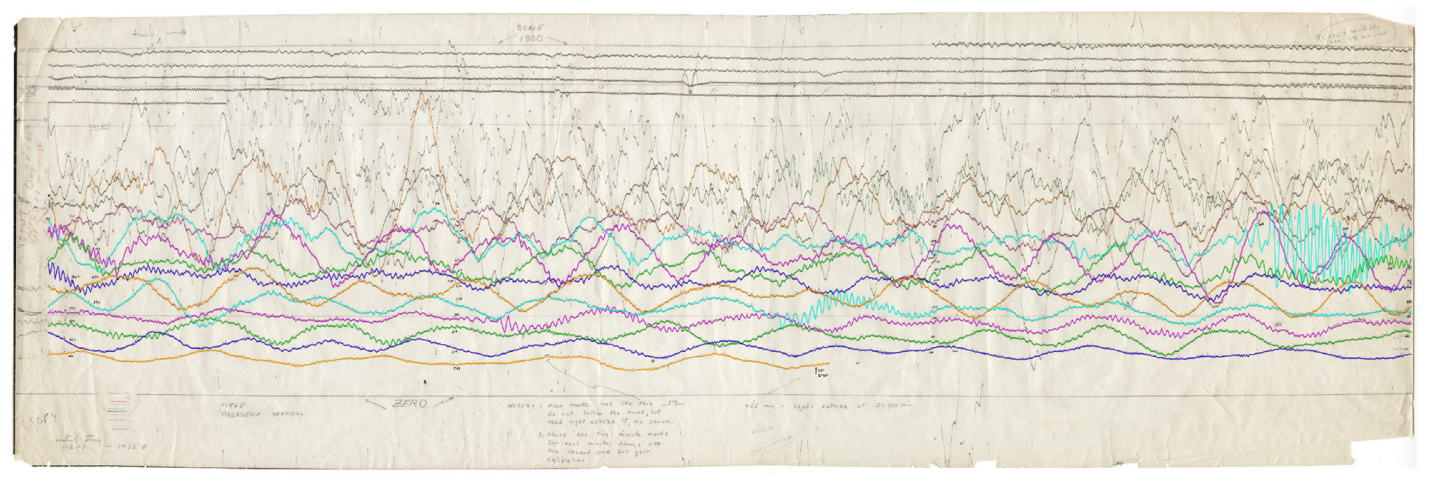

Figure 10. Comparison of the vertical component of the PAS Press-Ewing seismogram (a and d) with the synthetics computed for the $\lambda=140^{\circ}$ (b) and $\lambda=90^{\circ}$ (c) models for the 1960 Chilean earthquake. The high-frequency signal at about $38500 \mathrm{~s}$ is an $M_{\mathrm{S}}=6.4$ (ISC) aftershock.

Table 6. Peak-to-peak surface-wave amplitude in cm on PAS Press-Ewing seismogram for the 1960 Chilean earthquake.

\begin{tabular}{lccc}
\hline & & \multicolumn{2}{c}{ Syn. Amp. (Gain $\times 2300)$} \\
\cline { 3 - 4 } Phase & Obs. (cm) & $\lambda=90^{\circ}$ & $\lambda=140^{\circ}$ \\
\hline R7 & 5.4 & $16.1(9.24)$ & $6.2(9.51)$ \\
\hline
\end{tabular}

The numbers in parentheses are estimated Mw.

The 1960 Chilean earthquake was recorded with this instrument, and Kanamori \& Cipar (1974) used the record to determine the mechanism of the 1960 Chilean earthquake. Now having calibrated the ISA strainmeter we can compare the PAS and ISA records. Fig. 12 compares G2 and R2 of the 1960 Chilean earthquake recorded at ISA and PAS (Table 1, \#25). The ISA record shows direct extensional strain in $\mathrm{N} 38^{\circ} \mathrm{W}$ without any filter. The PAS record is from the Benioff strainmeter with the rod in NS orientation. The Pasadena strainmeter has a velocity transducer and its output is fed to a galvanometer with a period of $180 \mathrm{~s}$ and a nominal damping ratio of 4. However, the actual instrument constants were not documented well, and could have changed from time to time. The response is relatively constant over a period from 200 to 300 s so that G2 and $\mathrm{R} 2$ waves recorded on these two records can be compared approximately. The observed G2/R2 amplitude ratio is about the same between ISA and PAS. The R2 is in phase but G2 is almost $180^{\circ}$ out of phase between ISA and PAS. Since the great circle path is in between the strain rods of ISA and PAS, the opposite polarity of G2 between PAS and ISA is consistent with this geometry. However, the similar G2/R2 amplitude ratio at ISA and PAS is difficult to reconcile, because the amplitude ratio can be similar only if the great circle path evenly bisects the angle between the two strainmeter rods. We can think of at least 2 causes to explain this observation: (1) The incident path is off by about $15^{\circ}$ from the great circle path; 
(a)

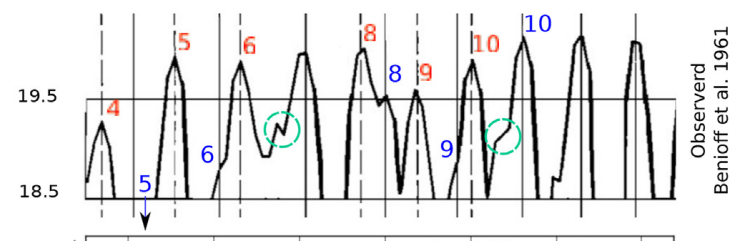

(b)

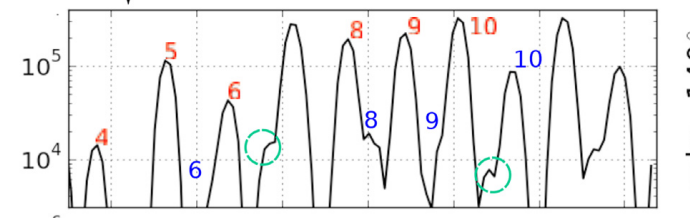

(c)

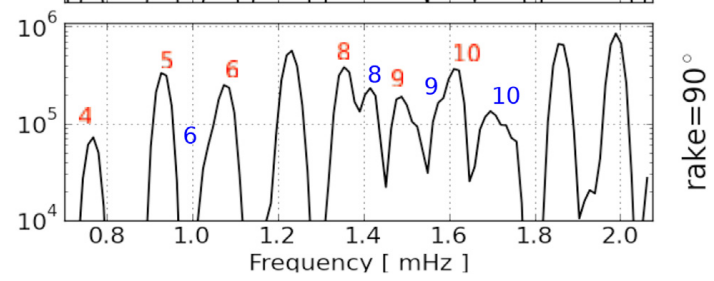

Figure 11. (a) Power spectrum of the EW component ultralong period seismogram at Pasadena for the 1960 Chilean earthquake (modified from Fig. 5; BPS-1961). (b) Power spectrum computed for the $\lambda=140^{\circ}$ model. (c) Power spectrum computed for the $\lambda=90^{\circ}$ model. Red and blue numbers are the toroidal and spheroidal order numbers, respectively.

(2) The strain field is locally rotated around the station for some reason. We examine the incident angle of $\mathrm{G}$ and Rayleigh waves at PAS, ISA and PFO using the surface waves from the 1995 Antofagasta, and the 2010 Maule earthquakes in Chile. We find that the incident ray is most likely within $\pm 5^{\circ}$ of the great circle path at periods longer than $200 \mathrm{~s}$. Thus, we reject (1). Regarding the perturbation of local strain field, as we will show in the next section, the ISA strain records of the 1964 Alaskan earthquake, the 1960 June 6 Chilean aftershock, and the 1957 Mongolia earthquake are consistent with the theoretical strain field without any sign of anomalous rotation. It is also consistent with the earth-tidal strain. In contrast, we had no means to calibrate the Pasadena strainmeter. Because of the high-pass filtering caused by the velocity transducer, no earth tide record is available for calibration.

The Pasadena strainmeter rod is only $20 \mathrm{~m}$ long and it was installed in a narrow open tunnel just adjacent to the structure of the Seismological Laboratory.

The effect of nearby tunnel wall on local tilt has been discussed by several investigators (e.g. appendix B of Zürn et al. 2015). In contrast, the Isabella strainmeter is deployed in a large tunnel and is less likely affected by the wall. Thus, if we are to choose between the ISA and PAS records for this study, the obvious choice would be the ISA record. This incompatibility is somewhat uncomfortable, but we cannot resolve this question at present.

\section{5 Ñaña (NNA), Peru}

Benioff et al. (1961) published a normal-mode spectrum of the 1960 Chilean earthquake obtained from strain seismograms recorded at Ñaña (NNA, $11.988^{\circ} \mathrm{S}, 76.842^{\circ} \mathrm{W}$ ), Peru (Supporting Information Fig. S8). Unfortunately, the original seismograms, either analogue or digitized, used to compute the spectrum are no longer available, but the toroidal to spheroidal spectral amplitude ratios can be estimated from the spectrum published in BPS-1961. Some questions regarding the orientations of the strainmeter rods remain. In BPS1961 , the orientations of the two strain rods are listed as $\mathrm{N} 51^{\circ} \mathrm{W}$ and $\mathrm{N} 39^{\circ} \mathrm{E}$. However, on the paper records of a short segment kept at the Caltech archive, $\mathrm{N} 51^{\circ} \mathrm{W}$ was changed to $\mathrm{N} 29^{\circ} \mathrm{W}$. In a later publication (Benioff 1963), the orientation of the Ñana strain record is clearly marked as $\mathrm{E} 29^{\circ} 35^{\prime} \mathrm{N}$ (i.e. N60.4 ${ }^{\circ} \mathrm{E}$ ). Also, the two components of NNA strain record are clearly marked as $\mathrm{N} 30^{\circ} \mathrm{W}$ and $\mathrm{E} 30^{\circ} \mathrm{N}$ (i.e. N60 ${ }^{\circ} \mathrm{E}$ ) in Press (1965). We assume that the orientations listed in the later papers are correct, and use $\mathrm{N} 61^{\circ} \mathrm{E}$ and $\mathrm{N} 29^{\circ} \mathrm{W}$, but some uncertainties remain.

Unfortunately, the spectrum of only one component in $\mathrm{N} 29^{\circ} \mathrm{W}$ direction was published in BPS-1961. The Naña record is noisy. Judging from the coherence between the ISA and NNA spectrum shown in fig. 1 of BPS-1961 (also Supporting Information Fig. S8), we consider only ${ }_{0} \mathrm{~S}_{6},{ }_{0} \mathrm{~S}_{8},{ }_{0} \mathrm{~S}_{9},{ }_{0} \mathrm{~S}_{10},{ }_{0} \mathrm{~T}_{6},{ }_{0} \mathrm{~T}_{8},{ }_{0} \mathrm{~T}_{9}$ and ${ }_{0} \mathrm{~T}_{10} \cdot{ }_{0} \mathrm{~S}_{7}$ and ${ }_{0} \mathrm{~T}_{7}$ are indistinguishable). The average of the power spectral ratios of ${ }_{0} \mathrm{~T}_{6} /{ }_{0} \mathrm{~S}_{6},{ }_{0} \mathrm{~T}_{8} /{ }_{0} \mathrm{~S}_{8},{ }_{0} \mathrm{~T}_{9} /{ }_{0} \mathrm{~S}_{9}$ and ${ }_{0} \mathrm{~T}_{10} /{ }_{0} \mathrm{~S}_{10}$ is 0.41 .

We compute the power spectrum of these modes for three models, PREM, S40RTS (Ritsema et al. 2011) and SP16b30 (Masters et al. 1996). Since we are primarily interested in whether the ratio of the power in toroidal modes to that in spheroidal modes is different between the $\lambda=90^{\circ}$ and $\lambda=140^{\circ}$ models, we compute the ratio of the geometrical average of power spectrum of toroidal and spheroidal modes,

$R=\frac{\text { geometrical average of power spectra }{ }_{0} \mathrm{~T}_{i}(i=6,8,9,10)}{\text { geometrical average of power } \operatorname{spectra}_{0} \mathrm{~S}_{i}(i=6,8,9,10)}$

and compare them with the observed ratio. Table 7 shows the result.

Since the spectral structure is complex, the ratios are considerably different even for the two 3-D models. Nevertheless, the observed ratio, 0.41 , is much closer to the ratios for the $\lambda=140^{\circ}$ model $\left(0.457,0.185\right.$ and 0.362 for the three models) than the $\lambda=90^{\circ}$ model $(0.116,0.074$ and 0.074$)$. However because of the noisy data, the result is only of marginal significance.

The results of additional analyses on surface waves are summarized in Supporting Information Section S5.

\subsection{Tsukuba (TSK), Japan}

More than ten seismic stations with long-period pendulum seismographs were in operation globally at the time of the 1960 Chilean earthquake. Among them are those operated by the Lamont Geological Observatory in cooperation with local institutions during the International Geophysical Year (IGY). Alsop (1964) analysed longperiod vertical component seismograms at eight stations around the world and published the spectra of spheroidal modes. Cifuentes \& Silver (1989) analysed the vertical component of many of these records to determine the low-frequency characteristics of the 1960 Chilean earthquake. The main focus of Alsop's (1964) study was on the normal-mode periods rather than amplitudes. Cifuentes \& Silver (1989) assumed a low-angle thrust mechanism for the Chilean earthquake and demonstrated that the normal-mode data are consistent with the assumed mechanism if the uncertainties in the instrument response are allowed for. In these studies, only vertical component records were used. For our present study, it is essential to use both vertical and horizontal components, because the relative excitation of toroidal and spheroidal modes is the key to resolving the mechanism. It is also essential to have either time domain data with surface wave trains with orbit index 1 or 2 (i.e. G1, R1, G2 and R2), or high-quality spectral data for a period longer than $560 \mathrm{~s}$ (i.e. frequency lower than $1.8 \mathrm{mHz}$ ). Unfortunately, these pendulum instruments are often clipped for the first few hours, and we lose the key information for constraining the mechanism. Also, the response of these pendulum instruments at long periods (longer than $500 \mathrm{~s}$ ) is not satisfactory for our purpose. For example, as shown in 


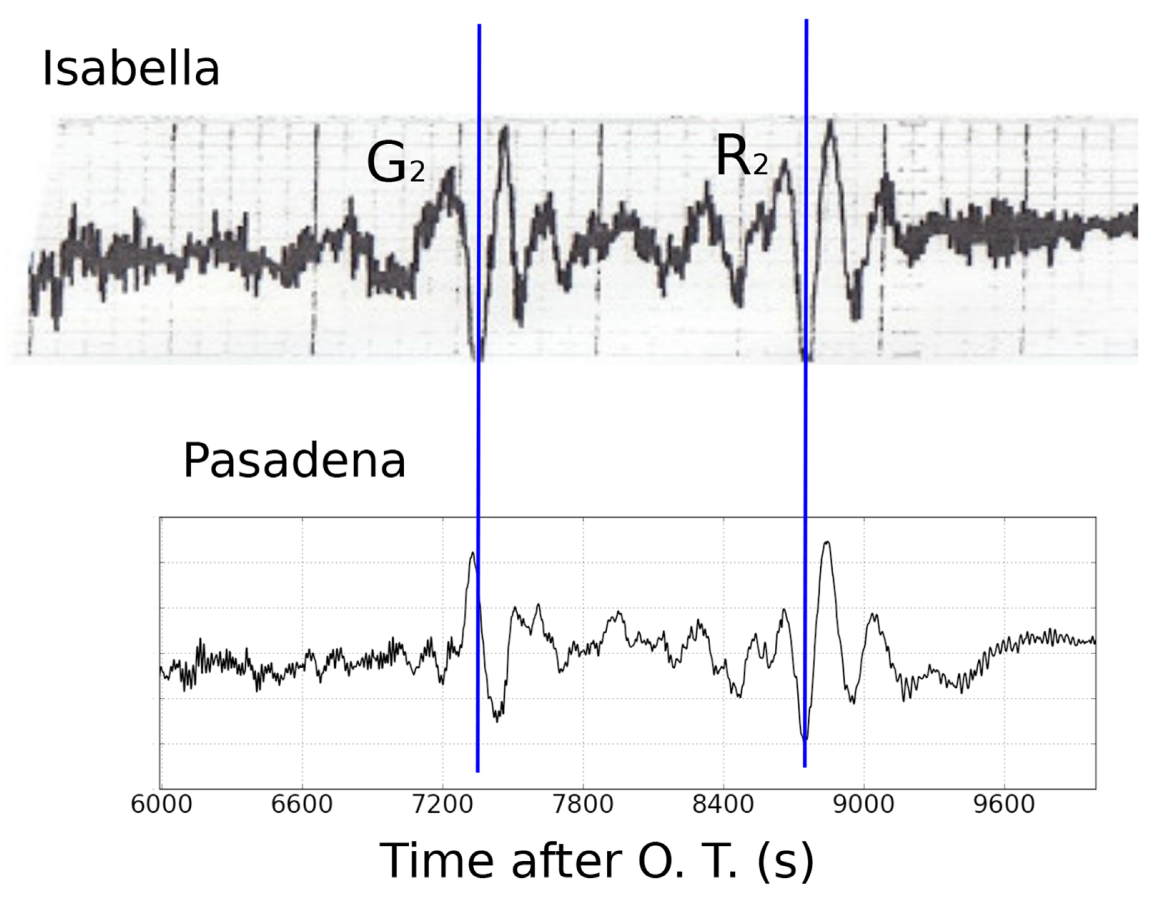

Figure 12. Comparison of the strain seismograms at ISA (N38.8 W) (top) and PAS (NS) (bottom) for the 1960 Chilean earthquake.

Table 7. Ratio of geometrical average of power spectrum at NNA for the 1960 Chilean earthquake.

\begin{tabular}{ccccccccc}
\hline & \multicolumn{2}{c}{ PREM } & & \multicolumn{2}{c}{ S40RTS } & & \multicolumn{2}{c}{ SP16b30 } \\
\cline { 2 - 3 } Obs. & $\lambda=90^{\circ}$ & $\lambda=140^{\circ}$ & & $\lambda=90^{\circ}$ & $\lambda=140^{\circ}$ & & $\lambda=90^{\circ}$ & $\lambda=140^{\circ}$ \\
\hline 0.41 & 0.116 & 0.457 & & 0.074 & 0.185 & & 0.074 & 0.362 \\
\hline
\end{tabular}

Figs 13(c) and (d), the spectral amplitude of the seismogram we are concerned with over a frequency band of $1-1.8 \mathrm{mHz}$ is about $30 \mathrm{~m} \mathrm{~s}$. Since the duration of our record is $50660 \mathrm{~s}$ (\#26 and \#27, Table 1), this spectral amplitude translates to the average time-domain trace amplitude of approximately $2 *(30 \mathrm{~m} \mathrm{~s}) / 50660 \mathrm{~s}=1.2 \mathrm{~mm}$ (see Supporting Information Section S2) which is too small for accurate spectral measurements.

Nevertheless, in view of the potential importance of these records, we investigate the records from Mount Tsukuba Observatory (TSK, $36.211^{\circ} \mathrm{N}, 140.110^{\circ} \mathrm{E}$ ) of the Earthquake Research Institute (ERI) of the University of Tokyo. Fortunately high quality copies of the paper records are archived at ERI and were made available to us. We digitized the three component records at a sampling rate of $1 \mathrm{~s}$ from 4:40 UT, 5/23/1960 to 4:04 UT, 5/24/1960. The records are completely off-scale for about $9 \mathrm{hr}$ and $29 \mathrm{~min}$ after the origin time and are not usable.

The instrument response parameters for the period that brackets 1960 May 22 (the date of the Chilean earthquake) are published in the TSK Bulletin and the response curves are shown in Fig. D3. These response curves are somewhat different from those given by Miller (1963), especially for the vertical component. Since the response was known to have changed over time (Miller 1963), these responses should be considered only approximate.

Given the limited long-period characteristics of these instruments, we analyse these data as follows. The location of TSK (azimuth $=275^{\circ}$ ) is very unique for distinguishing the models with $\lambda=90^{\circ}$ and $140^{\circ}$. For the $\lambda=90^{\circ}$ model, TSK is almost in the nodal direction of $\mathrm{G}$ waves and the toroidal modes for order numbers higher than 5 (Fig. $3 \mathrm{~g}$ ). In contrast, for the $\lambda=140^{\circ}$ model, both $\mathrm{G}$ and $\mathrm{R}$ and toroidal and spheroidal modes are expected with about equal amplitudes at TSK (Fig. 3g). Also the backazimuth of Chile at TSK is $104.5^{\circ}$. Thus, the amplitude on the NS component is expected to be very small for the $\lambda=90^{\circ}$ model, while the $\lambda=140^{\circ}$ model would produce the NS and EW component records with about the same amplitude. This situation can be best illustrated by Fig. 13(a), which compares the normal mode spectrum of the synthetic displacement records for the $\lambda=90^{\circ}$ and $\lambda=140^{\circ}$ models over a frequency band from 0 to $3 \mathrm{mHz}(330 \mathrm{~s}$ ) (Table 1, \#26). We compute all the spectra for the record starting at $34140 \mathrm{~s}(9.48 \mathrm{hr})$ after the origin time with a duration of $50660 \mathrm{~s}$ (14 hr $4 \mathrm{~min}$ and $20 \mathrm{~s}$ ) with a 20 per cent Hanning taper both in the beginning and at the end. The spectral amplitudes of the vertical and EW component are essentially the same for the two models, but the NS component spectrum is much smaller for the $\lambda=90^{\circ}$ model (red in Fig. 13a) than the $\lambda=140^{\circ}$ model (green in Fig. 13a). Thus, we initially thought that we can distinguish the two models easily. Unfortunately, two factors make the comparison more difficult than we thought. First, we need to convolve the instrument response with the synthetic displacement record. Fig. 13(b) is the spectrum thus computed for the instrument-convolved records (Table 1, \#27). For this computation we use a generic response for the TSK type instruments: $T_{s}=15 \mathrm{~s}$, $T_{g}=75 \mathrm{~s}, h_{s}=1 ., h_{g}=1 ., \sigma^{2}=0.25, V_{\max }=1000$. Hereafter we call this the IGY response. Although the difference of the NS component spectrum between the two models is still visible, it is less obvious because of the diminishing gain of the IGY response at long period. These spectra are computed without the effect of rotational mode coupling. If the effect of mode coupling due to rotation and the lateral structural heterogeneity given by the earth model S40RTS is 

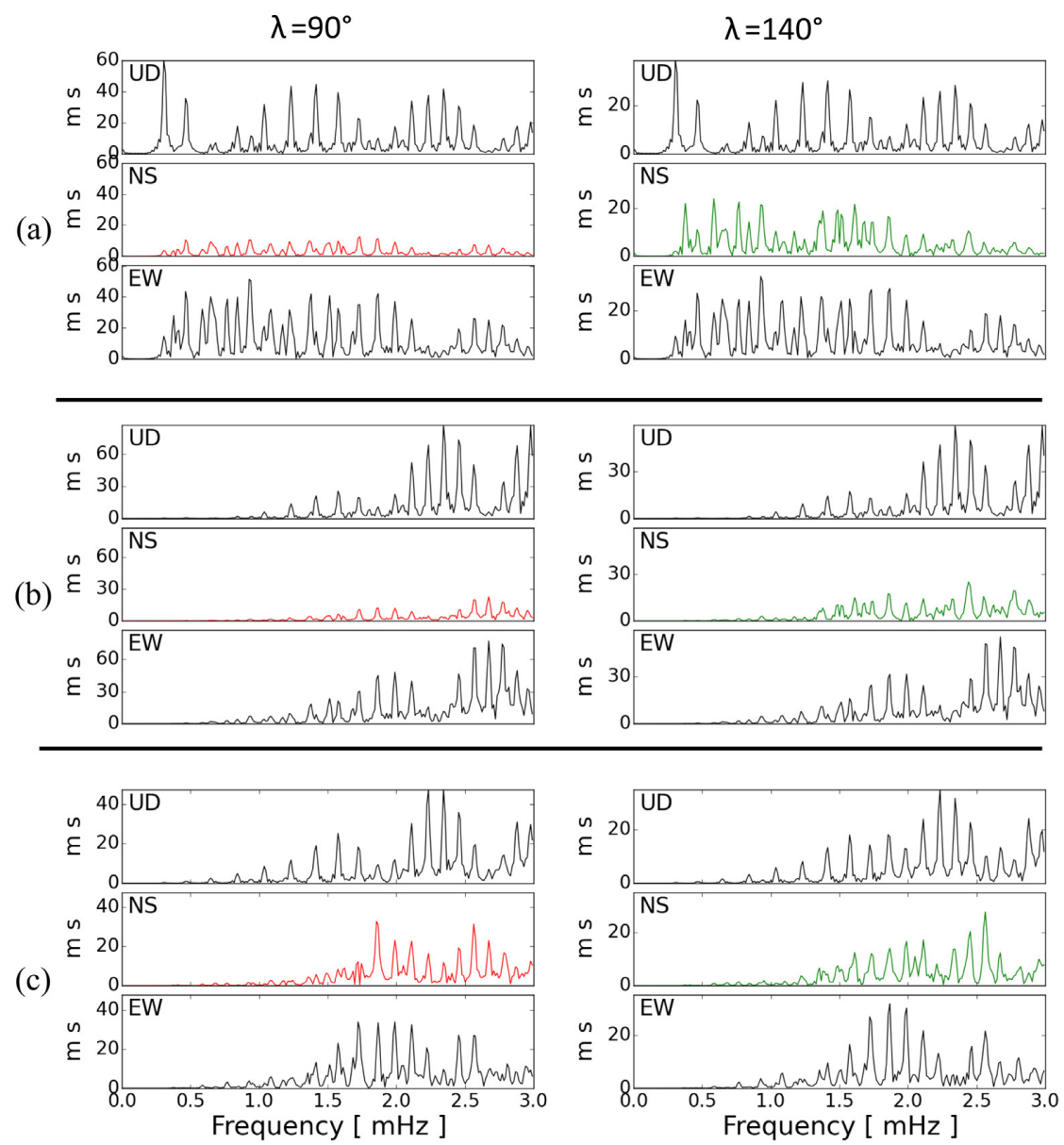

(a) Synthetic displacement

(point source, no coupling)

(b) Synth. disp. * IGY response

(point source, no coupling)

(c) Synth. disp.*IGY response

(finite source, rotation, 3D)

(d) TSK Observed

(d)

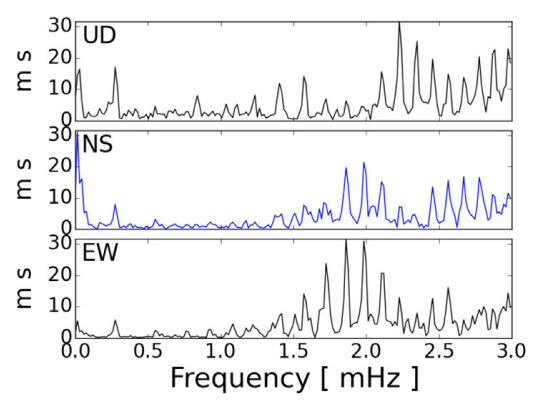

Figure 13. (a) Comparison of the synthetic spectra at TSK for the mechanisms with $\lambda=90^{\circ}$ and $\lambda=140^{\circ}$. (b) Same as (a) but instrument response is convolved. (c) Same as (b) but the effect of rotational and 3-D (S40RTS) mode coupling is included. (d) Spectra of the seismograms observed at TSK.

included, we obtain the spectra shown in Fig. 13(c) (Table 1, \#28). Since the spheroidal modes around $1.86 \mathrm{mHz}\left({ }_{0} \mathrm{~S}_{11}\right)$ and $2.78 \mathrm{mHz}$ $\left.{ }_{0} \mathrm{~S}_{19}\right)$ are strongly coupled with the nearby toroidal modes ${ }_{0} \mathrm{~T}_{12}$ and ${ }_{0} \mathrm{~T}_{20}$, respectively, the NS components exhibit prominent energy around these frequencies, and the difference in the NS component spectrum for the two models becomes even less obvious (red and green in Fig. 13c). Then the question is, given the noise in the data, whether we can distinguish the two models.

Fig. 13(d) shows the spectrum of the digitized observed TSK seismogram (Table 1, \#29). We multiplied UD, NS and EW components by $1.79,1.14$ and 1.0 , respectively. These factors are chosen to make the peak amplitude ratios of UD/EW and NS/EW at frequencies lower than $2 \mathrm{mHz}$ about the same between the observed and the synthetics in an overall sense. The calibration curves given by Miller (1963) show that the gain of the UD component is approximately 2.5 times lower than those of NS and EW at long period. On the other hand the calibration curves computed from the TSK Bulletin (Fig. D3) show that the gain of the UD component is about 1.26 times lower than that of the EW component, and the NS component is 1.15 times smaller than the EW component. Thus the adjustment of the gain we made above is reasonable. Given the noise in the data, it would be difficult to distinguish the two models.

Our results are not incompatible with the result of Cifuentes \& Silver (1989) because, given the uncertainties in the instrument calibration of old instruments, if we use only the vertical component the azimuthal variation of long-period Rayleigh waves and spheroidal modes can be made compatible with either $\lambda=90^{\circ}$ or $\lambda=140^{\circ}$ model.

\subsection{Wellington (WEL), New Zealand, Milne-Shaw record}

The 1960 Chilean earthquake recorded on the N-S component Milne-Shaw seismograph at Wellington $\left(41.280^{\circ} \mathrm{S}, 174.770^{\circ} \mathrm{E}\right)$ clearly shows G3 and R3 wave trains (Fig. 14, Table 1, \#30). It is very rare to see surface waves with the orbit index of 3 or larger on the classic seismograms like the Milne-Shaw. The synthetic waveforms computed for the $\lambda=140^{\circ}$ and $\lambda=90^{\circ}$ models are essentially the same in waveform and amplitude, and we cannot distinguish these two models. Fig. 14 compares the observed and synthetics $\left(\lambda=140^{\circ}\right.$ and $\left.\lambda=90^{\circ}\right)$ (Table $\left.1, \# 31\right)$. The amplitude ratios of the observed to the synthetic are 0.46 and 0.50 for G3 and R3, respectively. These correspond to $M_{\mathrm{w}}=9.33$ and 9.35 , respectively. However, these estimates depend on the instrument calibration. For example, on the Milne-Shaw seismogram at Auckland, G3 and R3 amplitudes are about 5 times smaller than those at Wellington. Since the static gain of the Auckland record is 150, $3 / 5$ of that of the Wellington record (Charlier \& Van Gils 1953), the observed records at Auckland and Wellington are not compatible in amplitude. At long period, the gain of the mechanical instrument is proportional to $\left(T_{s} T\right)^{2}$ ( $T$ : ground motion period, $T_{s}$ : natural period of the pendulum), and some drift of $T_{s}$ may be responsible for the change in gain. Also at the dominant period of G3 and R3 recorded 
1960 Chile Wellington Milne-Shaw NS

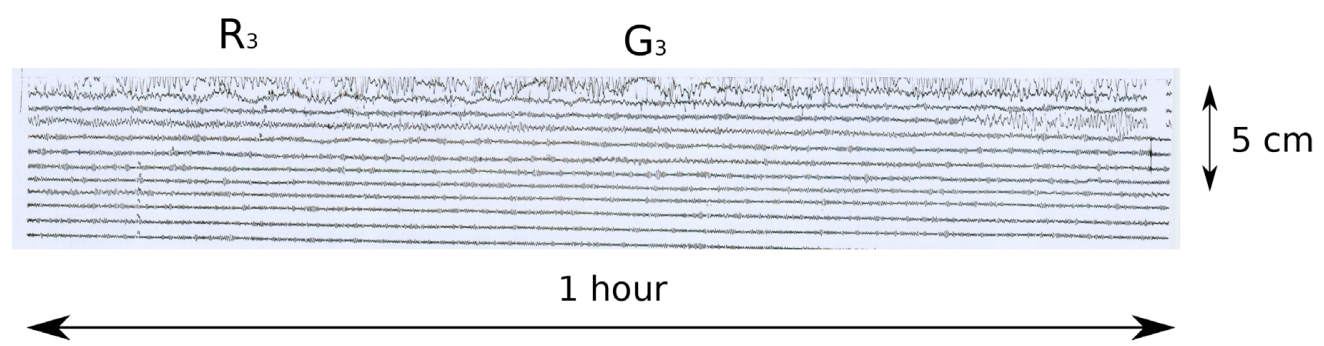

(a)

(b)

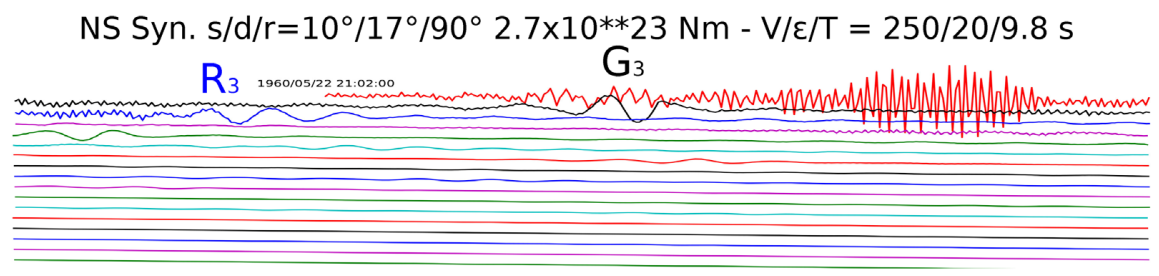

(c)

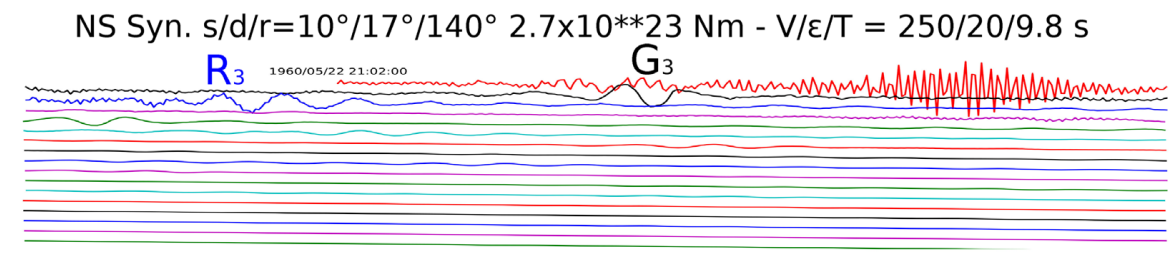

Figure 14. Comparison of G3 and R3 recorded on the N-S component Milne-Shaw seismogram at Wellington (WEL), New Zealand, for the 1960 Chilean earthquake with synthetic waveforms. (a) observed; (b) computed for the $\lambda=90^{\circ}$ model; (c) computed for the $\lambda=140^{\circ}$ model.

on the Milne-Shaw records (about $160 \mathrm{~s}$ ), the effect of attenuation and of the source spectrum can be significant, thus, the $M_{\mathrm{w}}$ estimates from the Wellington record are subject to some uncertainty.

\subsection{Other records}

The 1960 Chilean earthquake was recorded at Trieste, Italy (Bolt \& Marussi 1962; Braitenberg \& Zadro 2007), Palisades (PAL), Resolute (RES), Seven Falls (SFA) (Okal \& Talandier 1991), and Matsushiro (MAT), Japan.

For the records at PAL, RES and SFA, because of the uncertainties in the instrument constants, we cannot definitively decide which of the two models $\left(\lambda=90^{\circ}\right.$ versus $\left.\lambda=140^{\circ}\right)$ is better. However, unless the response used for PAL is drastically wrong, the observed/synthetic amplitude ratio of R4 appears too large to be compatible with the $\lambda=90^{\circ}$ model (Supporting Information Section S6).

The records at Trieste and Matsushiro are compatible with either the $\lambda=90^{\circ}$ or $\lambda=140^{\circ}$ models, as briefly discussed in Supporting Information Sections S7 and S8.

\section{ISA STRAINMETER RECORDS OF OTHER EARTHQUAKES}

A possibility remains that the anomalously large $\mathrm{G} / \mathrm{R}$ ratio (for the given strainmeter orientation) of the 1960 ISA record could be of instrumental origin. The tunnel surrounding the strainmeter may have perturbed the local strain field and what was measured may not have been the extensional strain in the rod direction. However, as shown in Fig. 1(c), rotation of strain field of as large as $30^{\circ}$ would be required to explain the observed G/R ratio, if $\lambda=90^{\circ}$. Such a rotation is probably too large to be caused by any local structural effect. Another possibility is that the suspension system of the rod and the displacement transducer may have been affected by transverse motion, thereby causing a spurious longitudinal signal (i.e. cross-coupling). Since these possibilities cannot be completely ruled out, we investigate the performance of the ISA strainmeter using the records of several other earthquakes.

\subsection{The 1964 Alaskan earthquake}

The most direct comparison can be made with the 1964 Alaskan earthquake $\left(M_{\mathrm{w}}=9.2\right)$. As shown in Fig. 4, while the spheroidal modes of the Alaskan earthquake were recorded clearly at ISA $\left(\mathrm{N} 38.8^{\circ} \mathrm{W}\right.$ rod), the toroidal modes at periods longer than $600 \mathrm{~s}$ are very small compared with the spheroidal modes. Since the angle $\alpha$ is small, $11.8^{\circ}$, this observation is expected.

The normal-mode spectrum was computed mainly for determination of the modal period from very long hand-digitized records with limited dynamic range and signal-to-noise ratio. In particular, in the later part of the record, the details of the amplitude patterns can be affected by complex propagation path effects, mode coupling and noise. Thus, we first investigate the time-domain surface waves with orbit index of 2 and 3 which more directly reflect the radiation pattern. By the time of the Alaskan earthquake another strainmeter rod had been installed at ISA in the $\mathrm{N} 51^{\circ} \mathrm{E}$ direction (Smith 1966). Analogue records of the initial part of the ISA strain seismograms are still available for both the $\mathrm{N} 38.8^{\circ} \mathrm{W}$ and $\mathrm{N} 51^{\circ} \mathrm{E}$ components. Fig. 15 compares these records with the synthetics (Table 1, \#32, \#33). The mechanism parameters used for computation are strike, $\phi_{\mathrm{s}}=\mathrm{N} 115^{\circ} \mathrm{W}, \operatorname{dip}, \delta=10^{\circ}$, and rake, $\lambda=90^{\circ}$, depth, $H=20 \mathrm{~km}$. The source consists of six subevents distributed over $600 \mathrm{~km}$ (more details in Appendix A). These time series records show almost perfect agreement between the synthetic and observed for both 
(a)
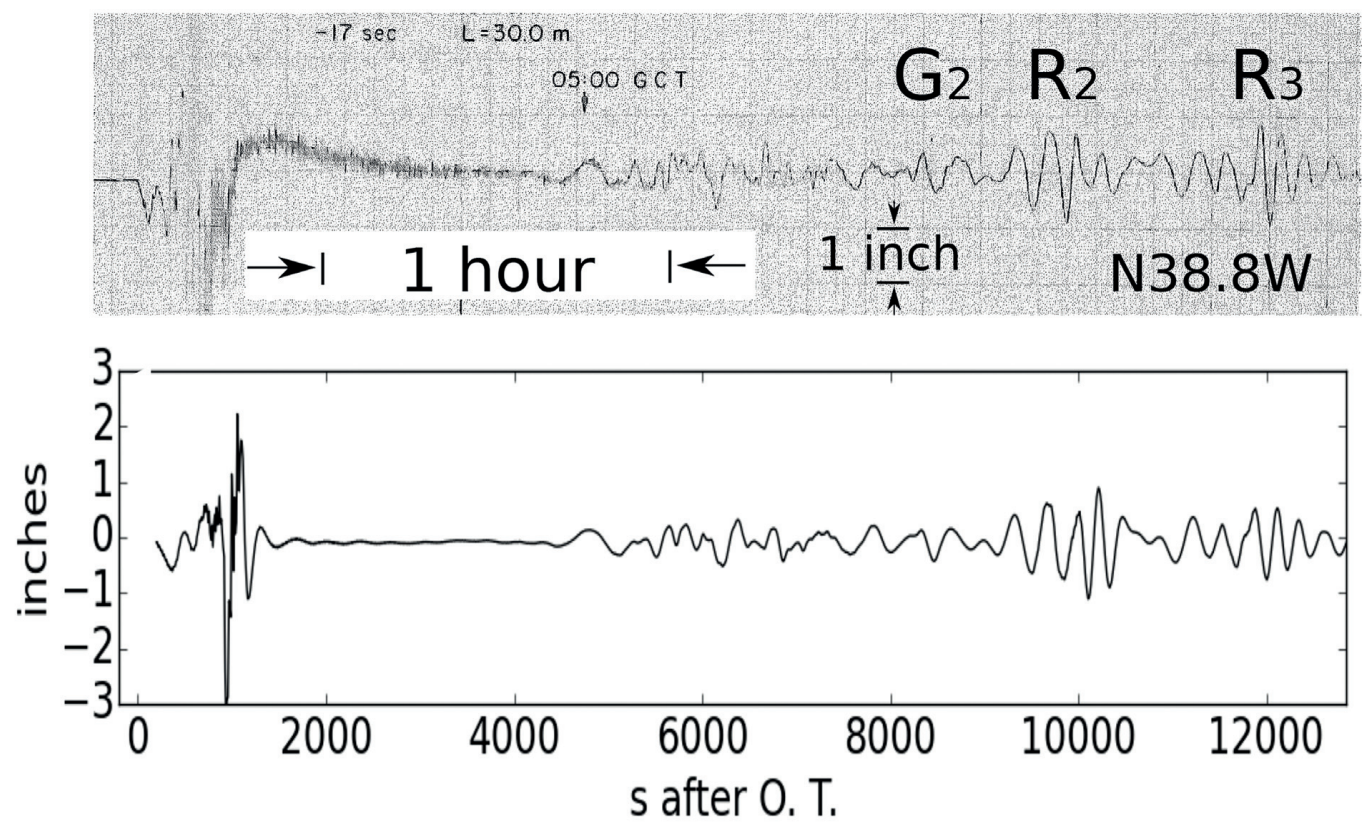

(b)
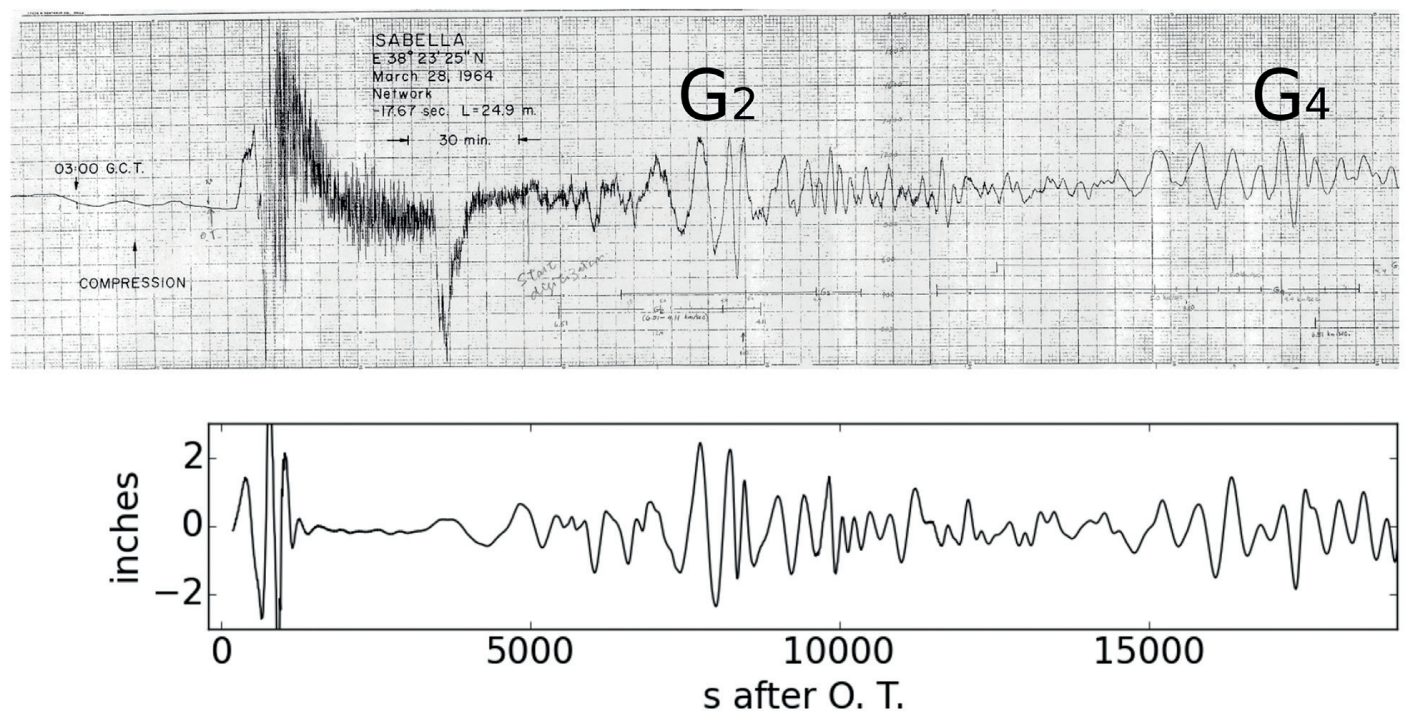

Figure 15. Comparison of the observed and 1-D synthetic surface waves recorded at ISA for the 1964 Alaskan earthquake. The source mechanism is $\left(\phi_{\mathrm{s}}=245^{\circ}\right.$, $\delta=10^{\circ}, \lambda=90^{\circ}$ ) with a seismic moment of $7.5 \times 10^{22} \mathrm{Nm}$. (a) N38.8 $\mathrm{W}$ component. (b) N51.2 ${ }^{\circ} \mathrm{E}$ component.

$\mathrm{N} 38.8^{\circ} \mathrm{W}$ and $\mathrm{N} 51^{\circ} \mathrm{E}$ components confirming that the ISA strainmeter was functioning completely normally for the 1964 Alaskan earthquake.

We also compare the observed normal-mode spectrum with that computed for the Alaskan earthquake (Fig. 16a, Table 1,\#34). The observed $(\mathrm{T} / \mathrm{S})_{\text {power }}$ ratios on the $\mathrm{N} 38.8^{\circ} \mathrm{W}$ component are in general consistent with those of the synthetic, given the background noise, indicating no evidence for anomalous behaviour of the ISA strainmeter.

We make a similar comparison for the $\mathrm{N} 51^{\circ} \mathrm{E}$ component strain record as shown in Fig. 16(b) (Table 1, \#35). For this component, a digitized record is available. The observed and synthetic Fourier spectrum computed for the RPREM model is similar. The T/S ratio of the average spectral amplitudes for the modes is 0.60 and agrees reasonably well with the observed ratio, 0.78 , given the background noise of about $0.4 \mu$-strain s. However, the spectral amplitudes computed for the two 3-D models, SP16b30 and S40RTS, are visibly different from that for RPREM. It is interesting that these three models yield essentially the same waveforms for the time window that includes G2, R2 (very small) and G4 as shown in Fig. 15. This is the main argument for the normal behaviour of the ISA strainmeter.

We tested the three earth models for the PFO strain spectrum for the 2010 Maule, Chile, earthquake. We did not see any obvious differences as shown in Supporting Information Fig. S5. However, as discussed in Supporting Information Section S9, the variability of spectrum for different models is not systematic, suggesting that the long path length (nearly 30 times around the earth with a group 
(a) Alaska 1964, ISA_N38.8W B6s_245109035_225 3D_S40RTS [17100 s + 471240 s; $0.2-.0 .2]$
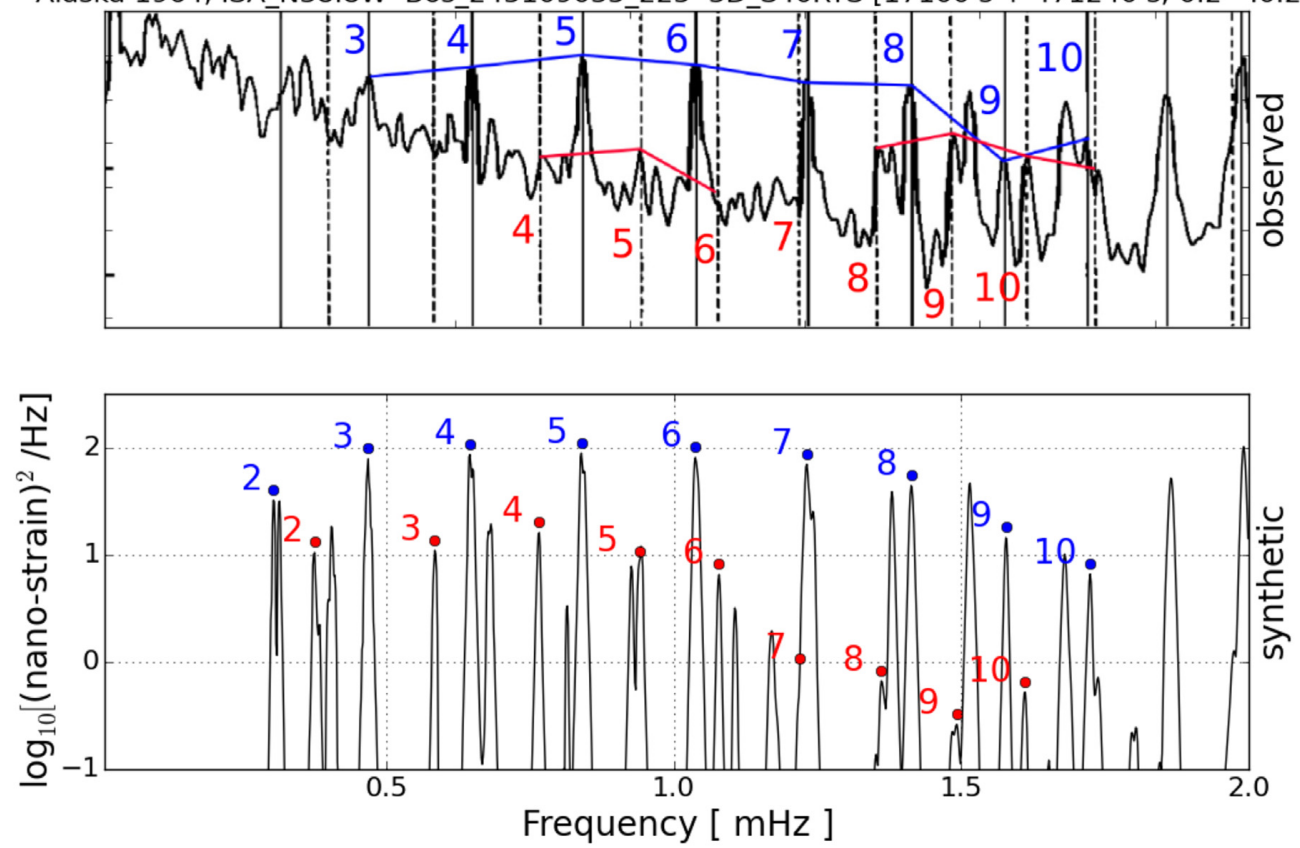

(b)

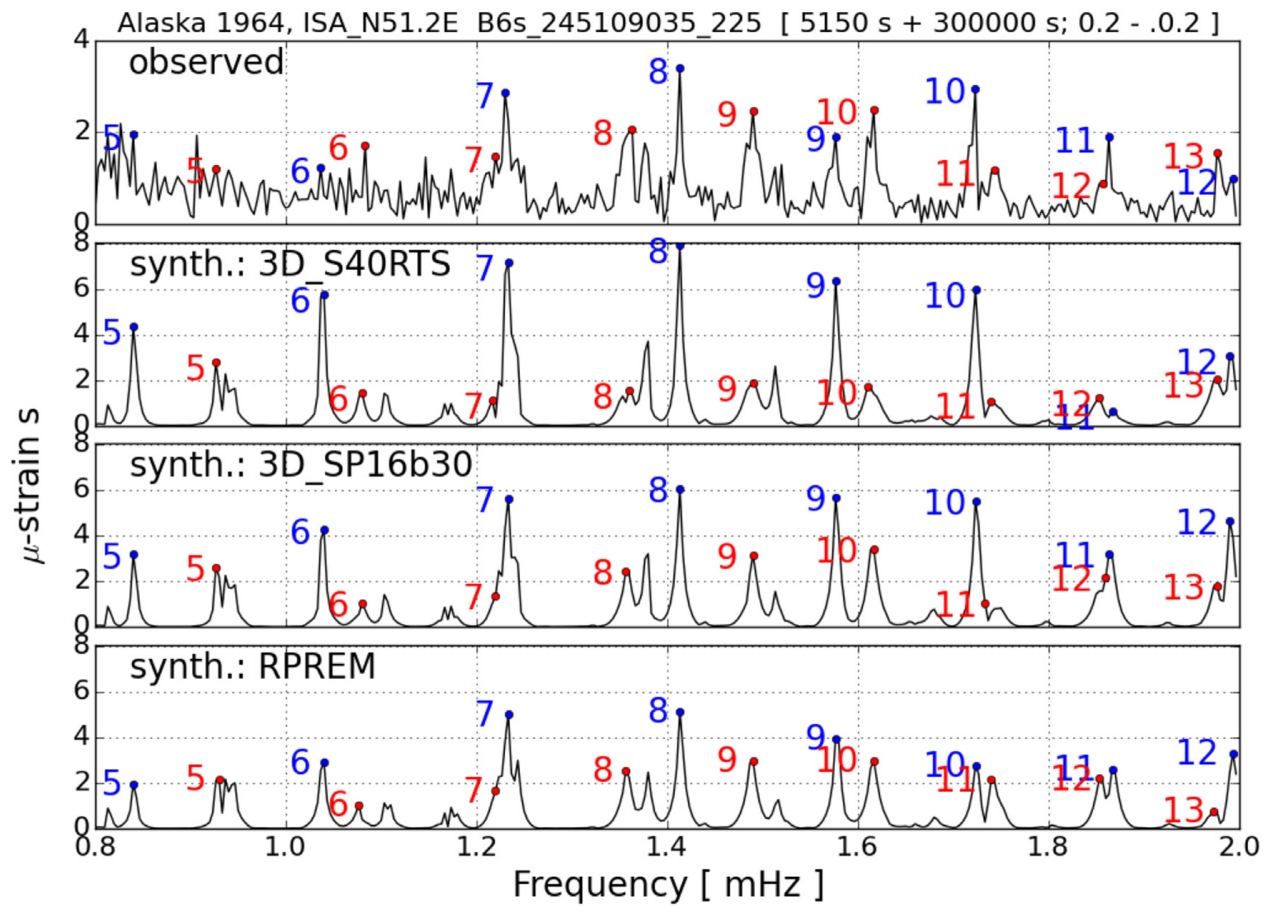

Figure 16. Comparison of the observed and synthetic normal-mode spectrum at ISA for the 1964 Alaskan earthquake. (a) N38.8 $\mathrm{W}$ component. Top: observed; bottom: synthetic. (b) N51. $2^{\circ} \mathrm{E}$ component. Top: observed; bottom three: synthetic spectra for three earth models.

velocity of $4 \mathrm{~km} / \mathrm{s}$ ) could cause large variability of spectral amplitude for a particular source-station-strainmeter geometry, and the use of spectral amplitude for testing the source model may not be definitive.

\subsection{The 1960 June 6 slow earthquake in Chile $\left(M_{\mathrm{w}}=7.7\right.$ aftershock)}

A large $\left(M_{\mathrm{w}}=7.7\right)$ aftershock of the 1960 Chilean earthquake occurred on 1960 June 6. Kanamori \& Stewart (1979) studied this event earlier and found that the $\mathrm{L} / \mathrm{R}$ ratio of Press-Ewing records from California is consistent with an EW trending right-lateral strike-slip mechanism. However, because of the poor first-motion data and the unknown source delay, the sense of the fault motion (RL or LL) was poorly constrained. Then, the 2007 Aysén swarm activity led Kanamori \& Rivera (2017) to think that an NS trending right-lateral strike-slip is a more likely mechanism for the June 6 event. Kanamori \& Rivera (2017) made a detailed analysis of this record and found that the seismogram is consistent with a right-lateral strike-slip event on the Liquiñe-Ofqui fault with a good 
agreement between the observed and synthetic waveforms as shown in Fig. 17 (Table 1, \#36). This mechanism is also consistent with the L/R ratio of surface waves observed in California for the 1960 June 6 event (fig. 12 of Kanamori \& Rivera 2017). Thus, the ISA strainmeter was most likely functioning normally on 1960 June 6 . There is no indication on the continuous strip-chart record that the instrument was modified between the May 22 main shock and the June 6 aftershock. Thus, the ISA strainmeter most likely functioned properly for the May 22 main shock.

\subsection{The 1957 Mongolian earthquake}

We make another comparison using the 1957 Mongolian earthquake record published in Benioff (1959) (Fig. 18a, Table 1, \#37). We compute the synthetics using the mechanism given by Okal (1976), (strike, $\varphi_{\mathrm{s}}=103^{\circ}, \operatorname{dip}, \delta=53^{\circ}$, rake, $\lambda=32^{\circ}$, Table 1 , \#38). Figs 18(a) and (b) compare the observed and synthetic direct strain records. Although the details cannot be resolved, the overall G2/R2 ratio is consistent between the observed and synthetics. Benioff (1959) also showed a record of the same earthquake from another recording channel with a CR (capacitor-registor) differentiator and a galvanometer with a period of $10 \mathrm{~min}$ (Table 1, \#39). According to Benioff (1959), this record is essentially an integral of the direct recording. Figs 18(c) and (d) (Table 1, \#40) show the comparison. The G1/R1 ratio of the synthetic, 0.28 , is smaller than the observed, 0.62 , but we can show that minor adjustment of the mechanism parameters (e.g. increase in $\varphi_{\mathrm{s}}$, increase in $\delta$, decrease in $\lambda$, or combination of them) can bring the ratio in better agreement. For example, Figs 18(e) and (f) (Table 1, \#40) show, respectively, the synthetics computed with $\left(\varphi_{\mathrm{s}}=103^{\circ}, \delta=53^{\circ}, \lambda=18^{\circ}\right)(\mathrm{G} 1 / \mathrm{R} 1 \mathrm{ra}-$ tio $=0.43)$ and $\left(\varphi_{\mathrm{s}}=103^{\circ}, \delta=75^{\circ}, \lambda=32^{\circ}\right)(\mathrm{G} 1 / \mathrm{R} 1$ ratio $=0.53)$. Given the uncertainties in the old records, and the spatial complexity of the Mongolian earthquake, we consider these mechanisms compatible with Okal's (1976) solution.

These comparisons demonstrate that the ISA strainmeter functioned normally in 1957, on 1960 June 6 and in 1964. A reasonable conclusion is that it functioned normally too at the time of the 1960 Chilean earthquake, and the anomalously large $\mathrm{G} / \mathrm{R}$ (or $\mathrm{T} / \mathrm{S}$ ) ratio observed at ISA for the 1960 Chilean earthquake reflects the real mechanism of the earthquake, rather than instrumental artefact.

\section{SUMMARY OF THE OBSERVATIONS}

If the ISA strainmeter was measuring the extensional strain in the rod direction as expected, the large observed $\mathrm{G} / \mathrm{R}$ and $\mathrm{T} / \mathrm{S}$ ratios are not compatible with the conventional low-angle thrust model $\left(\lambda=90^{\circ}\right)$. An increase of rake to $140^{\circ}\left(\lambda=140^{\circ}\right.$ model $)$ can explain the observation well, but this choice is not unique. The $\lambda=140^{\circ}$ model can explain the OGD strainmeter record much better than the $\lambda=90^{\circ}$ model. Since we could accurately calibrate both the sensitivity and the polarity of these direct strainmeters using the tidal strain, the results obtained from these records are far more robust than those from other records. The results indicate that the $M_{\mathrm{w}}$ of the 1960 Chilean earthquake is $9.50 \pm 0.25$. The T/S ratio inferred from the Pasadena ultralong period pendulum seismogram and the $G / R$ ratio determined from the BRK Press-Ewing records support the above conclusion. The $\lambda=140^{\circ}$ model is compatible with other observations available, such as the NNA (Ñañ) strainmetrer records, ${ }_{0} \mathrm{~S}_{2}$ splitting pattern observed on the ISA and TSK (IGY) records, Trieste tiltmeter records, and G3 and R3 recorded on the Wellington Milne-Shaw record. The experimental Benioff linear strain record at PAS is not compatible with the ISA strain record unless we invoke some unknown local effects or instrumental problems. We cannot resolve this at present.

Regarding whether the ISA strainmeter was working as expected, the good agreement between the observed ISA strainmeter record of the 1960 June 6 aftershock and the synthetic record provides the strongest evidence that the ISA strainmeter was working properly at the time of the main shock. Also, we do not find any obviously anomalous behaviour of the ISA strainmeter from the recordings of the 1957 Mongolia earthquake, the 1964 Alaskan earthquake, and the recording of the tide on the day of the main shock. Thus, although we cannot test the strainmeter directly, we proceed with the assumption that the ISA strainmeter was functioning properly.

One caveat about the interpretation is that both ISA and OGD are fairly close to the radiation node of Rayleigh waves for the $\lambda=140^{\circ}$ model, and the waveforms observed at these stations may be unreliable. However, as shown in Supporting Information Section S10, we find no serious problems with observations at nodal stations.

\section{ALTERNATIVE MODELS}

The $\lambda=140^{\circ}$ model is derived from the conventional thrust model by what we consider is the simplest modification $\left(\lambda=90^{\circ}\right.$ to $\left.140^{\circ}\right)$, and is not a unique solution. Here we consider the following 2 alternatives. First, we vary the fault strike. However, changing the fault strike without changing the rake angle is not a viable solution as shown below. As discussed earlier, because of the small $\alpha\left(4.5^{\circ}\right)$, the strain amplitude of incoming G2 must be much larger than that of R2 to produce $\mathrm{G} 2$ and $\mathrm{R} 2$ with comparable amplitude on the ISA strain record (Fig. 3a). Correcting for the propagation effects of surface waves, we can show that the ratio of the source factor of the vertical component of Rayleigh wave to that of the transverse component of Love wave (i.e. the ratio of the radiation pattern of Love to Rayleigh waves at about $300 \mathrm{~s}$ ) must be approximately 4.7 to produce such a large ratio.

Fig. 19 shows the spectral radiation pattern of Rayleigh and $G$ waves, and the $\mathrm{G} / \mathrm{R}$ ratio for 3 fault geometries. For a pure thrust, the $\mathrm{G} / \mathrm{R}$ ratio is less than 1.9 , which means that changing the fault strike cannot explain the observed large ratio, 4.7. In contrast, for a vertical strike-slip, the ratio can be very large. For an oblique slip model with $\lambda=140^{\circ}$, the ratio $\mathrm{G} / \mathrm{R}$ can reach close to 5 .

We can also consider the following alternative. The $\lambda=140^{\circ}$ is equivalent to adding a strike-slip $\left(\lambda=180^{\circ}\right)$ component to the dip slip $\left(\lambda=90^{\circ}\right)$ on the fault plane $\left(\delta=17^{\circ}\right)$ with a moment 1.2 times larger than that of the thrust component. We find that replacing the strike-slip component with a vertical $\left(\delta=90^{\circ}\right)$ strikeslip component can have a similar effect. Specifically, we write a seismogram with strike $\phi_{s}$, dip $\delta$ and rake $\lambda$ as a function of time $t$ as, $S\left(t ; \phi_{s}, \delta, \lambda\right)$. Then,

$S_{d}(t)=S(t ; 10,17,90)+C_{d} S(t ; 10,17,180)\left(C_{d}\right.$ is a constant $)$

represents seismograms of oblique slip faults on a fault dipping $17^{\circ}$. Similarly,

$S_{s}(t)=S(t ; 10,17,90)+C_{s} S(t ; 10,90,180)\left(C_{s}\right.$ is a constant $)$

represents a seismogram for a combination of a pure dip slip fault on a dipping fault and a pure vertical strike-slip fault. If, $C_{d}=$ $-\cot 140^{\circ}$, then $S_{d}$ is the seismogram of the $\lambda=140^{\circ}$ model. We find that if $C_{s}$ is 0.4 , both $S_{d}$ and $S_{s}$ have about the same G/R amplitude ratio, but the overall amplitude is different. Thus, a combination 


\section{6/6/1960 Chile earthquake}

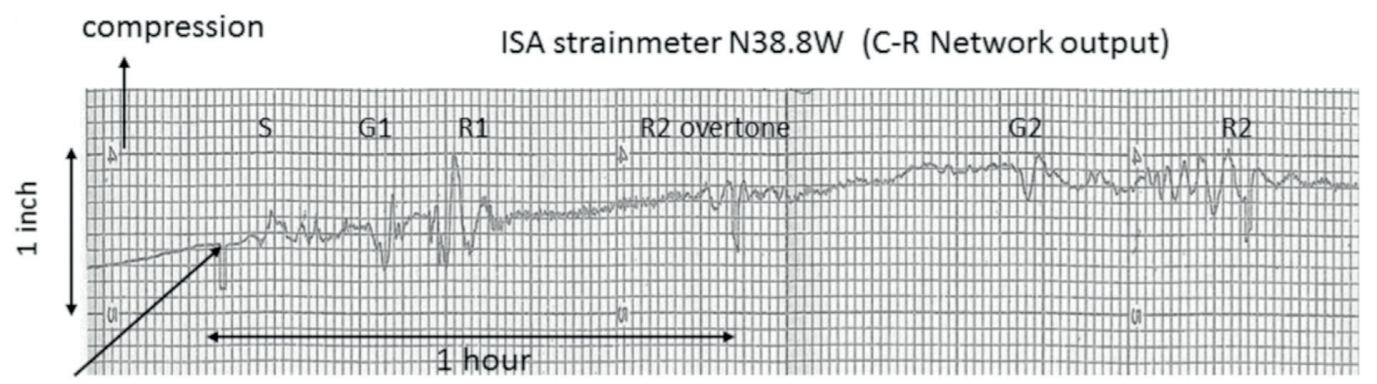

June 6, 1960 06h16.3m

\section{Synthetic $\mathrm{s} / \mathrm{d} / \mathrm{r}=354^{\circ} / 88^{\circ} / 176^{\circ} \mathrm{H}=12 \mathrm{~km}$ sf_c_95 $\mathrm{Mw}=7.7$}

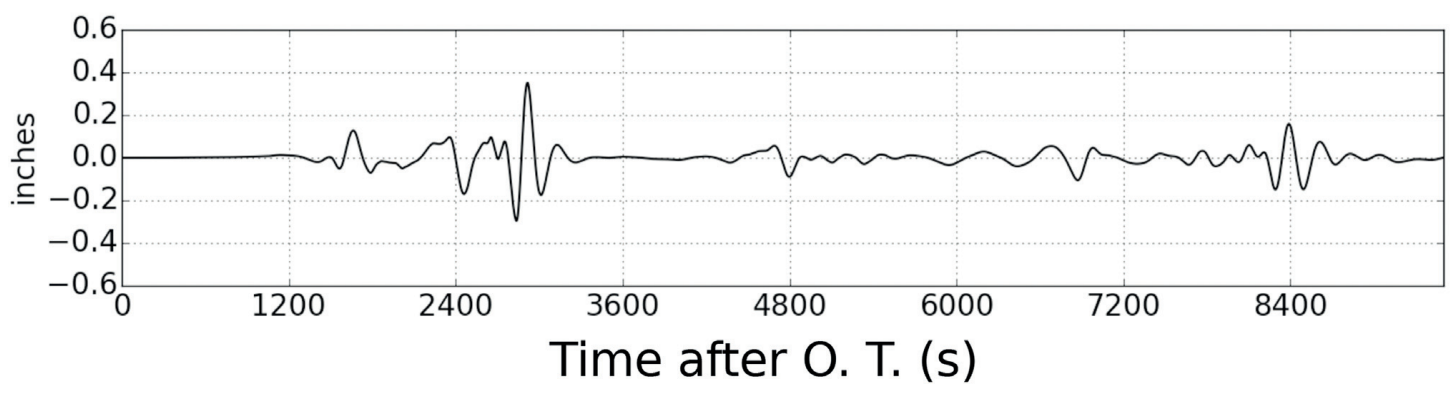

Figure 17. Observed and synthetic strain seismograms at ISA $\left(\mathrm{N} 38.8^{\circ} \mathrm{W}\right)$ for the 1960 June 6 aftershock $\left(M_{\mathrm{w}}=7.7\right.$; slightly modified from Kanamori \& Rivera 2017).

of a pure thrust fault $\left(\delta=17^{\circ}\right)$ and a simultaneous vertical strikeslip fault can explain our data as well and is a viable solution. In this case by matching the amplitude of the observed and synthetic seismograms of G2 and R2 at ISA, we obtain $M_{\mathrm{w}}=9.37$ for the thrust event and $M_{\mathrm{w}}=9.07$ for the strike-slip event. This model is motivated by the presence of the Liquiñe-Ofqui fault (LOF) which is a major right-lateral strike-slip fault extending over $1000 \mathrm{~km}$ northsouth along the Chilean coast. As far as we know, no evidence for a large slip on this fault during the 1960 Chilean earthquake has been reported. However, we note that the large aftershock with $M_{\mathrm{w}}=7.7$ on 1960 June 6, was a slow event on the Liquiñe-Ofqui fault and has not been widely noted (Kanamori \& Rivera 2017). This event may be somewhat deep and may not have produced obvious surface expression.

The two-fault model presented above (one pure dip slip and one pure strike-slip) can be considered as an end-member model, but it is probably more realistic to consider a range of models that involve the LOF with a varying degree as follows. We consider two basic fault models: a low-angle oblique fault with $\phi=10^{\circ}, \delta=17^{\circ}$, and rake $=\lambda$, and a vertical strike-slip model with $\phi=10^{\circ}, \delta=90^{\circ}$, and rake $=180^{\circ}$. We write the seismograms for these models with a unit moment by $S_{O}(t ; 10,17, \lambda)$ and $S_{S}(t ; 10,90,180)$, respectively. Then the seismogram for a doublet consisting of these two models can be written as

$S(t)=C_{O} S_{O}(t ; 10,17, \lambda)+C_{S} S_{S}(t ; 10,90,180)$

where $C_{O}$ and $C_{S}$ are the seismic moment of the oblique and strikeslip model, respectively. Then we try to determine $C_{O}$ and $C_{S}$ for a given $\lambda$ so that the difference between the moment tensor of the doublet and that of our basic oblique $\left(\lambda=140^{\circ}\right)$ fault model $S_{O}(t ; 10,17,140)$ with $M_{\mathrm{w}}=9.5$ is minimized in the least square sense. The result is shown in Table 8 . We consider this doublet fault mechanism as a viable model.

It is interesting to note that the first-motion diagram of Model 1 and 6 are visibly different, but the surface-wave radiation patterns (as a function of azimuth) are very similar for all the models.

\section{CONCLUSION AND IMPLICATIONS}

The anomalously large ratio of $\mathrm{G}$ to $\mathrm{R}$ waves, and toroidal to spheroidal modes recorded on the ISA strainmeter for the 1960 Chilean earthquake indicates that its mechanism is significantly different, at least at periods longer than $300 \mathrm{~s}$, from the conventional low-angle thrust mechanism typical of great subduction-zone earthquakes. Although the mechanism cannot be determined uniquely, an oblique slip with a rake $\lambda=130^{\circ}$ to $140^{\circ}$ is the simplest mechanism that can explain the strainmeter records at ISA, OGD and NNA, and the long-period displacement record at BRK and PAS.

The overall geometry of faulting of the 1960 Chilean earthquake has been established by a series of geodetic studies by Plafker \& Savage (1970); Linde \& Silver (1989); Barrientos \& Ward (1990), and Moreno et al (2009), with some differences among different models. Also, tsunami data have been used to estimate the slip distribution (Fujii \& Satake 2013). Our result adds a strike-slip component to these models. The models obtained from geodetic and tsunami data are mainly based on the vertical displacement together with some horizontal strain data; no direct data on horizontal displacement field were used.

Plafker \& Savage (1970) examined the triangulation data from the Central Valley of Chile which cover the period from 1951 to 1967. Although they found some component of right-lateral slip near the north end of the fault, the data near the centre of the fault $\left(40^{\circ} \mathrm{S}\right)$ indicate only small lateral slip. According to Savage 
(a)

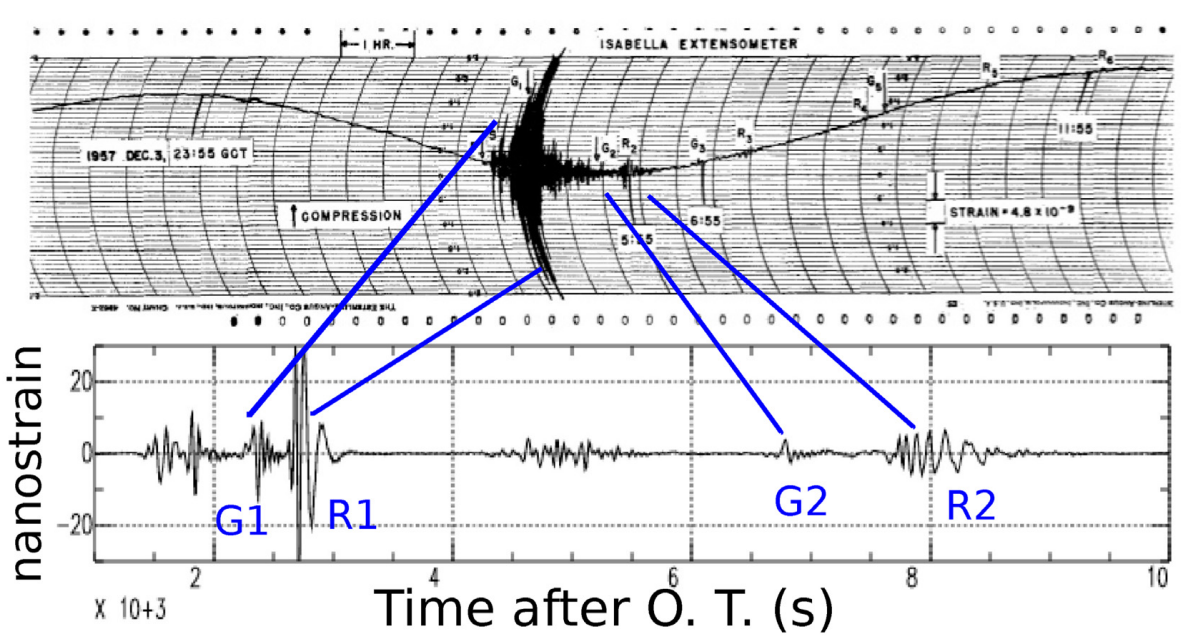

(c)

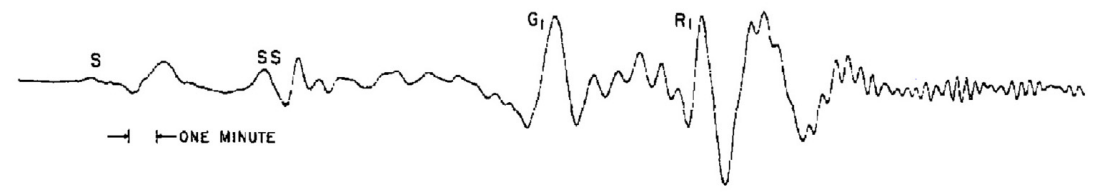

(d)
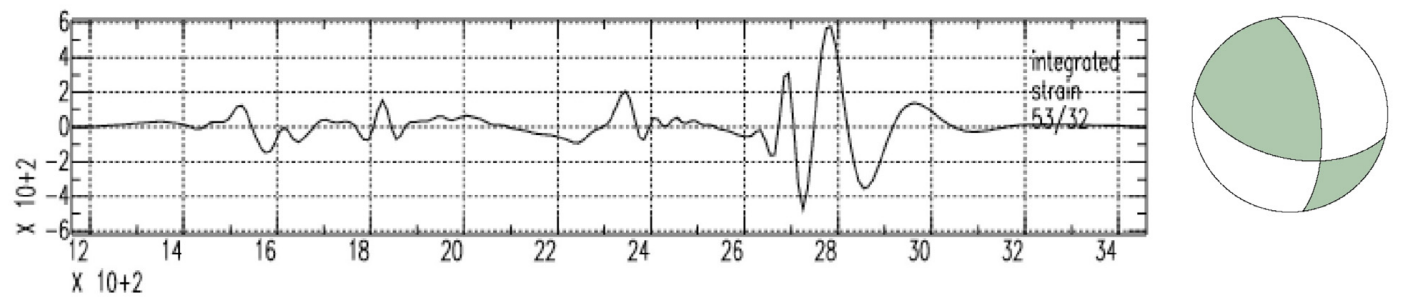

(e)
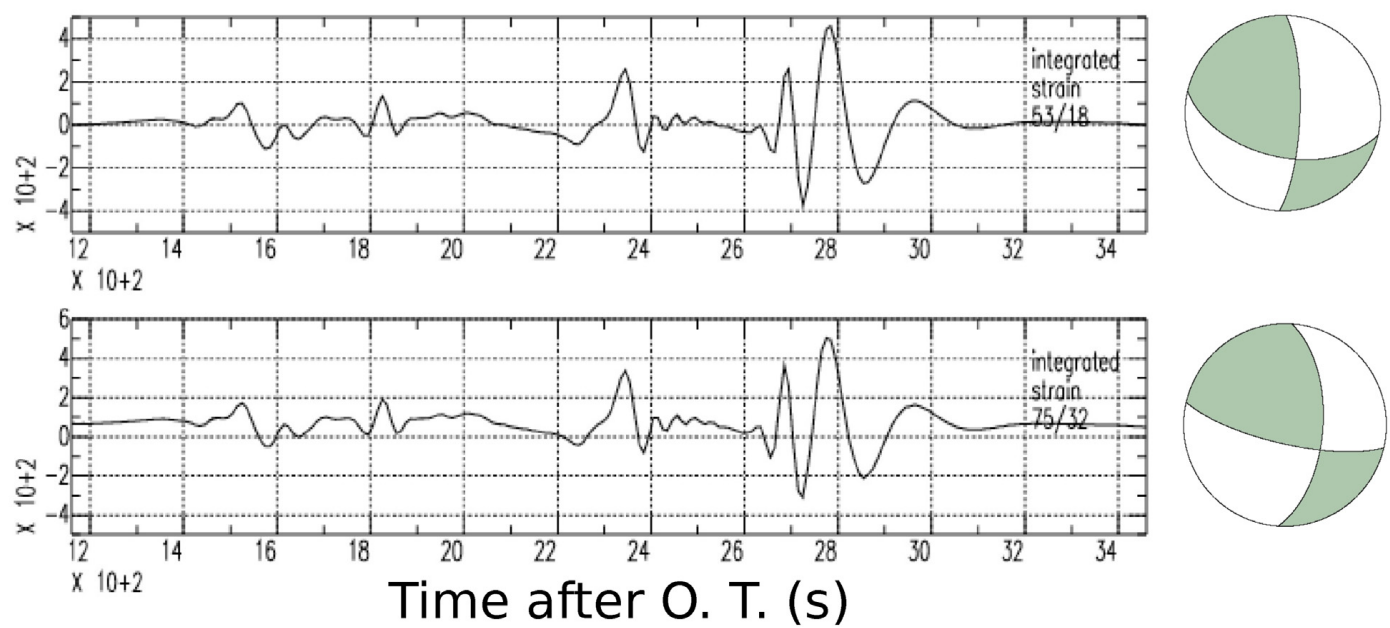

Figure 18. The 1957 Mongolian earthquake recorded with the ISA strainmeter $\left(\mathrm{N} 38.8^{\circ} \mathrm{W}\right)$ and its comparison with the synthetic waveforms. (a) Direct strain (Benioff 1959). (b) Synthetic direct strain. (c) Observed filtered record (Benioff, 1959, 1960). (d) Synthetic filtered record $\left(\varphi_{\mathrm{s}}=103^{\circ}, \delta=53^{\circ}, \lambda=32^{\circ}\right)$. (e) Synthetic filtered record $\left(\varphi_{\mathrm{s}}=103^{\circ}, \delta=53^{\circ}, \lambda=18^{\circ}\right)$. (f) Synthetic filtered record $\left(\varphi_{\mathrm{s}}=103^{\circ}, \delta=75^{\circ}, \lambda=32^{\circ}\right)$.

(2010, written communication), the observed strain is not consistent with a large amount of strike-slip for most fault models. However, Savage pointed out that one could construct a model of distributed slip extending further east of the triangulation array so that the right-lateral strain contributions from the deeper and shallower parts cancel. This leaves a possibility that one can construct a model that is compatible with the seismic and geodetic data. Detailed comparison of our model with these geodetic and tsunami (mainly static) models is beyond the scope of this paper, but we briefly discuss some implications of our oblique or multiple-fault models for static displacement field in Supporting Information Section S11.

For the estimation of seismic moment, we heavily weight the estimates from the amplitudes of G2 and R2 recorded on the ISA strainmeter (Fig. 3, Table 3), because the path is the shortest, the instrument can be accurately calibrated by the earth tide, and the instrument has good long-period response. The estimate we obtain is $2.7 \times 10^{23} \mathrm{Nm}\left(M_{\mathrm{w}}=9.55\right)$. However, considering all the possible uncertainties we feel that it would be reasonable to assign 


\section{Rayleigh (black) and Love (G, red) wave radiation pattern and $\mathrm{G} / \mathrm{R}$ ratio (blue). $\mathrm{H}=20 \mathrm{~km}, \mathrm{~T}=325 \mathrm{~s}$}
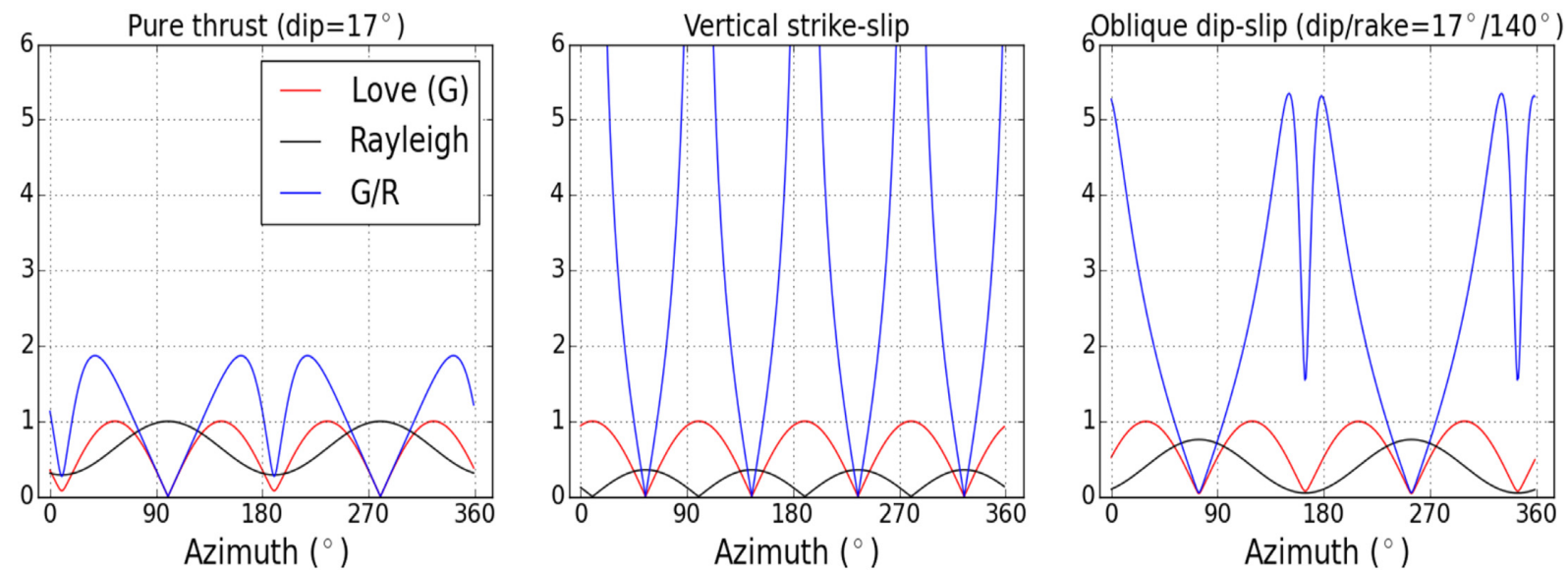

Figure 19. Radiation patterns and G/R ratios for three fault geometries. The source depth is at $33 \mathrm{~km}$, and the period used is $325 \mathrm{~s}$.

Table 8. Doublet source models for the 1960 Chilean earthquake.

\begin{tabular}{lccc}
\hline Model & $\lambda\left({ }^{\circ}\right)$ & $C_{\mathrm{O}}\left(\times 10^{23} \mathrm{~N} \mathrm{~m}\right)$ & $C_{\mathrm{S}}\left(\times 10^{23} \mathrm{~N} \mathrm{~m}\right)$ \\
\hline 1 & 90 & $1.44\left(M_{\mathrm{w}}=9.37\right)$ & $0.502(9.07)$ \\
2 & 100 & $1.64(9.41)$ & $0.404(9.00)$ \\
3 & 110 & $1.85(9.44)$ & $0.296(8.91)$ \\
4 & 120 & $2.00(9.47)$ & $0.186(8.78)$ \\
5 & 130 & $2.14(9.49)$ & $0.083(8.55)$ \\
6 & 140 & $2.24(9.50)$ & 0 \\
\hline
\end{tabular}

an uncertainty of $\frac{1}{4}$ unit to $M_{\mathrm{w}}$. With the very limited number of reliable records, it is difficult to give a statistically rigorous error estimate. This $M_{\mathrm{w}}$ is somewhat larger than the estimates obtained mainly from geodetic and tsunami data $\left[M_{\mathrm{w}}=9.02\right.$ to 9.22 (Plafker $\&$ Savage 1970); $M_{\mathrm{w}}=9.22$ (Plafker 1972); $M_{\mathrm{w}}=9.25$ (Barrientos $\&$ Ward 1990); $M_{\mathrm{w}}=9.26$, (Moreno et al. 2009); $M_{\mathrm{w}}=9.2$ (Fujii $\&$ Satake 2013)]. However, given the uncertainty of $\frac{1}{4}$ unit, as far as the thrust component is concerned, our result is not that different from these results, if we allow slip at large depth. In fact, Linde \& Silver's (1989) model has significant slip at depth with $M_{\mathrm{w}}=9.4$ to 9.53 .

Although the slip direction associated with the 2010 Maule, Chile, earthquake appears to be approximately parallel to the convergence direction of the Nazca plate with respect to the South American Plate, a close inspection of the mechanism determined with the long-period (passband, 200-1000s) W phase (Lay et al. 2010a; NEIC (https://earthquake.usgs.gov/earthquakes/eventpage/ official20100227063411530_30/executive) indicates that the direction of the seismic slip motion is approximately $\mathrm{N} 88^{\circ} \mathrm{E}$, and thus rotated clock-wise from the Nazca-South America plate convergence direction $\mathrm{N} 76^{\circ} \mathrm{E}$ by $12^{\circ}$. This means that some right-lateral strain caused by plate convergence remained unreleased by the 2010 event. If this strain is to accumulate in the volume comparable to the main shock, it would be comparable to that of an $M_{\mathrm{w}}=8.3$ earthquake. Thus, if this strain continues to accumulate for several events like the 2010 event, a large amount of strike-slip strain can accumulate and can be eventually released in a large event like the 1960 earthquake. Although the subduction zone in south Chile has generated great earthquakes with an interval of about 100 to 130 years, many recent field studies have found that geological data such as uplift, subsidence and tsunami and lake sediment deposits suggest that the 1960 event was significantly larger than its predecessors in 1837 and 1737 (Cisternas et al. 2005; Moernaut et al. 2014; Garrett et al. 2015). From the sedimentary record of seismic shaking and tsunami inundation, Cisternas et al. (2017) found that three earthquakes in AD 898-1128, 1300-1398 and 1575 resembled the 1960 event. When a large amount of strike-slip strain has accumulated it may trigger a larger event than normal, and the 1960 Chilean earthquake may have been one such event. If this is the case, we cannot always expect a similar behaviour for all the great earthquakes occurring in the same subduction zone. This variability needs to be considered in long-term hazard assessment of subduction-zone earthquakes.

In the places where plate convergence is very oblique like Sumatra, the Philippines, and southwest Japan, a prominent strike-slip fault often develops on land to accommodate the strike-slip component of plate motion (Fitch 1972). In south Chile, the Liquiñe Ofqui fault, a $1000 \mathrm{~km}$ long right-lateral fault, may be taking up some right-lateral strain caused by oblique subduction of the Nazca plate (Cembrano et al. 1996; Lange et al. 2008; Agurto et al. 2012). However, the displacement on this fault alone is not large enough to explain the large strike-slip component suggested by the mechanism of the 1960 Chilean earthquake. It is possible that the Liquiñe Ofqui fault can be a surface manifestation of much larger scale deep seated process; the right-lateral strike-slip strain may be accommodated at depths, even in the asthenosphere, and is released from time 
to time in a great earthquake which is larger than the average great earthquakes in the region. Wang et al. (2007) found evidence for active dextral shear motion of the LOF zone which can be described as block translation at $6.5 \mathrm{~mm} \mathrm{yr}^{-1}$.

Goldfinger et al. (1992, 1997) suggest that west-northwesttrending left-lateral faults in the Juan de Fuca plate that cut across the megathrust boundary represent shear deformation within an overall right-lateral shear driven by deep coupling between the obliquely descending plate and the North American mantle. This model is similar to that proposed by Wells \& Coe (1985). The right-lateral deformation associated with the 1960 Chilean earthquake may be a seismological manifestation of similar right-lateral shear in south Chile.

Although we believe that the seismological evidence for the mechanism of the 1960 Chilean earthquake being significantly different from the typical low-angle thrust is robust, exactly how different it is still remains uncertain. We present here as one of the simplest models an oblique fault model with half thrust and half strike-slip motion on the same fault plane. However, it is possible that the source of the 1960 Chilean earthquake consisted of multiple events which occurred on different faults. The 2009 Tonga-Samoa Is. earthquake is such an example. Li et al. (2009); Beavan et al. (2010) and Lay et al. (2010b) showed that this earthquake is a doublet consisting of an $M_{\mathrm{w}}=8.1$ earthquake which occurred on a normal fault in the outer rise and a thrust earthquake with $M_{\mathrm{w}}=8.0$ that occurred on the megathrust boundary about $80 \mathrm{~s}$ apart. The mechanism of the combined event appeared significantly different from either a simple normal fault or a thrust fault mechanism.

Another issue is the precursor discussed by Kanamori \& Cipar (1974); Kanamori \& Anderson (1975) and Cifuentes \& Silver (1989). Kanamori \& Cipar's (1974) interpretation depends entirely on the Pasadena strain record. Despite the incompatibility of the PAS record with the ISA record, the long-period waveform on this record still looks qualitatively good. The analysis of Kanamori \& Andersom (1975) and Cifuentes \& Silver (1989) is based on normalmode spectral interference patterns, but mode coupling due to the earth ellipticity and rotation may be responsible for the interference patterns. Thus, we consider that the evidence for the precursor is only marginal unless some new data corroborate the earlier results. We discuss more details on this in Supporting Information Section S12. In this regard, the strainmeter records at Naña, Peru, are obviously most important because of its long-period response, short distance, and the relatively fast recording paper speed, but our analysis of these records was severely hampered by the large noise on the record, and we have not been able to draw any useful conclusion. Although the result of this paper is not entirely independent of the precursor, the period range involved in the precursor is very different from the main shock so that the precursor, if it exists, would not affect the main conclusion of this paper.

\section{ACKNOWLEDGEMENTS}

We thank Stewart Smith who provided us with the detailed backup materials used for his 1966 study which played a key role for understanding the instrument characteristics of the Isabella strain record. Frank Press provided us with key information on the Isabella strain record used for the 1960 Chilean earthquake study. Duncan Agnew provided us with the strainmeter record of the 2010 Maule, Chile, earthquake recorded at the Piñon Flat Observatory. Guy Masters made available to us hand-digitized data of the Isabella strain seismograms for the 1960 Chilean and the 1964 Alaskan earthquakes archived at the Scripps Institution of Oceanography. Walter Zürn read a preliminary version of the manuscript and provided useful feedback to improve it. We appreciate the effort of Emile Okal and an anonymous reviewer who carefully read the manuscript and raised important questions on some of the key issues. Comments from Shingo Watada were helpful for clarifying some key points.

This work would not have been possible without help from colleagues who sent us, upon our request, the copies of the seismograms of the Chilean earthquake. Following is a partial list.

Peggy Hellweg: Berkeley Seismographic Stations, University of California, Berkeley. Shingo Watada: Earthquake Research Institute, the University of Tokyo.

Brian Ferris: Geonet, New Zealand.

Nobuo Hamada, Noriko Kamaya, and Jumpei Shimizu: Japan Meteorological Agency.

Jim Mori: Kyoto University.

Norihito Umino, Toru Matsuzawa, Tomotsugu Demachi, and Satoshi Hirahara: Tohoku University.

The Data Management System of the Incorporated Research Institutions for Seismology (http://www.iris.edu/hq/) was used to access the seismic data from the Global Seismic Network and Federation of Digital Seismic Network stations. We used Syngine web service at the Data Management Center of Incorporate Research Institutions for Seismology (Syngine, IRISURL https://service.iris.edu/irisws/syngine/, last accessed 2017 July 20) for computing some of the synthetic seismograms. The Green's functions are pre-computed with the AxiSEM (Nissen-Meyer et al. 2014) for several 1-D reference models.

\section{REFERENCES}

Agurto, H, Rietbrock, A, Barrientos, S, Bataille, K \& Legrand, D. 2012. Seismo-tectonic structure of the Aysén Region, Southern Chile, inferred from the $2007 M_{\mathrm{w}}=6.2$ Aysén earthquake sequence, Geophys. J. Int., 190, 116-130.

Alsop, L.E., 1964. Spheroidal free periods of the earth observed at eight stations around the world, Bull. seism. Soc. Am., 54, 755-776.

Alsop, L.E., Sutton, G.H. \& Ewing, M., 1961. Free oscillations of the earth observed on strain and pendulum seismographs, J. geophys. Res., 66, 631-641.

Alterman, Z., Jarosch, H. \& Pekeris, C.L., 1959. Oscillations of the Earth, Proc. R. Soc. A, 252, 80-95.

Barrientos, S.E. \& Ward, S.N., 1990. The 1960 Chile earthquake: inversion for slip distribution from surface deformation, Geophys. J. Int., 103, 589598.

Beavan, J., Wang, X., Holden, C., Wilson, K., Power, W., Prasetya, G., Bevis, M. \& Kaotoke, R., 2010. Near-simultaneous great earthquakes at Tonga megathrust and outer rise in September 2009, Nature, 466, 959-963.

Benioff, H., 1935. A linear strain seismograph, Bull. seism. Soc. Am., 25, 283-309.

Benioff, H., 1959. Fused-quartz extensometer for secular, tidal, and seismic strains, Bull. geol. Soc. Am., 70, 1019-1032.

Benioff, H., 1960. Long-period seismographs, Bull. seism. Soc. Am., 50, $1-13$.

Benioff, H., 1962. Movements on major transcurrent faults, in Continental Drift, pp. 103-134, ed. Runcorn, S. K., Academic Press.

Benioff, H., 1963. Source wave forms of three earthquakes, Bull. seism. Soc. Am., 53, 893-903.

Benioff, H., Press, F. \& Smith, S., 1961. Excitation of the free oscillations of the Earth by earthquakes, J. geophys. Res., 66, 605-619.

Ben-Menahem, A., 1971. The force system of the Chilean earthquake of 1960 May 22, Geophys. J. R. astr. Soc., 25, 407-417.

Bolt, B.A. \& Marussi, A., 1962. Eigenvibrations of the Earth observed at Trieste, Geophys. J. R. astr. Soc., 6, 299-311. 
Braitenberg, C. \& Zadro, M., 2007. Comparative analysis of the free oscillations generated by the Sumatra-Andaman Islands 2004 and the Chilean 1960 earthquakes, Bull. seism. Soc. Am., 97, S6-S17.

Brune, J.N., Benioff, H. \& Ewing, M., 1961. Long-period surface waves from the Chilean Earthquake of May 22, 1960, recorded on linear strain seismographs, J. geophys. Res., 66, 2895-2910.

Cembranno, J., Hervé, F. \& Lavenu, A., 1996. The Liquiñe Ofqui fault zone: a long-lived intra-arc fault system in southern Chile, Tectonophysics, 259, 55-66.

Charlier, C. \& Van Gils, J.M., 1953. Liste des Stations Seismologiques Mondiales, Observatoire royal de Belgique, Service séismologique.

Cifuentes, I.L. \& Silver, P.G., 1989. Low-frequency source characteristics of the great 1960 Chilean earthquake, J. geophys. Res., 94, 643-663.

Cisternas, M. et al., 2005. Predecessors of the giant 1960 Chile earthquake, Nature, 437, 404-407.

Cisternas, M., Garrett, E., Wesson, R., Dura, T. \& Ely, L., 2017. Unusual geologic evidence of coeval seismic shaking and tsunamis shows variability in earthquake size and recurrence in the area of the giant 1960 Chile earthquake, Mar. Geol., 385, 101-113.

Dahlen, F.A., 1969. The normal modes of a rotating, elliptical earth, II, Near resonant multiplet coupling, Geophys. J. R. astr. Soc., 18, 397-436.

Dahlen, F.A. \& Sailor, R.V., 1979. Rotational and elliptical splitting of the free oscillations of the Earth, Geophys. J. R. astr. Soc., 58, 609-623.

Deuss, A. \& Woodhouse, J.H., 2001. Theoretical free-oscillation spectra: the importance of wide band-coupling, Geophys. J. Int., 146, 833-842.

Duputel, Z., Tsai, V.C., Rivera, L. \& Kanamori, H., 2013. Using centroid time-delays to characterize source durations and identify earthquakes with unique characteristics, Earth planet. Sci. Lett., 374, 92-100.

Dziewonski, A.M. \& Anderson, D.L., 1981. Preliminary reference Earth model, Phys. Earth planet. Inter, 25, 297-356.

Fitch, T.J., 1972. Plate convergence, transcurrent faults, and internal deformation adjacent to southeast Asia and the Western Pacific, J. geophys. Res., 77, 4432-4460.

Fujii, Y. \& Satake, K., 2013. Slip distribution and seismic moment of the 2010 and 1960 Chilean earthquakes inferred from tsunami waveforms and coastal geodetic data, Pure appl. Geophys., 170, 1493-1509.

Garrett, E., Shennan, I., Woodroffe, S., Cisternas, M., Hocking, E. \& Gulliver, P., 2015. Reconstructing paleoseismic deformation, 2: 1000 years of great earthquakes at Chucalén, south central Chile, Quat. Sci. Rev., 113, $112-122$.

Geller, R.J. \& Stein, S., 1977. Split free oscillation amplitudes for the 1960 Chilean and 1964 Alaskan earthquakes, Bull. seism. Soc. Am., 67, 651660 .

Gilbert, F., 1971. Excitation of the normal modes of the Earth by earthquake sources, Geophys. J. Int., 22, 223-226.

Gilbert, F., 1980. An introduction to Low frequency seismology, in Fisica dell'interno della Terra, Rendiconti della Scuola Internazionale di Fisica "Enrico Fermi", Varenna, Italy, course LXXVII, pp. 41-81, eds Dziewonski, A. M. \& Boschi, E., North-Holland.

Gilbert, F. \& Dziewonski, A.M., 1975. An application of normal mode theory to the retrieval of structural parameters and source mechanisms from seismic spectra, Phil. Trans. R. Soc. Lond., A, 278, 187-269.

Gilman, R., 1960. Report on some experimental long-period seismographs, Bull. seism. Soc. Am., 50, 553-559.

Goldfinger, C., Kulm, L.D., Yeats, R.S., Appelgate, B., MacKay, M.E. \& Moore, G.F., 1992. Transverse structural trends along the Oregon convergent margin: Implications for Cascadia earthquake potential and crustal rotations, Geology, 20, 141-144.

Goldfinger, C., Kulm, L.D., Yeats, R.S., McNeill, L. \& Hummon, C., 1997. Oblique strike-slip faulting of the central Cascadia submarine forearc, $J$. geophys. Res., 102, 8217-8243.

Hagiwara, T., 1958. A note on the theory of the electromagnetic seismograph, Bull. Earthq. Res. Inst. Univ. Tokyo, 36, 139-164.

Ichinose, G., Somerville, P., Thio, H.K., Graves, R. \& O’Connell, D., 2007. Rupture process of the 1964 Prince William Sound, Alaska, earthquake from the combined inversion of seismic, tsunami, and geodetic data, $J$. geophys. Res., 112, B07306, doi:10.1029/2006JB004728.
Kanamori, H., 1970. The Alaska earthquake of 1964: radiation of longperiod surface waves and source Mechanism, J. geophys. Res., 75, 50295040.

Kanamori, H. \& Anderson, D.L., 1975. Amplitude of the Earth's free oscillations and long-period characteristics of the earthquake source, J. geophys. Res., 80, 1075-1078.

Kanamori, H. \& Cipar, J.N., 1974. Focal process of the great Chilean earthquake May 22, 1960, Phys. Earth planet. Inter., 9, 128-136.

Kanamori, H. \& Rivera, L., 2017. An $M_{\mathrm{w}}=7.7$ slow earthquake in 1960 near the Aysén Fjord region, Chile, Geophys. J. Int., 211, 93-106.

Kanamori, H. \& Stewart, G.S., 1979. A slow earthquake, Phys. Earth planet. Inter., 18, 167-175.

Karato, S.-I. \& Karki, B.B., 2001. Origin of lateral variation of seismic wave velocities and density in the deep mantle, J. geophys. Res., 106, 21 771-21 783.

Krawcyzk, C., the SPOC team, 2003. Amphibious seismic survey images plate interface at 1960 Chile earthquake, EOS, Trans. Am. geophys. Un., 84, 301-305.

Lange, D., Cembrano, J., Rietbrock, A., Haberland, C., Dahm, T. \& Bataille, K., 2008. First seismic record for intra-arc strike-slip tectonics along the Liquiñe Ofqui fault zone at the obliquely convergent plate margin of the southern Andes, Tectonophysics, 455, 14-24.

Lay, T., Ammon, C.J., Kanamori, H., Koper, K.D., Sufri, O. \& Hutko, A.R., 2010a. Teleseismic inversion for rupture process of the 27 February 2010 Chile $\left(M_{\mathrm{w}} 8.8\right)$ earthquake, Geophys. Res. Lett., 37, L13301, doi:13310.11029/12010GL043379.

Lay, T., Ammon, C.J., Kanamori, H., Rivera, L., Koper, K.D. \& Hutko, A.R., 2010b. The 2009 Samoa-Tonga great earthquake triggered doublet, Nature, 466, 964-968.

Li, X., Giardini, D. \& Woodhouse, J., 1991. The relative amplitudes of mantle heterogeneity in P velocity, S velocity and density from free-oscillation data, Geophys. J. Int., 105, 649-657.

Li, X., Shao, G. \& Ji, C., 2009. Rupture process of 2009 Mw 8.1 Samoa earthquake constrained by joint inverting teleseismic body, surface waves and local strong motion, in AGU Fall Meeting Abstracts.

Linde, A.T. \& Silver, P.G., 1989. Elevation changes and the great 1960 Chilean earthquake: support for aseismic slip, Geophys. Res. Lett., 16, 1305-1308.

Luh, P.C., 1974. Normal modes of a rotating, self gravitating inhomogeneous earth, Geophys. J. R. astr. Soc., 38, 187-224.

Masters, G., Johnson, S., Laske, G. \& Bolton, H., 1996. Developments in high-pressure, high-temperature research and the study of the Earth's deep interior-A shear-velocity model of the mantle, Philosophical Transactions of the Royal Society of London, Phil. Trans. R. Soc. Lond., A, 354, 1385-1411.

Matsumoto, K., Sato, T., Takanezawa, T. \& Ooe, M., 2001. GOTIC2: a program for computation of oceanic tidal loading effect, J. Geodetic Soc. Japan, 47, 243-248.

Miller, H.J., 1963. Calibration of long-period seismographs at thirteen stations throughout the world, ARPA Sci. Rep., Adv. Res. Projects Agency, Santa Monica, CA.

Moernaut, J., Daele, M.V., Heirman, K., Fontijn, K., Strasser, M., Pino, M., Urrutia, R. \& De Batist, M., 2014. Lacustrine turbidites as a tool for quantitative earthquake reconstruction: new evidence for a variable rupture mode in south central Chile, J. geophys. Res., 119, 1607-1633.

Moreno, M.S., Bolte, J., Klotz, J. \& Melnick, D., 2009. Impact of megathrust geometry on inversion of coseismic slip from geodetic data: application to the 1960 Chile earthquake, Geophys. Res. Lett., 36, L16310, doi:10.1029/2009GL039276.

Ness, N.F., Harrison, J.C. \& Slichter, L.B., 1961. Observations of the free oscillations of the earth, J. geophys. Res., 66, 621-629.

Nissen-Meyer, T., van Driel, M., Stähler, S.C., Hosseini, K., Hempel, S., Auer, L., Colombi, A. \& Fournier, A., 2014. AxiSEM: broadband 3-D seismic wavefields in axisymmetric media, Solid Earth, 5, 425-445.

Okal, E.A., 1976. A surface-wave investigation of the rupture mechanism of the Gobi-Altai (December 4, 1957) earthquake, Phys. Earth planet. Inter, 12, 319-328. 
Okal, E.A. \& Talandier, J., 1991. Single-station estimates of the seismic moment of the 1960 Chilean and 1964 Alaskan earthquakes, using the mantle magnitude $\mathrm{M}_{\mathrm{m}}$, Pure appl. Geophys., 136, 103-126.

Plafker, G., 1965. Tectonic Deformation Associated with the 1964 Alaska Earthquake: The earthquake of 27 March 1964 resulted in observable crustal deformation of unprecedented areal extent, Science, 148, 16751687.

Plafker, G., 1972. Alaskan earthquake of 1964 and Chilean earthquake of 1960: Implications for arc tectonics, J. geophys. Res., 77, 901-925.

Plafker, G. \& Savage, J., 1970. Mechanism of the Chilean earthquakes of May 21 and 22, 1960, Bull. geol. Soc. Am., 81, 1001-1030.

Press, F., 1965. Displacements, strains, and tilts at teleseismic distances, $J$. geophys. Res., 70, 2395-2412.

Press, F., 1966. Seismological information and advances, in Advances in Earth Sciences, pp. 247-286, ed. Hurley, P.M., M.I.T. Press.

Press, F., Ewing, M. \& Lehner, F., 1958. A long-period seismograph system, EOS, Trans. Am. geophys. Un., 39, 106-108.

Press, F., Ben-Menahem, A. \& Toksöz, M.N., 1961. Experimental determination of earthquake fault length and rupture velocity, J. geophys. Res., 66, 3471-3485.

Ritsema, J., Deuss, A., van Heijst, H.J. \& Woodhouse, J.H., 2011. S40RTS: a degree-40 shear-velocity model for the mantle from new Rayleigh wave dispersion, teleseismic traveltime and normal-mode splitting function measurements, Geophys. J. Int., 184, 1223-1236.

Robertson, G.S. \& Woodhouse, J.H., 1995. Evidence for proportionality of $\mathrm{P}$ and $\mathrm{S}$ heterogeneity in the lower mantle, Geophys. J. Int., 123, 85-116.

Ruiz, S. \& Madariaga, R., 2018. Historical and recent large megathrust earthquakes in Chile, Tectonophysics, 733, 37-56.

Scherwath, M., Flueh, E., Grevemeyer, I., Tillman, F., Contreras-Reyes, E. \& Weinrebe, W., 2006. Investigating subduction zone processes in Chile, EOS, Trans. Am. geophys. Un., 87, 265-269.

Smith, S.W., 1966. Free oscillations excited by the Alaskan earthquake, $J$. geophys. Res., 71, 1183-1193.

Stauder, W. \& Bollinger, G., 1966. The focal mechanism of the Alaska earthquake of March 28, 1964, and of its aftershock sequence, J. geophys. Res., 71, 5283-5296.

Wada, T., Furuzawa, T. \& Ono, H., 1963. Source-mechanism of the Chilean earthquake from spectra of long-period surface waves (in Japanese), Zisin, 16, 181-187.

Wang, K., Hu, Y., Bevis, M., Kendrick, E., Smalley, R., Vargas, R.B. \& Lauría, E., 2007. Crustal motion in the zone of the 1960 Chile earthquake: detangling earthquake-cycle deformation and forearc-sliver translation, Geochem. Geophys. Geosyst., 8, Q10010, doi:10.1029/2007GC001721.

Wells, R.E. \& Coe, R.S., 1985. Paleomagnetism and geology of Eocene volcanic rocks of southwest Washington, implications for mechanisms of tectonic rotation, J. geophys. Res., 90, 1925-1947.

Woodhouse, J.H., 1980. The coupling and attenuation of nearly resonant multiplets in the earth's free oscillation spectrum, Geophys. J. R. astr. Soc., 61, 261-283.

Woodhouse, J.H., 1988. The calculation of eigenfrequencies and eigenfunctions of the free oscillations of the Earth and the Sun, in Seismological Algorithms, pp. 321-370, ed. Doornbos, D.J., Academic Press.

Woodhouse, J.H. \& Dahlen, F.A., 1978. The effect of a general aspherical perturbation on the free oscillations of the earth, Geophys. J. R. astr. Soc., 53, 335-354.

Woodhouse, J.H. \& Girnius, T.P., 1982. Surface waves and free oscillations in a regionalized earth model, Geophys. J. R. astr. Soc., 68, 653-673.

Zürn, W., Ferreira, A., Widmer-Schnidrig, R., Lentas, K., Rivera, L. \& Clévédé, E., 2015. High-quality lowest-frequency normal mode strain observations at the Black Forest Observatory (SWGermany) and comparison with horizontal broad-band seismometer data and synthetics, Geophys. Suppl. Mon. Not. R. astr. Soc., 203, 1787-1803.

\section{SUPPORTING INFORMATION}

Supplementary data are available at $G J I$ online.

Table S1. Details of Computation and Processing of Data and Synthetics.

Table S2. The amplitudes $a_{0}, a_{b}$ and $\bar{a}$ in nanostrain.

Table S3. Peak-to-peak amplitude at three stations.

Figure S1. Top: Benioff ratio $\Gamma$. Bottom: T/S amplitude ratio as a function of $l$ for the $\lambda=90^{\circ}$ case for the 1960 Chilean earthquake at ISA station.

Figure S2. Top: Benioff ratio $\Gamma$. Bottom: T/S amplitude ratio as a function of $l$ for the $\lambda=140^{\circ}$ case for the 1960 Chilean earthquake at ISA station.

Figure S3. Normal-mode spectrum for (a) $\lambda=90^{\circ}$ and (b) $\lambda=140^{\circ}$ cases. Top: without splitting and coupling; middle: with splitting only; bottom: with splitting and coupling for the 1960 Chilean earthquake at ISA station.

Figure S4. The amplitude decay of each normal mode as a function of time $\left(1 \times 10^{5} \mathrm{~s}=1.157 \mathrm{~d}\right)$.

Figure S5. Normal-mode strain spectrum (NW-SE component) for the 2010 Maule, Chile, earthquake recorded at PFO, California.

Figure S6. Power spectrum of the Pasadena ultralong period seismogram for three different time windows (duration $=1250 \mathrm{~min}$ ) for the 1960 Chilean earthquake $\left(\lambda=140^{\circ}\right)$. (a) From 21:01 May 22 ( $1 \mathrm{hr}$ and $50 \mathrm{~min}$ after the origin time). (b) From 05:11, May 23 (10 hr after the origin time). (c) From 20:11 May 23 (25 hr after the origin time).

Figure S7. The power spectral amplitudes of toroidal (red) and spheroidal (blue) modes for the $\lambda=140^{\circ}$ and $\lambda=90^{\circ}$ models of the 1960 Chilean earthquake at Pasadena. (a) From 21:01 May 22 (1 $\mathrm{hr}$ and $50 \mathrm{~min}$ after the origin time). (b) From 20:11 May 23 (25 $\mathrm{hr}$ after the origin time).

Figure S8. Power spectrum of the strain record at NNA for the 1960 Chilean earthquake (from Fig. 1 of BPS-1961). Blue: Spheroidal; Red: Toroidal.

Figure S9. Comparison of the observed and synthetic seismograms of the 1960 Chilean earthquake. R4 at PAL and G6 at RES. The response of the instrument is assumed to be $T_{s}=15 \mathrm{~s}, T_{g}=75 \mathrm{~s}$, $h_{s}=1 ., h_{g}=1 ., \sigma=0.25, V_{\max }=1000$.

Figure S10. Comparison of the observed and synthetic seismograms of the 1960 Chilean earthquake. G4 at SFA. The seismograph is Wood-Anderson with $T_{s}=1 \mathrm{~s}, h_{s}=0.8$, gain $=2500$. Synthetics computed for (a) the 10 sources model, (b) point source with a $90 \mathrm{~s}$ duration.

Figure S11. Benioff long-period seismograms of the 1960 Chilean earthquake recorded at Matsushiro, Japan. (a) EW component (pendulum period/galvanometer period/peak gain $=1 \mathrm{~s} / 62 \mathrm{~s} / 9640)$. The bottom three lines contain R3 and R4. (b) NS component (pendulum period/galvanometer period/peak gain $=1 \mathrm{~s} / 70 \mathrm{~s} / 7330$ ). The bottom three lines contain G3 and G4. (c) Magnified figure of the boxed portion shown in (b). (d) Radiation pattern of $G$ and Rayleigh waves for $\lambda=90^{\circ}$ model. The location of the stations ISA and MAT are indicated. (e) Radiation pattern of $\mathrm{G}$ and Rayleigh waves for $\lambda=140^{\circ}$ model.

Figure S12. Comparison of the acceleration spectra at Grotta Gigante computed for the two models, $\lambda=90^{\circ}$ and $\lambda=140^{\circ}$, of the 1960 Chilean earthquakes (record length: $2580 \mathrm{~min}$; beginning: 300 min after the origin time).

Figure S13. Normal-mode strain spectrum at BFO (N60 E component) for the 2004 Sumatra earthquake. 
Figure S14. Comparison of 1-D and 3-D synthetic seismograms of the 1960 Chilean earthquake $\left(\lambda=140^{\circ}\right)$ for the station Palisades (PAL). The 1-D and 3-D synthetics are computed for PREM and S40RTS (Ritsema et al. 2011), respectively.

Figure S15. Comparison of the observed and synthetic seismograms of the 2011 Tohoku-Oki earthquake for the station Harvard (HRV).

Figure S16. Comparison of the observed and synthetic seismograms of the 2010 Maule, Chile, earthquake for the station PFO.

Figure S17. Static displacement field for a dip-slip $\left(\delta=17^{\circ}\right.$, $\left.\lambda=90^{\circ}\right)$ fault (left column) and an oblique slip $\left(\lambda=140^{\circ}\right)$ fault (right column) for a $1000 \times 200 \mathrm{~km}^{2}$ fault. The left edge of the fault is placed along the trench at a depth of $5 \mathrm{~km}$.

Figure S18. Static displacement field for a dip-slip $\left(\delta=17^{\circ}\right.$, $\left.\lambda=90^{\circ}\right)$ fault (left column) and an oblique slip $\left(\delta=17^{\circ}, \lambda=140^{\circ}\right)$ fault (right column) for a $1000 \times 350 \mathrm{~km}^{2}$ fault. The left edge of the fault is placed along the trench at a depth of $5 \mathrm{~km}$.

Figure S19. Normal-mode spectrum of the 1960 Chilean earthquake. (a) Spectrum of the Pasadena Press-Ewing seismogram (vertical component) and the UCLA gravity meter record (Benioff et al. 1961; Ness et al. 1961; Kanamori \& Anderson 1975). The spectral holes at 0S10 (blue dot) and 0S21 (red dot) are indicated. (b) Spectrum of the Pasadena Press-Ewing seismogram (vertical component) (Cifuentes \& Silver 1989).

Figure S20. Spectrum of Pasadena Press-Ewing seismogram (vertical component). (a) Spectrum of the observed seismogram. (b) Spectrum of the synthetic seismogram for a point source with $\lambda=90^{\circ}$. (c) Spectrum of the synthetic seismogram for a finite source with $\lambda=90^{\circ}$. (d) Spectrum of the synthetic seismogram for a finite source with $\lambda=140^{\circ}$.

Please note: Oxford University Press is not responsible for the content or functionality of any supporting materials supplied by the authors. Any queries (other than missing material) should be directed to the corresponding author for the paper.

\section{APPENDIX A: RUPTURE MODEL OF THE 1960 CHILEAN AND THE 1964 ALASKAN EARTHQUAKES}

\section{A.1 The 1960 Chilean Earthquake}

Our finite fault model for the 1960 May 22 Chilean earthquake is a line source based on the general features of the geodetic models of Moreno et al. (2009) and Barrientos \& Ward (1990) scaled to a total moment of $2.7 \times 10^{23} \mathrm{Nm}$ (Figs Ala and b). It spans about $1000 \mathrm{~km}$ from the Arauco peninsula $\left(37^{\circ} \mathrm{S}, 73.3^{\circ} \mathrm{W}\right)$, close to the city of Concepción to the Tres Montes peninsula $\left(46 .{ }^{\circ} \mathrm{S}, 75 .{ }^{\circ} \mathrm{W}\right)$, near the Chile Triple Junction. The model is made of 10 equally spaced point sources separated by $1^{\circ}$ in latitude. From north to south the seismic moments of the 10 sources (unit $10^{22} \mathrm{Nm}$ ) are: 0.11 , $1.66,3.83,4.80,5.27,3.36,2.36,3.00,2.44$ and 0.17 , respectively. Table A1 provides the details of this model. The seismic moment is mainly concentrated in the northern half with a peak value between Osorno and Puerto Montt $\left(\sim 41^{\circ} \mathrm{S}\right)$. The moment-rate function of each point source is an isosceles triangle with a half duration, $t_{1 / 2}$ determined from its seismic moment following the scaling relation, $t_{1 / 2}=2.6 \times 10^{-6} M_{0}^{1 / 3}\left(t_{1 / 2}\right.$ in s, and $M_{0}$ in Nm; Duputel et al. 2013). Following Press et al. (1961), the rupture is assumed to be from north to south at a constant speed. Three rupture speeds, $V_{r}=3.0,3.5$ and $3.8 \mathrm{~km} \mathrm{~s}^{-1}$ were tested, with corresponding rupture durations of 333,286 and $263 \mathrm{~s}$.
Although most computations of synthetic seismograms in this paper were done by summing up the seismograms computed for each subevent, we show equivalent moment-rate functions and momentrate spectra for a point source placed at the epicentre. Figs A1(c) and (d) show, respectively, the moment-rate functions and spectra as viewed from the azimuth of ISA along the minor arc, from the azimuth of ISA along the major arc, and from the azimuth normal to the fault strike. These moment-rate functions and spectra are useful for designing filters to use for quick computations of approximate source finiteness.

\section{A.2 The 1964 Alaska earthquake}

To compute the ISA synthetic strain record for the 1964 March 27 Alaska earthquake, we use a simple single fault plane model constructed by referring to Plafker (1965), Stauder \& Bollinger (1966), Kanamori (1970) and Ichinose et al. (2007) with a total moment of $7.94 \times 10^{22} \mathrm{Nm}\left(M_{\mathrm{w}}=9.2\right)$. The focal mechanism is a shallow dipping $\left(\delta=10^{\circ}\right)$ pure thrust fault with a strike of $245^{\circ} \mathrm{N}$. It spans $500 \mathrm{~km}$ from $\left(61.019^{\circ} \mathrm{N}, 147.50^{\circ} \mathrm{W}\right)$, close to Anchorage, to Kodiak Island. The model is made of six equally spaced point sources separated by $100 \mathrm{~km}$ at a depth of $20 \mathrm{~km}$. From northeast to southwest the seismic moments of the six sources are (in units of $10^{22} \mathrm{Nm}$ ): $0.99,1.49,1.98,1.49,1.49$ and 0.50 , respectively (Table A2, Figs A2a and b). The moment-rate function of each point source is an isosceles triangle with a half duration determined from the scaling relation of Duputel et al. (2013). The azimuth of the rupture propagation is $225^{\circ} \mathrm{N}$ and the rupture speed $3.5 \mathrm{~km} \mathrm{~s}^{-1}$ with a rupture duration of $143 \mathrm{~s}$. Since ISA is located at a wide angle with respect to the rupture direction, no significant directivity was observed at this station.

\section{APPENDIX B: COMPUTATION OF LINEAR STRAIN FROM DISPLACEMENT MEASUREMENTS ON THE EARTH SURFACE}

When we estimate the strain at a station from the displacement records we take spatial derivatives of the displacements. We compute three components of displacement seismograms $u_{r}, u_{\theta}$ and $u_{\phi}$ at two neighbouring points A and B. At short period (e.g. shorter than $300 \mathrm{~s}$, i.e. wavelength $<1500 \mathrm{~km}$ for surface waves), the Earth's sphericity can be ignored, and the extensional strain, $e_{l l}$, can be simply given by $e_{l l}=\frac{\Delta u_{l}}{\Delta l}$, where $u_{l}$ is the displacement component in the strain rod direction and $\Delta l$ is the length of the strain rod. At long periods the sphericity becomes important, and we need the following correction:

$$
\frac{u_{r}}{R_{\mathrm{E}}}+\frac{u_{t}}{R_{\mathrm{E}}} \cot \theta \sin \delta
$$

where $R_{E}$ is the radius of the earth, $\theta$ is the colatitude of the station, $\delta$ is the azimuth of the strain rod measured from the north, and $u_{t}$ is the displacement component transverse to the strain rod. In the above, the first and the second terms are the extensional strain in the rod direction caused by $u_{r}$ and $u_{t}$, respectively.

An alternative more direct way is given in the following.

We consider two nearby points on the surface of the Earth $A$ and $B$, and track their relative distance evolving with time. Let $\boldsymbol{r}_{A}(t)$ and $\boldsymbol{r}_{B}(t)$ be the positions of $A$ and $B$ with respect to the centre of the Earth as function of time. $\boldsymbol{r}_{A}(t)$ and $\boldsymbol{r}_{B}(t)$ can be written in terms 
(a)

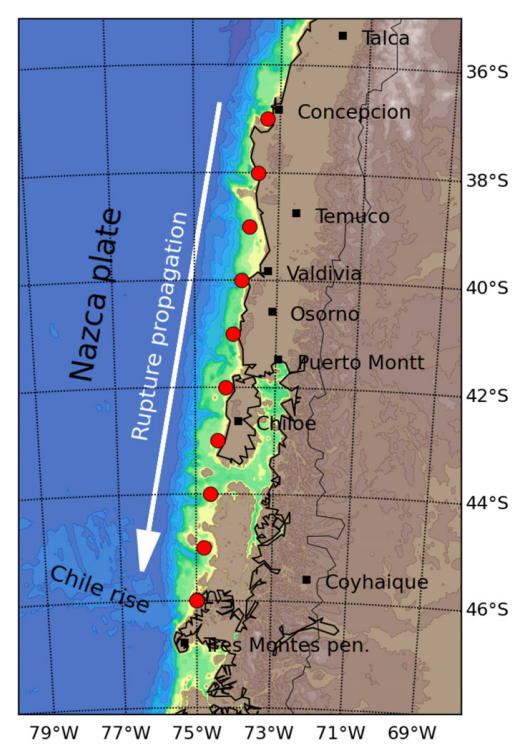

(c)

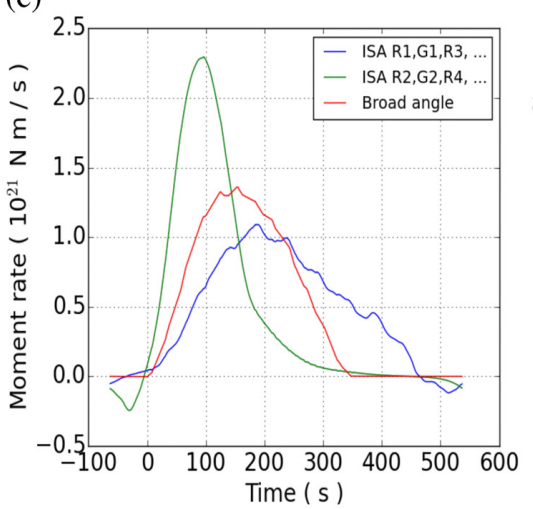

(b)

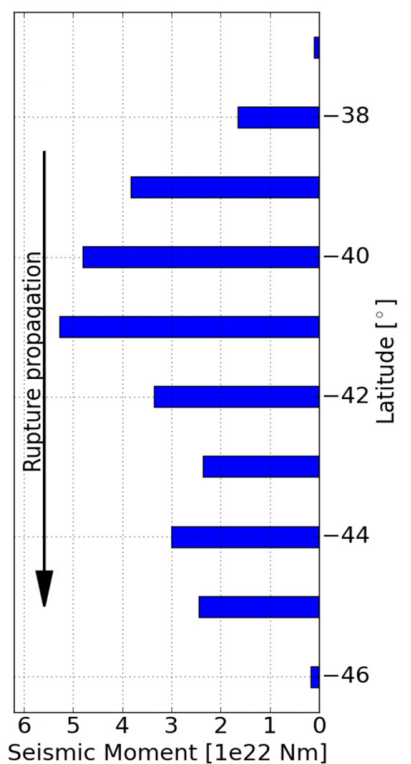

(d)

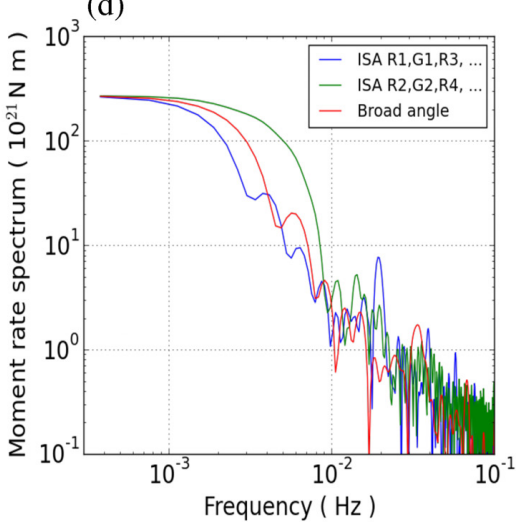

Figure A1. Finite source model of the 1960 May 22 Chilean earthquake. (a) Map view. Red dots indicate the locations of ten point sources. The arrow indicates the rupture propagation. (b) The bar graph shows the seismic moment for each point source. (c) Moment-rate functions viewed from three azimuths. (d) Corresponding moment-rate spectra.

Table A1. Location, time delay (with respect to 1960/5/22 19:11:18 UTC) and seismic moment for the elementary point sources of the M10s model for the 1960 Chile earthquake.

\begin{tabular}{lccccc}
\hline No & Lat. & Lon. & Depth $(\mathrm{km})$ & Time $(\mathrm{s})$ & $\mathrm{M}_{0}\left(10^{22} \mathrm{Nm}\right)$ \\
\hline 1 & -37.000 & -73.300 & 20.0 & 0.0 & 0.11 \\
2 & -38.000 & -73.489 & 20.0 & 29.6 & 1.66 \\
3 & -39.000 & -73.678 & 20.0 & 59.1 & 3.83 \\
4 & -40.000 & -73.867 & 20.0 & 88.7 & 4.80 \\
5 & -41.000 & -74.056 & 20.0 & 118.3 & 5.27 \\
6 & -42.000 & -74.244 & 20.0 & 147.9 & 3.36 \\
7 & -43.000 & -74.433 & 20.0 & 177.4 & 2.36 \\
8 & -44.000 & -74.622 & 20.0 & 207.0 & 3.00 \\
9 & -45.000 & -74.811 & 20.0 & 236.6 & 2.44 \\
10 & -46.000 & -75.000 & 20.0 & 266.2 & 0.17 \\
\hline
\end{tabular}

of the displacement at both points: $\boldsymbol{d}_{A}(t)$ and $\boldsymbol{d}_{B}(t)$,

Usually we write $\boldsymbol{d}_{A}(t)$ and $\boldsymbol{d}_{B}(t)$ in geographical coordinates:

$\boldsymbol{r}_{A}(t)=\boldsymbol{r}_{A}(0)+\boldsymbol{d}_{A}(t)$

$\boldsymbol{d}_{A}(t)=V_{A}(t) \hat{\boldsymbol{r}}_{A}-N_{A}(t) \hat{\boldsymbol{\theta}}_{A}+E_{A}(t) \hat{\boldsymbol{\phi}}_{A}$

$\boldsymbol{r}_{B}(t)=\boldsymbol{r}_{B}(0)+\boldsymbol{d}_{B}(t)$.

$\boldsymbol{d}_{B}(t)=V_{B}(t) \hat{\boldsymbol{r}}_{B}-N_{B}(t) \hat{\boldsymbol{\theta}}_{B}+E_{B}(t) \hat{\boldsymbol{\phi}}_{B}$. 
Table A2. Location, time delay (with respect to 1964/3/28 3:36:13 UTC) and seismic moment for the elementary point sources of the B6s model for the 1964 Alaska earthquake.

\begin{tabular}{lccccc}
\hline No & Lat. & Lon. & Depth $(\mathrm{km})$ & Time $(\mathrm{s})$ & $\mathrm{M}_{0}\left(10^{22} \mathrm{Nm}\right)$ \\
\hline 1 & 61.019 & -147.500 & 20.0 & 0.0 & 0.99 \\
2 & 60.356 & -148.687 & 20.0 & 28.6 & 1.49 \\
3 & 59.693 & -149.874 & 20.0 & 57.1 & 1.98 \\
4 & 59.029 & -151.061 & 20.0 & 85.7 & 1.49 \\
5 & 58.366 & -152.248 & 20.0 & 114.3 & 1.49 \\
6 & 57.703 & -153.435 & 20.0 & 142.9 & 0.50 \\
\hline
\end{tabular}

(a)

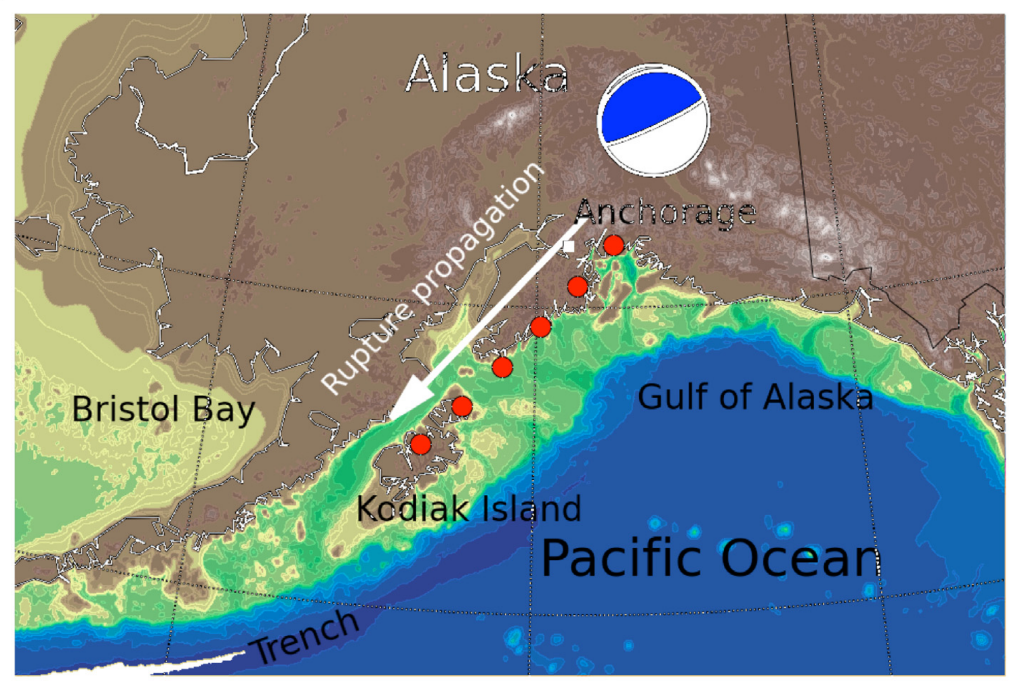

(b)

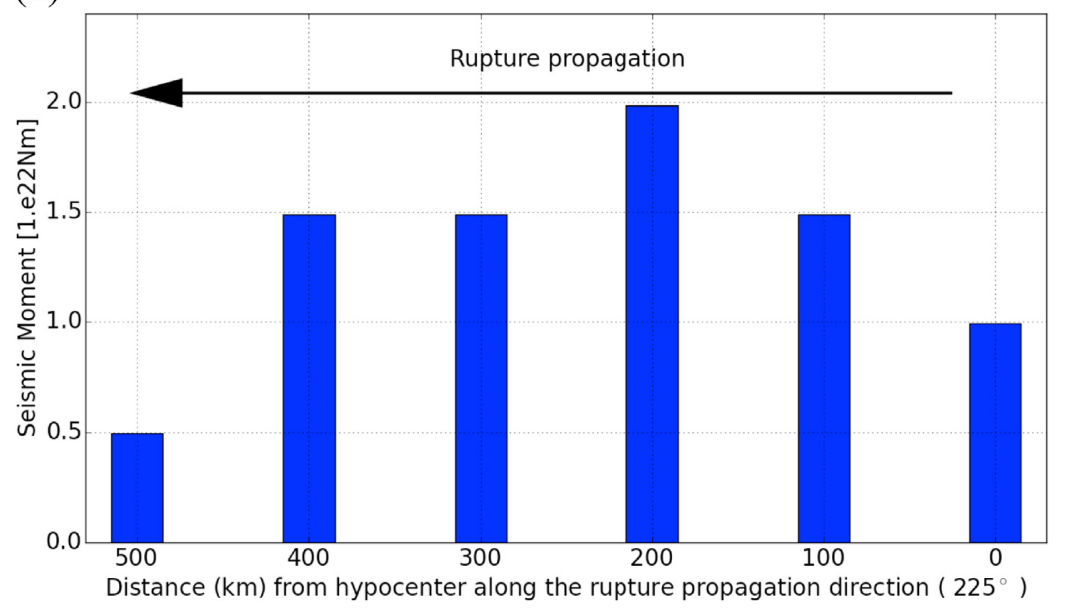

Figure A2. Finite source model of the 1964 March 28 Alaskan earthquake. (a) Map view. Red dots indicate the locations of six point sources. The arrow indicates the rupture propagation. (b) The bar graph shows the seismic moment for each point source.

The vectors $\hat{\boldsymbol{r}}_{A}, \hat{\boldsymbol{\theta}}_{A}$ and $\hat{\boldsymbol{\phi}}_{A}$ (as well as $\hat{\boldsymbol{r}}_{B}, \hat{\boldsymbol{\theta}}_{B}$ and $\hat{\boldsymbol{\phi}}_{\boldsymbol{B}}$ ) are unit vectors pointing to the local up, south and east directions. They depend on the position and are, in particular, different for points $A$ and $B$. The time functions $V_{A}(t), N_{A}(t), E_{A}(t), V_{B}(t), N_{B}(t)$ and $E_{B}(t)$ are the displacement seismograms at points $A$ and $B(V, N$, $E$; vertical up, north and east components). Alternatively we can use fixed unit vectors, say, $\hat{\boldsymbol{x}}$ on the equatorial plane pointing to Greenwich meridian, $\hat{\boldsymbol{y}}$ on the equatorial plane pointing to the $90^{\circ}$ meridian and $\hat{z}$ parallel to the polar axis pointing North. We then have

$\boldsymbol{d}_{A}(t)=X_{A}(t) \hat{\boldsymbol{x}}+Y_{A}(t) \hat{\boldsymbol{y}}+Z_{A}(t) \hat{z}$

$\boldsymbol{d}_{B}(t)=X_{B}(t) \hat{\boldsymbol{x}}+Y_{B}(t) \hat{\boldsymbol{y}}+Z_{B}(t) \hat{\boldsymbol{z}}$.

In this description the unit base vectors are independent of the observation point and all the spatial dependence is included in the scalar functions $X_{A}(t), Y_{A}(t), Z_{A}(t), X_{B}(t), Y_{B}(t)$ and $Z_{B}(t)$. These 
can be computed from the seismograms by rotation of the reference frame:

$X_{A}(t)=V_{A}(t) \sin \theta_{A} \cos \phi_{A}-N_{A}(t) \cos \theta_{A} \cos \phi_{A}-E_{A}(t) \sin \phi_{A}$

$Y_{A}(t)=V_{A}(t) \sin \theta_{A} \sin \phi_{A}-N_{A}(t) \cos \theta_{A} \sin \phi_{A}+E_{A}(t) \cos \phi_{A}$

$Z_{A}(t)=V_{A}(t) \cos \theta_{A}+N_{A}(t) \sin \theta_{A}$

where $\theta_{A}$ and $\phi_{A}$ are the geocentric co-latitude and longitude of point $A$. Similar expressions hold for $B$. Once the seismograms are transformed to this reference system we can immediately compute the elongation along any direction $\boldsymbol{n}$ as:

$\Delta_{n}(t)=\left[X_{B}(t)-X_{A}(t), \quad Y_{B}(t)-Y_{A}(t), \quad Z_{B}(t)-Z_{A}(t)\right] \cdot \boldsymbol{n}$

Taking in particular $\boldsymbol{n}=\left(\boldsymbol{r}_{B}(0)-\boldsymbol{r}_{A}(0)\right) /\left|\boldsymbol{r}_{B}(0)-\boldsymbol{r}_{A}(0)\right|$, we have the elongation along the direction joining $A$ and $B$ at $t=0$. There is no need here to apply explicit corrections for the Earth's surface curvature or the convergence of meridians.

\section{APPENDIX C: COMPUTATION OF SYNTHETIC SEISMOGRAMS}

Here we describe in detail the three kinds of synthetic seismograms mentioned in the main text and in Table 1:

Non Coupled (referred to as 'NC'):

Seismograms are computed by normal-mode summation (Gilbert 1971) for a non-rotating spherically symmetric earth model. In this case, no coupling and splitting are involved. The strains are estimated by numerical differentiation of the displacement as described in Appendix B. For these calculations (and all the following ones), the spherical model used is the preliminary reference earth model (PREM) of Dziewonski \& Anderson (1981).

Coupled (referred to as ' $C$ '):

Synthetics are built by normal-mode summation and perturbation theory (Gilbert \& Dziewonski 1975), including splitting and coupling due to the Earth's rotation and ellipticity, and the effect of 3-D lateral heterogeneities (Dahlen \& Sailor 1979, Woodhouse \& Dahlen 1978; Woodhouse 1980). Considering isolated modes, the displacement seismograms can be written as (Woodhouse \& Girnius 1982):

$\mathrm{u}(t)=\sum_{k} \operatorname{Re}\left[\left(r_{k}^{*} \mathrm{e}^{i H_{k} t} \mathrm{~s}_{k}\right) \mathrm{e}^{i v_{k} t}\right]$

where $k$ stands for a mode (e.g. containing angular order $l$, overtone number $n$, and the mode type: spheroidal or toroidal), $\boldsymbol{r}_{\boldsymbol{k}}$ is the receiver vector (e.g. displacement eigenfunctions), $\boldsymbol{s}_{\boldsymbol{k}}$ is the source $\operatorname{vector}\left(\boldsymbol{s}_{k}=\boldsymbol{M}: \varepsilon_{k}{ }^{*}\right), v_{k}$ is the complex degenerate eigenfrequency of mode $k$, and $\boldsymbol{H}_{\boldsymbol{k}}$ is the splitting matrix accounting for the splitting due to rotation, ellipticity and lateral heterogeneities. In the above, $\boldsymbol{M}$ is the source moment tensor and $\varepsilon_{k}$ is the strain tensor at the source. Similarly, the strain can be written by replacing the receiver vector by the expressions of the strain in spherical coordinates.

The calculations are performed over a frequency band of $0-3 \mathrm{mHz}$ considering a group-coupling approximation or quasi-degenerate perturbation theory (Dahlen 1969; Luh 1974; Woodhouse 1980), e. g. only considering coupling within a group of modes close in frequency, commonly called super-multiplets. Hence, in the above equation, the sum is now over the super-multiplets rather than over the isolated modes, and the splitting matrix is made of blocks corresponding to the self- or the cross-coupling of all the modes included in the considered super-multiplet. The groups used for the calculations are those defined in Deuss \& Woodhouse (2001).

To account for the 3-D lateral heterogeneities in the mantle, we use either shear velocity anomalies from S40RTS (Ritsema et al. 2011) with compressional velocity perturbations scaled from the shear velocity ones by a factor of 0.5 (e.g. Robertson \& Woodhouse 1995), or shear and compressional velocity anomalies from SP16b30 (Masters et al. 1996). For both models, perturbations in density are scaled from the shear velocity anomalies by a factor of 0.3 (e.g. Li et al. 1991; Karato \& Karki 2001).

Hybrid (referred to as 'HY'):

Displacement and strain seismograms over a broader frequency range (up to $40 \mathrm{mHz}$ ) are obtained by combining the ' $\mathrm{C}$ ' seismograms computed for a frequency band of $0-3 \mathrm{mHz}$ and the ' $\mathrm{NC}$ ' seismograms for frequencies band $3-40 \mathrm{mHz}$.

For all the above calculations, the mode catalogue is built with the program MINOS (Woodhouse 1988). Traces to be compared with inertial instrument data (e.g. Press-Ewing, STS-1, IGY) include instrument-gravity corrections (Gilbert 1980); this correction is not applied to strain traces.

\section{APPENDIX D: CALIBRATION}

\section{D.1 ISA (Isabella strainmeter in 1960)}

In 1960 , ISA had only one rod in $\mathrm{N} 38.8^{\circ} \mathrm{W}$ direction. The complete calibration procedure is described in Kanamori \& Rivera (2017). The direct strain record (Benioff 1962) was calibrated against the earth tide. The strain record obtained through a C-R (capacitorresistance) network was calibrated using the C-R circuit given in fig. 4 of Benioff (1963), the strip-chart record and the digitized record described in BPS-1961 and Smith (1966). Fig. D1(a) shows the response curve given in inch/nanostrain. To convert this to the one in count/nanostrain, the response shown in Fig. D1(a) should be multiplied by 156 (Fig. D1b).

\section{D.2 ISA (Isabela strainmeter in 1964)}

As described in Smith (1966), ISA had another rod in N51.2E direction in 1964. Since the direct strain record is no longer available for 1964, we cannot calibrate it directly with the tide. Smith (1966) presented a response curve for 1964 and 1960 (fig. 3 in Smith 1966). Judging from the description, we assume that the C-R network used for 1964 was a six-element network shown in fig. 8 of Benioff(1963) with $\mathrm{C} 1=\mathrm{C} 2=\mathrm{C} 3=200 \mu \mathrm{F}, \mathrm{R} 1=2 \mathrm{M} \Omega$ and $\mathrm{R} 2=\mathrm{R} 3=10$ $\mathrm{M} \Omega$. Fig. D1(a) shows the response curve thus computed. Although we cannot determine the gain factor for 1964 directly (no direct record is available), we position the 1964 curve relative to the 1960 curve (this is determined in Kanamori \& Rivera 2017) to be approximately consistent with fig. 3 of Smith (1966). The G wave phases G2 and G4 on the N51.2E component were recorded on the network analogue record (Fig. 15b) and on the digitized file. Comparing them we determine the conversion factor count/inch to be 210 counts per inch. Thus, to convert the curve in Fig. D1(a) to the one in count/nanostrain, the curve for 1964 in Fig. D1(a) should be multiplied by 210 . The response curve in count/nanostrain is shown in Fig. D1(b). The gain factor for the analogue record of the $\mathrm{N} 38.8 \mathrm{~W}$ component is $1 / 10$ of the $\mathrm{N} 51.2^{\circ} \mathrm{E}$ component record. 
Calibration of ISA strainmeter (black: 1960; red: 1964)
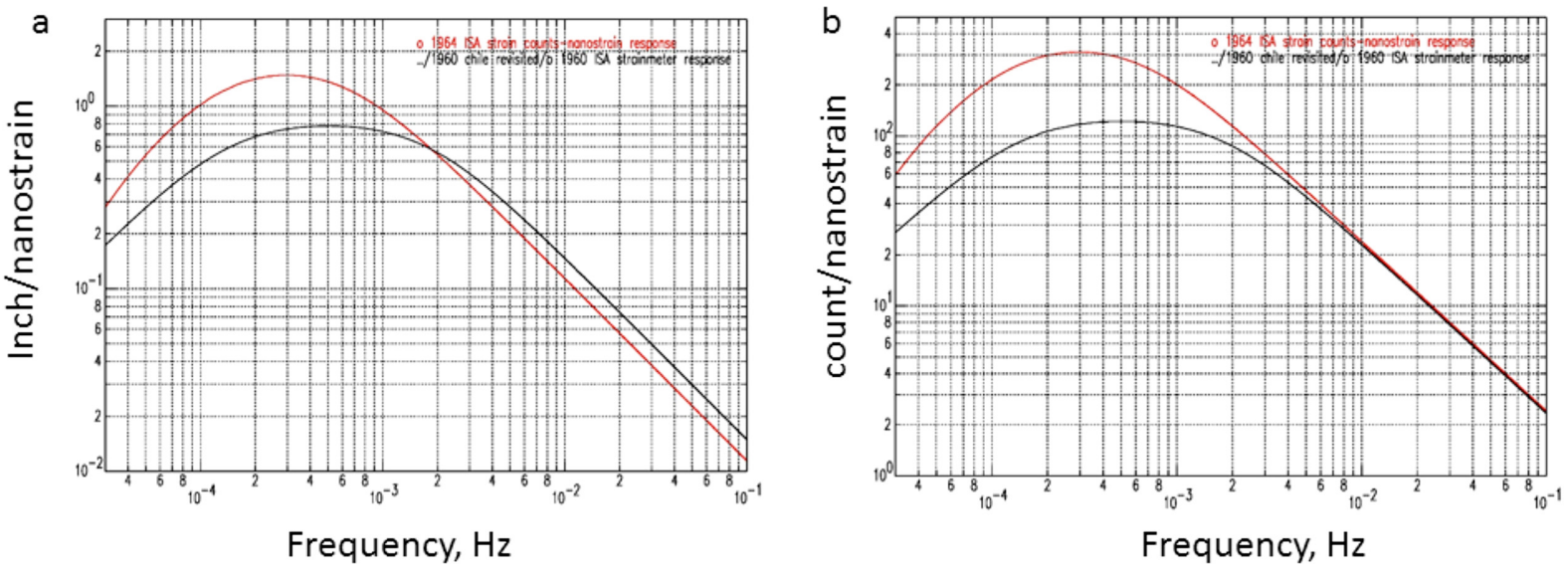

Figure D1. Response curves for the network output of the ISA strainmeter for the 1960 Chilean earthquake and the 1964 Alaskan earthquake. (a) Inch/nanostrain; (b) count/nanostrain.

\section{OGD Calibration Tidal extensional strain in $\mathrm{N} 30^{\circ} \mathrm{E}$ direction at OGD}

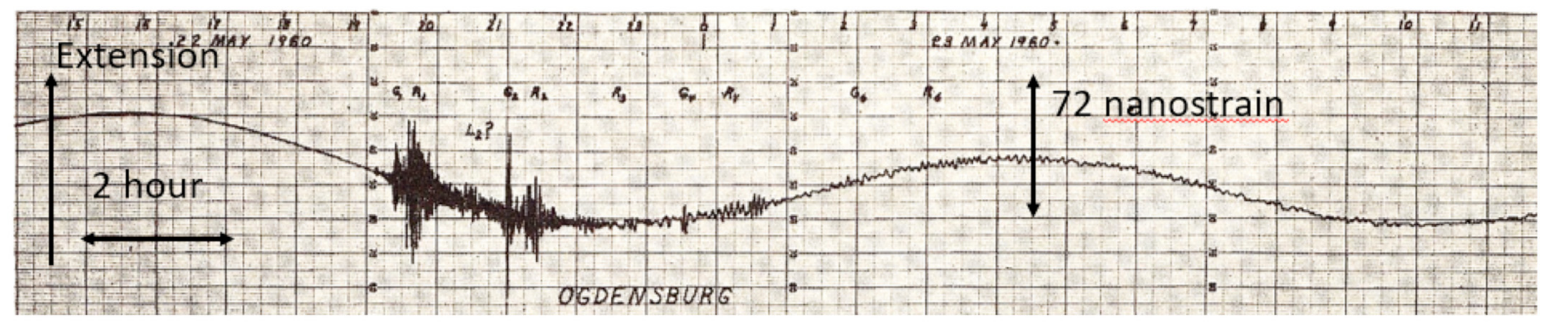

\section{Computed strain}

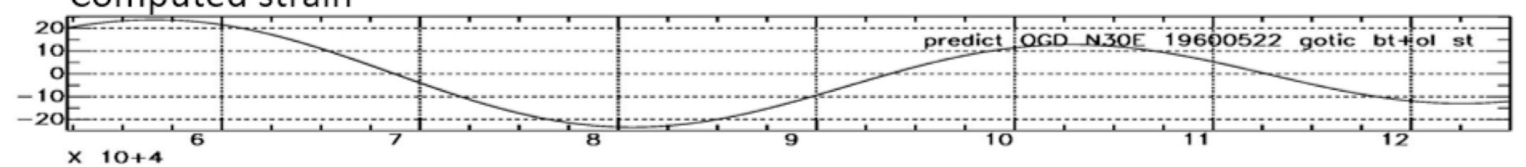

Figure D2. Calibration of the Ogdensburg (OGD) strainmeter $\left(\mathrm{N} 30^{\circ} \mathrm{E}\right)$ with the theoretical tidal strain.

Thus, although we could not directly calibrate the network data for the 1964 Alaskan earthquake, we believe that our calibration is approximately correct.

\section{D.3 OGD (Ogdensburg in 1960)}

We calibrate the OGD strain record using the earth tide as shown in Fig. D2. Since OGD is fairly close to the ocean, we added the ocean loading effect using the code written by Matsumoto et al. (2001).

\section{D.4 Tsukuba IGY-type long-period seismograph}

The response curves and the instrument constants for the TSK longperiod seismographs listed in the Tsukuba Observatory Bulletin are shown in Fig. D3. 


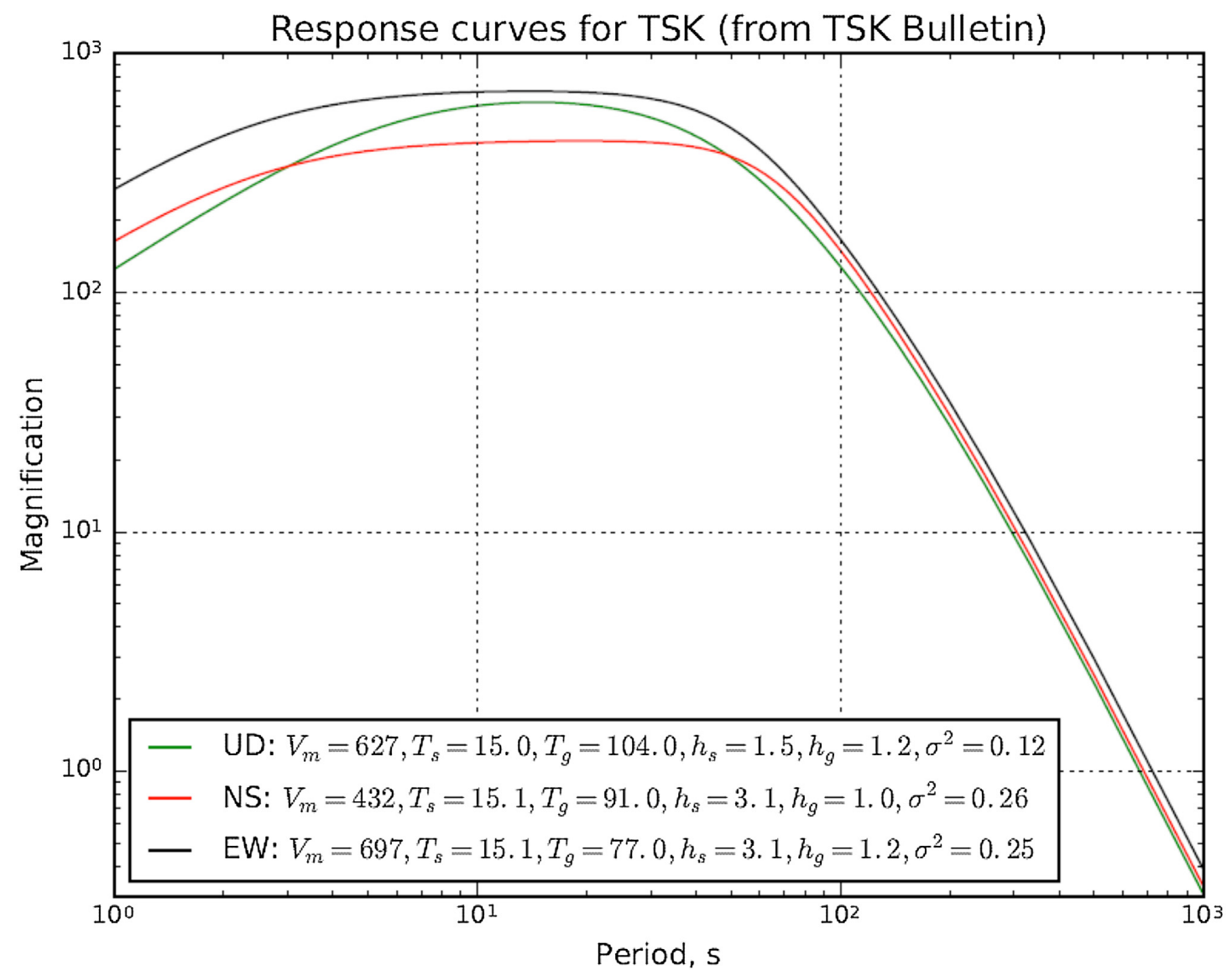

Figure D3. Response of the IGY type long-period seismograph at Tsukuba (TSK). $V_{\mathrm{m}}$ : peak magnification; $T_{\mathrm{s}}$ and $T_{\mathrm{g}}$ : periods of pendulum and galvanometer; $h_{\mathrm{S}}$ and $h_{\mathrm{g}}$ : damping constant of the pendulum and galvanometer; $\sigma^{2:}$ coupling constant. 